\title{
Propensity of West Virginia craftspeople to use electronic media for marketing their products
}

\author{
Karen Kay Norwood \\ West Virginia University
}

Follow this and additional works at: https://researchrepository.wvu.edu/etd

\section{Recommended Citation}

Norwood, Karen Kay, "Propensity of West Virginia craftspeople to use electronic media for marketing their products" (2002). Graduate Theses, Dissertations, and Problem Reports. 2467.

https://researchrepository.wvu.edu/etd/2467

This Dissertation is protected by copyright and/or related rights. It has been brought to you by the The Research Repository @ WVU with permission from the rights-holder(s). You are free to use this Dissertation in any way that is permitted by the copyright and related rights legislation that applies to your use. For other uses you must obtain permission from the rights-holder(s) directly, unless additional rights are indicated by a Creative Commons license in the record and/ or on the work itself. This Dissertation has been accepted for inclusion in WVU Graduate Theses, Dissertations, and Problem Reports collection by an authorized administrator of The Research Repository @ WVU.

For more information, please contact researchrepository@mail.wvu.edu. 


\title{
PROPENSITY OF WEST VIRGINIA CRAFTSPEOPLE TO USE ELECTRONIC MEDIA FOR MARKETING THEIR PRODUCTS
}

\author{
Karen Norwood \\ Dissertation submitted to the \\ College of Human Resources and Education \\ at West Virginia University \\ in partial fulfillment of the requirements \\ for the degree of \\ Doctor of Education \\ in \\ Technology Education
}

\author{
George Maughan, Ed.D., Chair \\ Scott Bower, Ed.D. \\ Urban Couch, M.F.A. \\ Van Dempsey, Ed.D. \\ Neal Shambaugh, Ed.D. \\ Department of Technology Education
}
Morgantown, West Virginia 2002

Keywords: adult education, artisan, co-operative, communication technology, craft marketing, Internet marketing 


\title{
ABSTRACT \\ PROPENSITY OF WEST VIRGINIA CRAFTSPEOPLE TO USE ELECTRONIC MEDIA FOR MARKETING THEIR PRODUCTS
}

\author{
Karen Norwood
}

The purpose of this study was to determine whether craftspeople in West Virginia were ready to use new communication technologies to market their products, by cooperative or other business structures. Survey respondents completed their self-reports and mailed questionnaires back to the researcher for both quantitative tabulation and documentation of additional comments.

The survey instrument focused on four areas of inquiry regarding craftspeople: (1) knowledge and skills of using electronic media for marketing; (2) experience, potential and interest in using communication technologies in cooperative or other group marketing efforts; (3) perceptions about the electronic communication infrastructure; and (4) perceptions of their degree of access to electronic media.

Analysis of the resulting data about readiness indicated that this population had little experience and knowledge of ideal cooperatives, nor of the use of new communication technologies for marketing. Other business strategies, such as investororiented firms, were thus more attractive. In general, craftspeople indicated that both the economy and the infrastructure for electronic marketing were good. Their access to communication technologies was hindered, however, by lack of expert human assistance, geographical features (ISDN lines limited), and personal finances. Another hindrance to employing communication technologies for marketing was that craftspeople prioritize production over marketing endeavors.

This constellation of information implies to the researcher that, indeed cooperative endeavors that left the employment of communication technologies for marketing to specialists, and the production of crafts to craftspeople, could provide better overall opportunities for profit. The research implied that use of the telephone remained of paramount importance for communication of all kinds, un-equaled by other electronic media for any and all kinds of interaction that might also result in marketing success. That did not, however, exclude the usefulness of the Internet for initiating and following up on matters involved with sales. Emerging technologies might be better exploited for marketing, advertising and self-promotion of craftspeople, and this remains a problem for further research involving adult education and training. 


\section{ACKNOWLEDGEMENTS}

I am indebted to so many people for their participation in my endeavor toward

this doctorate. It is next to impossible to list all of the individuals, but I will attempt to do so because I want each of them to know that they will all be remembered for their patience, kindness and assistance.

First, I want to thank my doctoral committee: Dr. Scott Bower, Mr. Urban Couch, Dr. Van Dempsey, Dr. George Maughan and Dr. Neal Shambaugh for the help and support they have given me with my dissertation. I appreciate their time, dedication and expertise providing essential critiques and recommendations. I give special thanks to George Maughan, Chair of my committee, for his guidance throughout the doctoral process. His coordination with Tim Mitchem to hold my oral defense by videoconference is much appreciated. I also express sincere gratitude to both Dr. Ernie Goeres and Dr. Dick Walls for their various contributions to my defense meeting as well as for their earlier assistance in analyzing data and preparing the document when my other committee members were not available for various reasons.

Others at WVU to whom I am especially indebted for their professional advice include: Dr. Paul DeVore, Dr. Barbara Fallon, Drs. Edna and David McBreen, Dr. David McCrory, Dr. Anne Nardi, Dr. Ann Oberhauser, Dr. Paul Siciliano, Dr. Denny Smith, and Dr. Jill Ware. Among the numerous employees who assisted me, I thank especially Char Allen, Kathy Fletcher and Carol Spiroff for their timely advice, coordination, computer consultation and institutional administration assistance.

The ongoing support and humor of the PMS (Procrastinators' Motivational Support) group members gave me constant encouragement and understanding throughout 
this process as we met bi-weekly over several years. Sandra Fallon, Sharon Goodman, Gordon McGregor, Jill Lewis Ware and numerous other colleagues aided me immensely as I addressed the issues involved in producing this document.

The love and moral support of Larry King is immeasurable. This dissertation is also the outcome of a remarkable system of support supplied by my other beloved friends and family living throughout the USA and Europe. Without everyone mentioned, completion of this work would not have been possible. For their assistance I am deeply grateful. 


\section{TABLE OF CONTENTS}

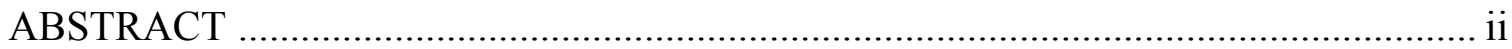

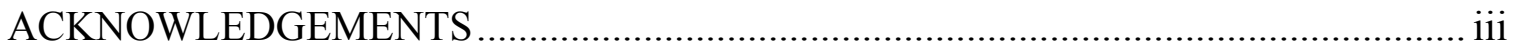

CHAPTER 1: INTRODUCTION AND BACKGROUND …………….........................

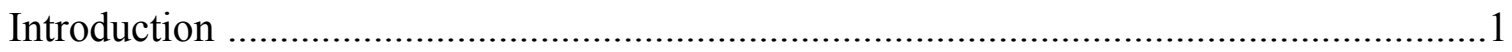

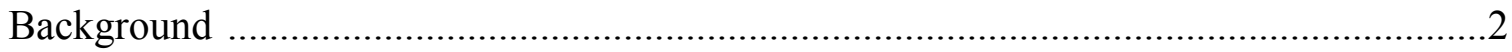

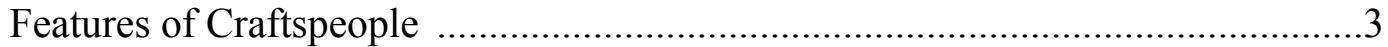

Legal Organization of Craft Production ........................................................5

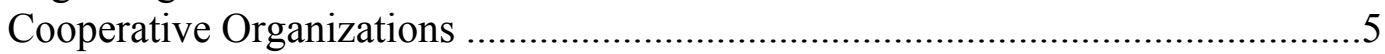

Communication and Information Systems for Marketing ......................................9

Plans of the West Virginia Commission on the Arts ………..............................10

Rural Life ....................................................................................

Communication Technology ................................................................12

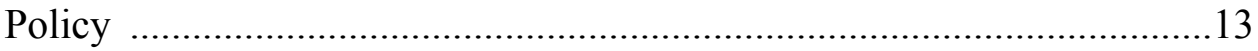

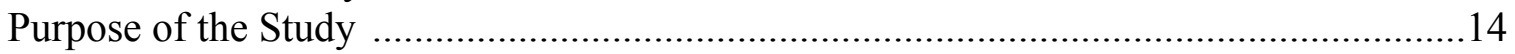

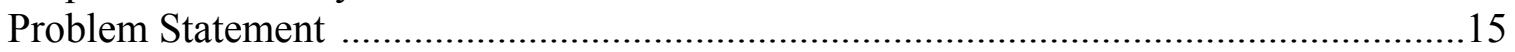

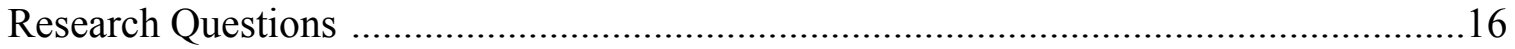

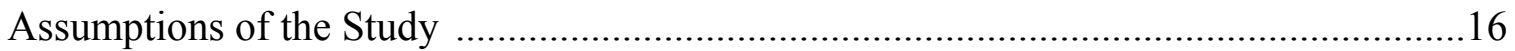

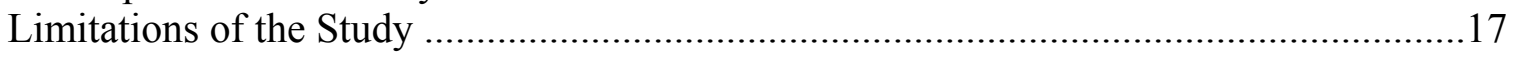

CHAPTER 2: REVIEW OF THE LITERATURE .....................................................19

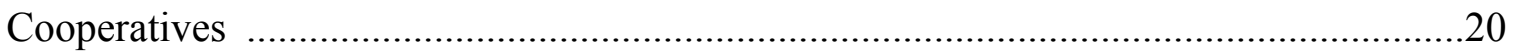

History and Background of Craft Cooperatives ………....................................20

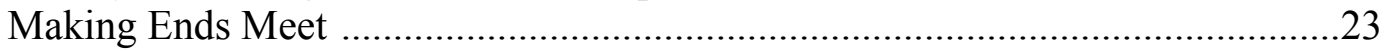

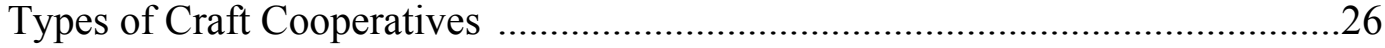

Manufacturing/production/worker .......................................................2.

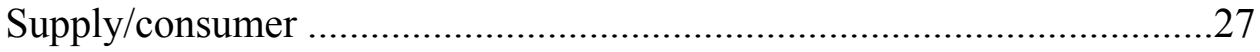

Marketing/advertising/promotion/sales ...............................................28

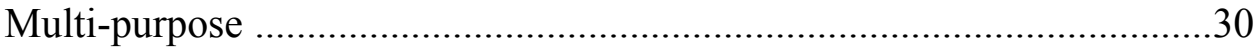

Characteristics and Organization of Coops Relevant to Craftspeople ...................32

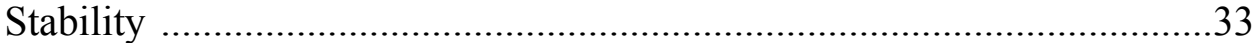

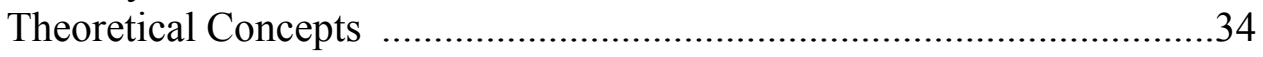

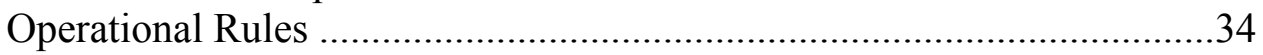

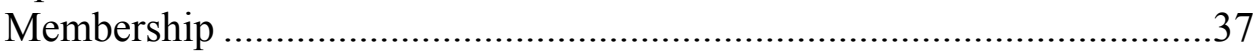

Investor-Oriented Firms (IOF) .................................................................................

History and Background of IOF Craftworker Firms ............................................38

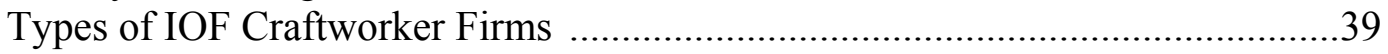

Characteristics and Organization of IOFs Relevant to Craftspeople .....................40

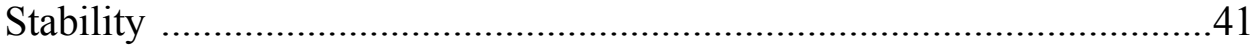

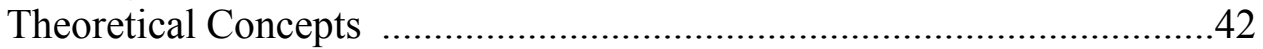

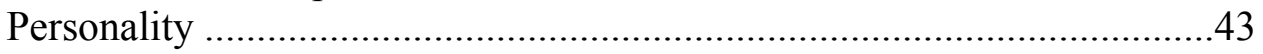




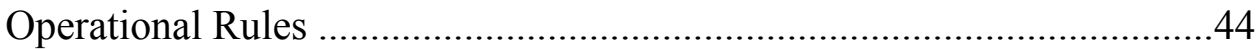

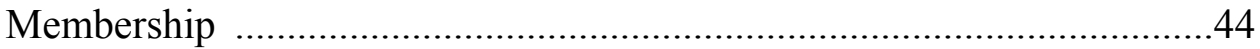

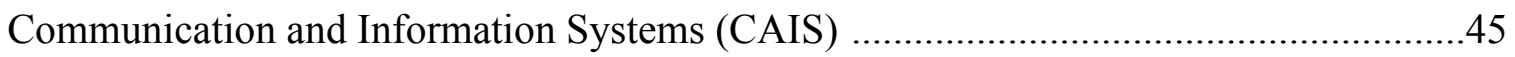

History and Background of CAIS Access and Use ………................................46

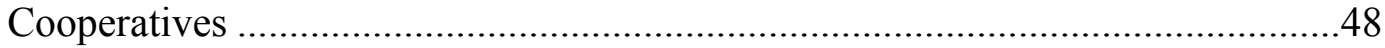

Elements Required for a Mature Infrastructure of Coops .........................49

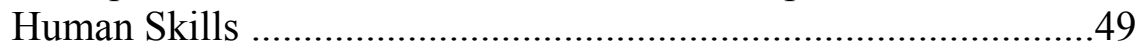

Technical Communication Devices ..........................................50

Networks and Systems ............................................................50

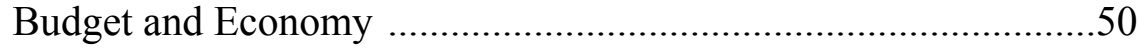

Policy and Law .......................................................................51

Capacity of Coops to Develop and Use CAIS Infrastructure ....................52

Investor-Oriented Firms (IOF) .......................................................................52

Elements Required for a Mature Infrastructure of IOFs ...........................52

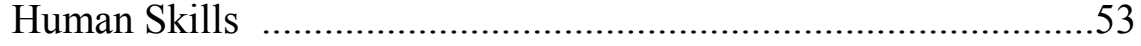

Technical Communication Devices ...........................................53

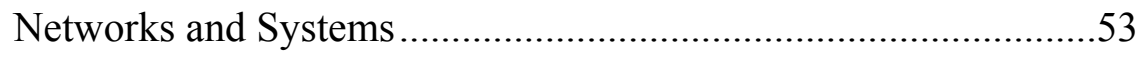

Budget and Economy .................................................................54

Policy and Law .......................................................................54

Capacity of IOFs to Develop and Use CAIS Infrastructure ......................55

Contemporary Marketing Efforts of Small Organizations ...............................................56

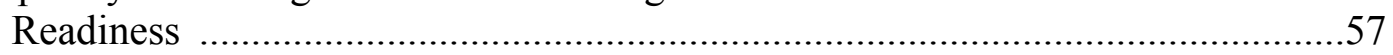

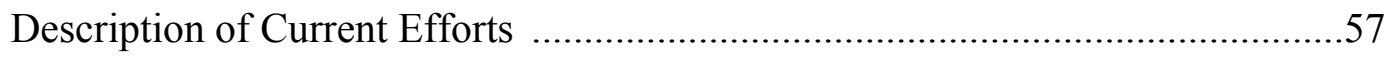

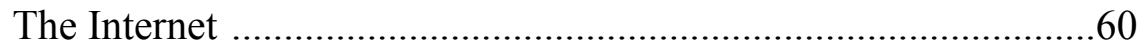

Summary of Literature Review ...........................................................................68

CHAPTER 3: RESEARCH METHODS AND PROCEDURES .....................................69

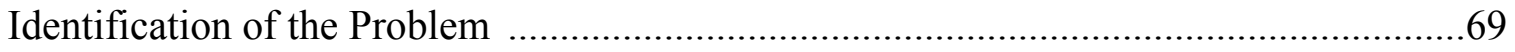

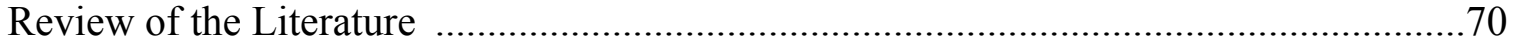

Development of the Survey Instrument .....................................................................

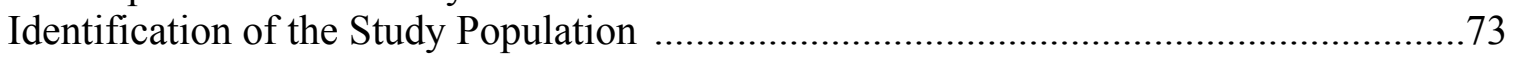

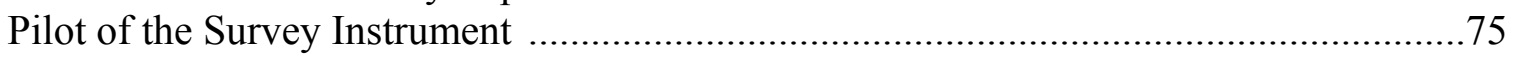

Administration of the Survey Instrument and Collection of Data .........................75

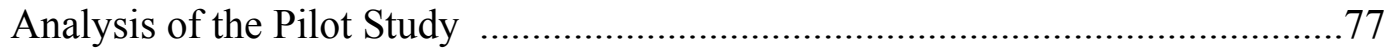

Findings from the Pilot Study .....................................................................78

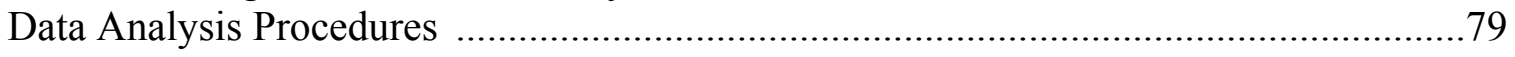

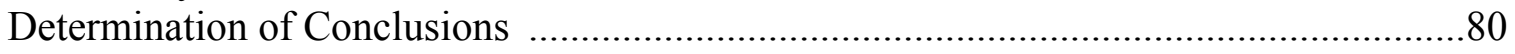

CHAPTER 4: ANALYSIS, FINDINGS AND SUMMARY ……………………….....83

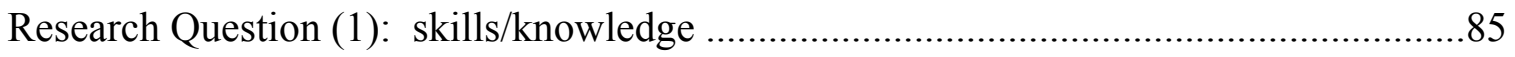

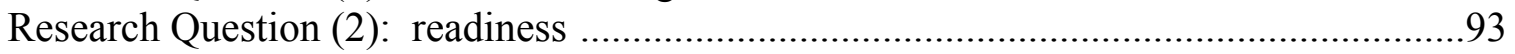

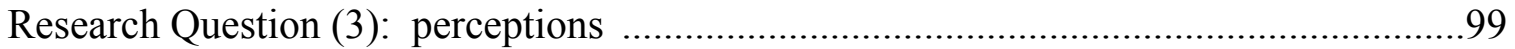

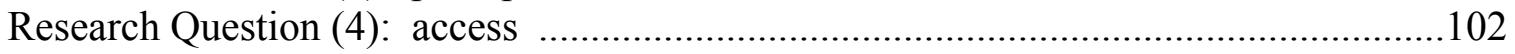




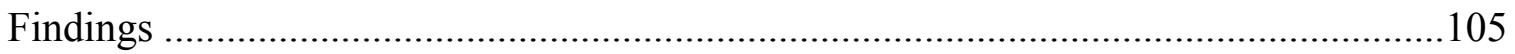

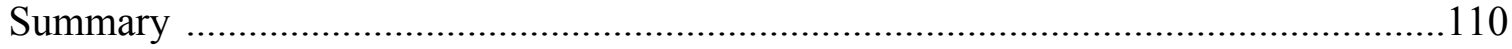

CHAPTER 5: CONCLUSIONS, IMPLICATIONS AND RECOMMENDATIONS FOR FURTHER RESEARCH ...............................112

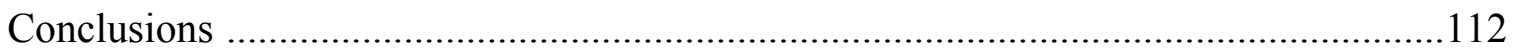

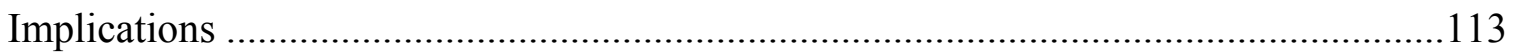

Recommendations for Further Research ................................................................117

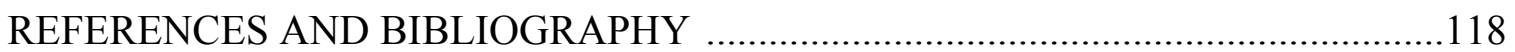

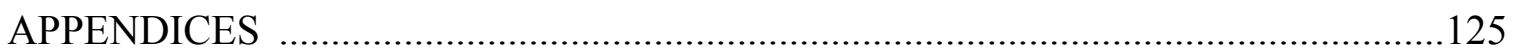

Appendix A: Pilot Survey Instrument with Definitions of Terms .....................125

Appendix B: Frequency Distribution of Pilot Survey Scores .............................141

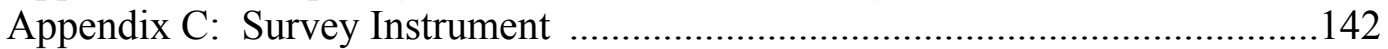

Appendix D: Cover Letter to Survey Questionnaire ...........................................149

Appendix E: Follow-up Postcard Reminder to Survey Participants ...................150

Appendix F: Comments Evoked by the Survey .................................................151

Appendix G: Research Questions ............................................................155

Appendix H: Relevant Marketing Website Information ..................................156

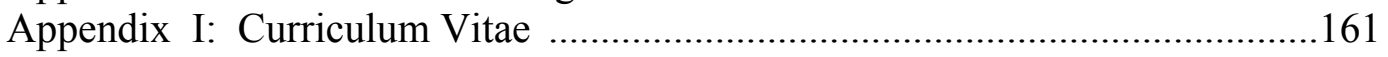

\section{LIST OF TABLES AND FIGURES}

Table 1. Strengths and Weaknesses Related to Marketing ………….................164

Table 2. Number of Participants Responding to Survey .......................................83

Table 3. Survey Questions Relevant to Research Questions ..................................85

Table 4. Mean Scores for Marketing Skills ......................................................86

Table 5. Mean Scores for Electronic Media Skills .............................................87

Table 6. Frequency Distribution for Electronic Media Skill Development ..........88

Table 7. Frequency Distribution for Additional Marketing Strategies .................89

Table 8. Frequency Distribution for Primary Media Used by Craftspeople ........92

Table 9. Frequency Distribution for Length of Time Having Practiced ...............94

Table10. Frequency Distribution for Number of Products Sold in 1999 .............97

Table11. Frequency Comparison of 1999 Sales in General and by Website ........97

Table12. Frequency Distribution for Use of the Internet .....................................102

Table13. Mean Scores for Personal Use of the Internet for Marketing ...............103

Table14. Frequency Distribution for Craftspeople with

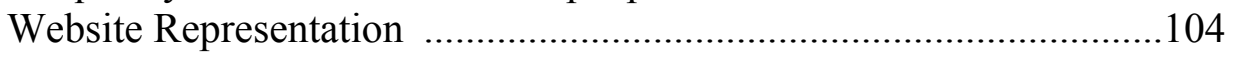

Figure 1. Communication Infrastructure Diagram ...........................................165 


\section{CHAPTER ONE: INTRODUCTION AND BACKGROUND}

\section{Introduction}

Craftspeople have traditionally worked alone or in small groups. That tradition is likely to continue in regard to craft production. As we begin the twenty-first century, however, technological advances and societal changes are occurring at an exponential rate. Advances in technological communication are being implemented for the production side of cooperative efforts, and these advances appear viable also to promote learning about, selecting and utilizing information systems to market craft products. The evolution of communication and information systems has been such that successful craft businesses will likely be advertising and promoting their products using additional means beyond traditional local fairs, festivals and exhibits. The evolving international marketplace makes regional cooperative efforts potentially viable for marketing craft wares beyond local areas.

This study addresses the marketing of West Virginia crafts from the assumption that, as is true for many products and markets, the process of matching buyers to sellers can be measurably enhanced by the use of electronic media. (Perreault \& McCarthy, 1997; Mancuso, 1992) The question as to how the use of electronic media may be facilitated must involve consideration of the features of craftspeople; the features of small manufacturing businesses, whether they are organized as cooperatives or as investororiented firms (IOFs); and the infrastructure requirements of communication and information systems (CAIS).

This study is intended to lead to training West Virginia adult craftspeople in the skills and knowledge about communication and information systems (electronic media) for marketing their work. The focus is on a cooperative's potential to assist with West 
Virginia craftspeoples' marketing endeavors. The choice of a cooperative organization rather than an IOF is somewhat predicated on the features of craftspeople and the craftmaking way of life. Both cooperatives and IOFs have been considered in the literature review to provide a background and comparison.

\section{Background}

Background includes description of the management and legal organization of craft production. A history and present position of cooperatives is presented. Marketing principles are elaborated. A plan by the West Virginia Commission on the Arts for the support of craft production and marketing concludes this section.

Four types of management organizations seem appropriate for craft production: 1) cooperatives, 2) flexible production networks, 3) 'micro' or cottage industries, and 4) home based businesses.

Cooperatives are defined as businesses formed by groups of people to obtain services more effectively or more economically than they can get on their own. Members of craft cooperatives own, finance, and operate the business for their mutual benefit (Hoyt, 1989; Evans, 1991; Greer, 1988; Halket, et. al., 1985; Leary \& Roy, 1975; Nash \& Nash, 1976; Williamson, 1980).

Flexible production networks are alternative economic strategies adopted in rural and semi-peripheral regions. They consist of spatially dispersed individuals and home workers aiming to earn an income from participation in group craft production. Activities include the coordination of orders and trouble-shooting during production. These are typically facilitated by using a telecommunications network (Hayden, 1990; Oberhauser, 1995; Windles, 1984). 
'Micro' industry includes what has been termed 'cottage' industry. In this study, the term refers to those craftspeople that produce their wares in a central location with approximately 1-15 craftworkers employed to complete an individual piece from beginning to end. All of these craft wares exemplify value-added production, or adding human creativity to raw materials (Halkett, et.al., 1985; Hayden, 1990; Smith, 1997).

Home-based businesses usually consist of a single craftsperson, or sometimes a family, producing a type of item in the home. These production methods may be linked to flexible production networks. The product may be a traditional design passed from one generation to another; or a design supplied by some other person for production in the home, or created and executed by the craftsperson (Halkett, et.al., 1985; Hayden, 1990; Windles, 1984).

\section{Features of Craftspeople}

General features of craftspeople's skills include both strengths and weaknesses. They are summarized here as they relate to this study on use of electronic media for cooperative marketing. Refer to Table 1 in the Appendix for a listing of general features about craftspeople, cooperatives and investor-oriented firms.

That production is not alienating is a major factor for these types of workers. The autonomy of laborers equates to job satisfaction. Craftspeople enjoy the flexibility in production location (e.g., at or near home or in proximity to supplies). Frequently, value is added to locally available resources (often indigenous raw materials) that are normally used as supplies. Low pollution levels are typical of these activities. These kinds of involvement tend to help develop strong community relations. Although workers are autonomous, neighbors feel connected because of these factors of supply, concern for the environment and simple daily involvement that occurs when individuals work close to 
where they live (Adams, Miles \& Yoder, 1986: Blake, 1989; Evans, 1991; Halket, Seymour \& Ely, 1985; Hunter, 1991; Leary \& Roy, 1975; Nash \& Nash, 1976;

Oberhauser, 1995). In regard to elements required for a mature communication infrastructure (discussed in Chapter 2), craftspeople tend to have the kinds of human skills and networks of peers essential for success.

The real goal of involvement for most craftspeople is the creation of the craft items: the need to market takes time and energy away from production activity. The production of most craftspeople is relatively unique and labor-intensive. Thus, many craft products require a relatively high sales price compared with mass-produced items. Economies of scale are usually absent or limited since they are usually not satisfying or feasible. Craftspeople's focus on producing their products makes access to markets difficult because the inherent niche marketing requires effort more happily spent on production. A clear lack of business savvy (i.e., skills and knowledge about marketing, advertising and sales) is evident amongst craftspeople. Lack of liquid personal capital is often cited as a deterrent to marketing and advertising for sales, although Small Business Development Administration Loans are currently available for these individuals (Bergeron \& Raymond, 1992; Groves, 1985; Halkett, et.al., 1985; Smith, 1997; Tjosvold \& Weicker, 1993).

Rural craftspeople tend to experience more marketing problems than their urban counterparts. Rural craftspeople, such as those in West Virginia, are relatively isolated because they live far from markets. They depend more on tourism than urban craftspeople. In a survey conducted by the West Virginia Commission on the Arts (WVCA), craftspeople indicated that expansion into electronic marketing endeavors would be helpful. 


\section{$\underline{\text { Legal Organization of Craft Production }}$}

Legal business organizations fall into three categories: proprietorships, partnerships, and corporations. Sub-categories of corporations include three types: regular, non-profit and cooperative. The differences between cooperative and noncooperative corporations are elucidated by the survey. Table 1 in the Appendix, Strengths and Weaknesses Related to Marketing, presents a summary of general merchant marketing features of artisans, cooperatives and investor-oriented firms.

Any small manufacturing business must address a number of operating concerns, including but not limited to: supplies, production, management, finances, personnel, record-keeping, taxes, as well as advertising, sales, promotion and marketing. Advertising, promotion and sales considerations are included as essentially connected to the marketing of craft products. This study emphasizes cooperatives as an effective means of training and marketing to correspond to the modern marketplace.

\section{Cooperative Organizations}

Six key concepts clarify the place for a cooperative in the US economy: the primary purpose is economic benefits for members. Members are usually patrons, members own and control the cooperative, qualifying patrons receive distribution of benefits, cooperatives are private organizations, and public policy establishes the institutional framework (Barton, 1989).

The organizational functions of cooperatives have their historical and theoretical base in institutions such as credit unions and agricultural industries. Coop businesses operate differently from other corporations in four distinct ways or principles of operation: 1) democratic control prevails, 2) ownership benefits are in proportion to use, 
3) service is at cost, and 4) there is a limited return on equity (Cobia, 1989). These criteria are further clarified following, because they may seem a bit vague.

The foundational principles of cooperative organization have evolved over the last century and a half, beginning with the Rochdale principles in England. Developed in 1844, the English 'rules of conduct and points of organization' were first published in 1860 in the Annual Almanac of the Rochdale Society. Four of the twelve original operating principles (referred to in the literature as "hard-core" traditional principles) remain as guidelines today: democratic control, patron ownership, business at cost, and limited dividends. The remaining eight Rochdale principles are less-consistently applied. As Barton (1989) says,

One of the distinctive features of the cooperative form of business is the promotion and adherence to a set of principles. Other forms of business, such as IOF corporations, do not openly claim to abide by a set of principles. Principles play a central role in the cooperative culture and define to a great extent the nature and role of cooperatives (p. 32).

Cooperatives, more than any other type of business, have tried to derive and justify their principles from various sources: theories of social and economic systems, experience, and beliefs. Timeless and universally valid (as some claim), these principles have become embodied in law and in common practice.

The primary use of principles is to serve as organizational guidelines for coop directors, managers, and legislators. Two criteria by which additional principles should be evaluated are compatibility with the cooperative definition and performance compared to the standard of doing what is best, especially for the member-patron. Unfortunately, there is much controversy associated with coop definitions caused by various 
interpretations of terminology such as principle, policy and practice. Yet, four distinctive classes of principles remain: Rochdale, traditional, proportional and contemporary. These principles apply to not only agricultural coops, but to nonagricultural coops of all types. According to Barton (1989),

Current practice is most closely aligned with traditional and contemporary principles. Many believe that further evolution will or should occur if cooperatives are to continue as effective economic institutions. The proportional principles are one possible set of guidelines for managing control, ownership and benefits (p. 33).

Following are lists delineating the three most relevant classes of cooperative principles organized by three business decision factors. Only the traditional principles share in the additional Rochdale business decision factor of a duty to educate (Barton, 1998). 
Traditional Principles

- Control

- Ownership

- Benefits

- Other

Contemporary Principles

- Control

- Ownership

- Benefits

Proportional Principles

- Control

- Ownership

- Benefits
1. Voting is by members on a democratic basis (a "hard-core" one-member, one vote system)

2. Membership is open

3. Equity is provided by patrons ("hard-core")

4. Ownership of voting stock is limited

5. Net income is distributed to patrons as patronage refunds on a "hard-core" cost basis

6. Dividend on equity capital is limited on a "hard-core" basis

7. Business is done primarily with member-patrons

8. Duty to educate

1. Voting is by member-users on a democratic or proportional basis

2. Equity is provided by patrons

3. Net income is distributed to patrons as patronage refunds on a cost basis

1. Voting is by members in proportion to patronage

2. Equity is provided by patrons in proportion to patronage

3. Net income is distributed to patrons as patronage refunds on a cost basis

While business success is based on many factors, only by understanding and adhering to principles can members, patrons, and managers operate cooperatives effectively in a capitalistic market economy. The ideal of principles is identified as transcending human-made laws, being instead more like canons that express a fundamental truth for a cooperative private enterprise in a contemporary market economy. The duty to educate ought not to be eliminated as one of the principles.

Four words beginning with the letter ' $\mathrm{P}$ ' are used to clarify marketing considerations: product, price, place and promotion are keys to any marketing strategy. The definition of a cooperative by Barton (1989) includes three additional 'P' words: principle, policy and practice. Cooperative principles are meant to preserve the essential 
objectives and uniqueness of this form of business. Cooperatives are structured in part by policies, or rules of management, which must change with conditions to allow and encourage the effectiveness of a cooperative. A practice, or customary action, can become antiquated over time because of contextual changes.

Barton (1989) describes the relationship as follows:

A change in environment sometimes requires a change in policies, which causes conflict with traditional practices. Many cooperative observers believe that some so-called principles are in fact obsolete, given current practices...If the principles are fundamental truths and laws of conduct, they should be invaluable in helping decision makers make cooperatives effective in meeting the economic needs of member-patrons. Another use of principles is to compare and classify cooperatives.

Espousal and adherence to a certain class of principles clearly identifies a philosophy as well as a relationship to policies and practices (pp. 24-27).

\section{Communication and Information Systems for Marketing}

Telecommunications networks, in harness with computers, can be used to create competitive advantage across a surprisingly broad range of activities from peripheral locations, including access to markets for selling goods and advertising services. If questions of limited access to networks and services constitute a major threat to peripheral regions, then it is the innovative use of telecommunications that provides the major opportunities. The significance of telecommunications has little to do with traditional telephony functions of interpersonal communications; it has, rather, greatly extended the economic potential of computing. It is the less developed regions that will have most to gain from the emergence of the network economy since information-rich 
environments could become universalized rather than localized features of the new economic, social and political landscape, or infrastructure (Gillespie, et.al., 1989). Communities, regions and their elected representatives must grasp the economic significance of advanced telecommunications as part of computer network innovations.

Infrastructure is the underlying foundation upon which a community depends for continuance and growth. In this study it is conceptually modeled to include: human skills, networks and systems, technical communication devices, budget and economy as well as policy and law. Communication and information systems are part of this larger infrastructure.

The appropriateness of electronic media for marketing applications by crafts cooperatives depends on the maturity of all five categories listed above. The readiness of craftspeople and craft coops to use information systems is a significant factor in the hindrance or promotion of the use of the telecommunications infrastructure. Readiness describes the state of being prepared to act immediately to achieve an identified goal. It depends on past experience and current potential. In this study readiness refers to the skills that are available to an individual or an organization for establishing or using electronic media to market craft products. The desire for electronic communications has been established by the 1997 plan of the West Virginia Commission on the Arts.

\section{Plans of the West Virginia Commission on the Arts}

The long-range plan of the West Virginia Commission on the Arts (WVCA) provides background to my study. That plan was created to assess the changing environment in which artists (including craftspeople) and cultural organizations work and West Virginia citizens and communities operate. It was completed by the participation of 140 West Virginia citizens through interviews, public meetings, 10 focus group sessions, 
correspondence and response to a survey. The purpose of the plan adopted in January 1997 was to maintain a highly visible and active public information program during fiscal years 1998-2000. (p. 6) The WVCA has an operating principle that is aimed at increasing audiences as well as the quality of artistic experiences as they attempt to integrate the arts into areas important to constituents. The plan involves various policies and guidelines relevant to marketing of craftwork and use of communication and information systems with an emphasis on rural communities, which are traditionally under-served by cultural programs.

The Commission aims to recognize and encourage West Virginia artists and craftspeople that produce wares as well as to help sustain cultural identity and improve the quality of life of communities. These goals involve developing increased capacity to use new information technologies to promote West Virginia artists and craftspeople, to provide them with information, and to facilitate their interactive communication with each other.

Major concerns were voiced at a 1996 focus group in Flatwoods, WV, a Braxton County town that happens to be located in the geographical center of the state. The Executive Director of Arts and Humanities, Lakin Cook, of the West Virginia Division of Culture and History, provided anonymous transcribed statements by participants in that focus group to the researcher. Excerpts relevant to this study are included here under three themes of Rural Life, Communication Technology, and Policy.

\section{$\underline{\text { Rural Life }}$}

- 'The arts aren't seen as an economic resource...only as a cultural resource. It is also a product.' 
- '...the biggest problem is places to market. We frequently drive 7 or 8 hours one-way to present our work at fairs. We have to leave [WV] to find markets. We need access to a clearinghouse of information...We must sell or we don't eat.'

\section{Communication Technology}

- 'We have a WV web site. You could put the information in there. A lot of craftspeople are getting on-line.'

- 'I received [an] underserved artist grant...It allowed me to computerize and do things I was never [before] able to do. [The] computer helped me participate in a computer art exhibition. [The grant and computer] let me set up a website design business as well. The Web gives us direct ways to market. We put up a site. We decided to link our site with other quality work. So we started a group site. More people will visit because there are more artists. Its chancy, but it allows artists to reach its markets directly without middlemen.'

- 'Telecommunications gives us a chance to live in a beautiful location and we can get materials and supplies with a phone call.'

- '[An] underserved grant helped us diversify our business. It has allowed us to go into an exciting new field and has potential to let us make and market work from a distance. We have the possibility of helping other artists as well.'

- 'West Virginia artists and craftsmen's guild could help. They could be the means to get information and training out.'

- 'Tamarack is a great program. I'd like to see a Tamarack North. But they don't have a computerized inventory control. They don't have [a] point of sale inventory system.' 
- 'Tamarack's website doesn't allow interaction. I recommend the WISE system. It's free. Most artists live within driving distance of a library. Artists who go to a local library should be able to tap into WISE and reach other WV resources and global [resources].'

- ' '[Photographic] slides could be put on the Web.'

- ' 'Be sure to make the Web site a way to purchase work or commission services.'

- 'Referrals to artists for commissions is a great gap that would make a big difference to our livelihoods.'

- 'This is a simple matter technologically.'

\section{$\underline{\text { Policy }}$}

- 'The really successful things [go] back to finding a public, we need something that inspires me to do more work or to achieve greater recognition...I wouldn't divert state money to information and services.'

- '...Public arts funding is doomed. We need to cultivate corporate sponsorships for fellowships...precedents have been set...[It] can be prestigious for the companies...Try to link a corporate interest with a specific art form.'

- 'Art and craft show sales are dropping nationally. National debate about cutting the NEA [National Endowment for the Arts] seeps down into consumers' consciousness.' (Bracketed information mine on these anonymous statements). As a result of this focus group, it can be summarized that, in practice, this population is knowledgeable about crucial elements of the infrastructure. The extent of comments regarding communication technology obviates the importance of telecommunication issues. The limited types of comments about policy reveal that this population is less knowledgeable about the potential extent of these issues than it might 
be. Comments about rural life reveal common sense. Throughout the commentary are references to other essential components of a mature infrastructure such as economy, networks and human skills.

\section{Purpose of the Study}

Value-added craft production has recently increased in the United States. Several factors have contributed to this growth. An increased interest in American heritage (including a diversity of ethnic craft skills), increased leisure time, greater emphasis on the personal qualities of hand-produced items, and need for additional income seem to be factors. Yet, an estimated 250,000 to 350,000 of the nation's 83 million craftspeople have earned meager profits from retail sales of their wares.

Efforts at self-support through craft production involve frustrations such as lack of market contact, lack of feasible access to sources of supply and lack of business training. Wholesaling involves much more than negotiation. It means solving problems in shipping, storage, financing, risk bearing, and market information. These considerations must be addressed either by the craftsperson or by a larger organization. The need for assistance with these problems has prompted craftspeople to form cooperative organizations (Halkett, et.al., 1985) in the past. The data from this survey will reveal that West Virginia craftspeople have marketing needs that can be well met by a use of cooperative enterprise.

Like most institutions, coops were created because of strongly perceived economic needs. The extent of a cooperative's growth and development until now has been due to its ability to effectively meet the needs of patrons in a capitalistic, competitive economy characterized by a changing economic environment. The future of 
these organizations will be determined by their ability to continue meeting those needs (Barton, 1989).

Marketing, advertising and self-promotion are key factors that influence the success of all small businesses. It follows that the success of Appalachian craftspeoples' businesses to survive in the 21 st century will likely depend on their readiness to adopt new marketing strategies. This is partially due to the international nature of the current business environment. It appears worthwhile for craftspeople to cooperatively engage in learning about and using communication and information systems for marketing their products. Utilization of communication and information systems for marketing wares will increasingly impact West Virginia craftspeoples' economic survival.

\section{Problem Statement}

Creative ideas and production of wares are not problems for craftspeople, but making a profit from their efforts has proven problematic. This implies that all types of craftspeople and craft organizations have learning needs regarding the ever-evolving communication and information systems as they relate to marketing, advertising, promotion and sales strategies. Many of these might best be addressed cooperatively.

Therefore, the goal of this research was to determine hindrances to the readiness of craftspeople to engage effectively in the use of a telecommunications infrastructure to market their products. Upon identification of the level of readiness, skill and knowledge needs can be characterized as either amenable to a cooperative intervention or not. To solve the problem of this research, four groups of survey questions were aimed at West Virginia craftspeople. 


\section{Research Questions}

The study addressed individual West Virginia craftspeople concerning four areas:

1) skills and knowledge, 2) readiness, 3) perceptions of infrastructure, and

4) perceptions of access to communication and information systems. A fifth set of questions involved demographics.

1. What are the skills and knowledge individual craftspeople have used to market their wares utilizing electronic media?

2. To what degree can existing individual readiness (experience and potential) fulfill the objectives of establishing and using electronic media for marketing their West Virginia craft wares?

3. What is the maturity of the existing infrastructure from individual craftpeoples' perceptions?

4. What is the perceived degree of access to electronic media by individual craftspeople for marketing their wares?

\section{Assumptions of the Study}

For the purposes of this study, the researcher assumed that the participants were living in southern Appalachia and were producing craft products in the state of West Virginia. Therefore, the sample group can be described as West Virginia craftspeople.

The following considerations were relevant to this study:

1. The reported perceptions of the craftspeople surveyed represented their personal experiences of marketing their products.

2. The inquiry areas identified through the review of literature provided an adequate basis upon which to construct the survey instruments. 
3. Craftspeople have the potential to include in their marketing strategies plans to utilize new communication and information systems or electronic media (beyond print, direct mail, fairs, festivals, retail and wholesale outlets) to reach consumers.

4. Readiness (experience and potential) is an important factor in craftspeoples' efforts to market their products using information systems. Developing these skills requires assistance, education and/or training to proficiently apply knowledge.

5. The individual craftsperson, as a member of a cooperative, can participate on multiple levels (individual as well as various categories of group effort are viable).

\section{Limitations of the Study}

The following limitations were identified for this study:

1. Research was limited to the identification and classification of knowledge and skills needed to market craft products using electronic media.

2. The population comprised only Appalachian craftspeople producing in the state of West Virginia, as contrasted with a possible comparative study.

3. Participation in the study was on a volunteer basis, with survey participants names and addresses acquired from the West Virginia Division of Culture and History from lists of craftspeople that submitted photographic slides of their work to be considered for inclusion in this database.

4. The number of usable surveys was relatively low, at 46 of the 60 returned. The 60 returned surveys came from a random sample mailing of 190 surveys from the identified population of 946 craftspeople. Whether this is a fully representative sample is undetermined, yet based on other educational researcher's samples, 
$20 \%$ has been considered an adequate statistical representation for this type of study. 


\section{CHAPTER TWO: REVIEW OF THE LITERATURE}

As business people, craftspeople might best be described as entrepreneurs.

Entrepreneurs are people who create business organizations. A disposition of willingness to consider various outlooks on life and an ability to cooperate and deal with differences of opinions and situations openly and effectively characterize the successful entrepreneur. Financially successful entrepreneurs have been found to be particularly active in networking with business people, regulators and union representatives.

This review considers the history of cooperative enterprise, its role for craftspeople, types of coops, the features of organizations of coops, and issues of membership.

Tjosvold \& Weicker (1993) state that considerable research has documented and extended the following theories of cooperation, competition and independence:

In cooperation, people believe their goals are positively linked so that as one moves toward goal attainment, others move toward reaching their goals. They understand that their goal attainment helps others reach their goals; they can be successful together. In competition, people believe their goals are negatively related so that one's success interferes with others'; one's successful goal attainment makes others less likely to reach their goals. People with independent goals consider their interests unrelated so that the goal attainment of one neither helps nor hinders other's goals (p. 12).

Entrepreneurs who develop cooperative goals (compared to competitive or independent goals) coordinate successfully with people in their network, thus developing their own businesses. These entrepreneurs tend to rely extensively on the informal networks of family, friends and business people, and less on the formal network of banks, accountants 
and lawyers. Cooperative entrepreneurs were found to express their own views freely. They tended to consider others' views open-mindedly, tried to understand what each other was trying to accomplish, disclosed important information, and in other ways worked toward mutual benefit. These cooperative goals and resulting interaction helped them to invent new ideas and motivated them to strengthen their businesses (Tjosvold \& Weicker, 1993).

\section{Cooperatives}

A review of the literature provides a rich description of some, but not all, aspects of cooperatives. Cooperative organizations have been resilient and adaptable. These forms of business have been used for hundreds of years and under very different types of governments. In all cases, cost or revenue allocation schemes devised by boards of directors and managers reflect the viability or strength of various coalitions associated with the cooperative.

\section{History and Background of Craft Cooperatives:}

\section{(Operational Principles of Organization and Legislation)}

Craft cooperative organizations have their historic and theoretical base in credit unions and in agriculture. Three important historic precedents deserve mention. Instead of policies, per se, coops today operate according to four classes of principles. The development of cooperative principles of organization and legislation have evolved in various ways since the Rochdale Society of England developed the first set of cooperative principles between 1844 and 1860: 1) business at cost, 2) democratic control, 3) limited dividends and 4) patron ownership remain principles relevant to today. While this study is intended as a contemporary analysis, two important US political events, both acts of legislation, over the past century shed light on the historic 
base of cooperatives. The first event was the Sherman Antitrust Act and the second event was the Capper-Volstead Act. Legislated in the US, the Sherman Antitrust Act of 1890 declared monopolies illegal and the Capper-Volstead Act of 1922 simply provided that farmers could organize marketing coops without violating antitrust laws. These are significant historic precedents, limiting and defining adaptations in principles and practices over time.

On the history of North American belief systems that equate economic power among competing businesses to yield the greatest benefit to society as a whole, Barton (1989) writes,

This concept was formalized by the Sherman Antitrust Act of 1890, which declared monopoly illegal. That law and others that refined it held that two or more parties could not get together to agree on prices and other restrictive marketing practices. In the late nineteenth and early twentieth centuries many agricultural producers found many farm input and product markets to be inadequate or unfair. Operating individually, they were unable to get needed supplies or sell their products at what they considered reasonable prices. Consequently, they organized farm supply cooperatives through which to buy farm inputs such as fertilizer, feed, fuel, and chemicals, and organized marketing cooperatives to help them market farm products such as grain milk, cotton, vegetables, and fruit at fair prices (p. 17).

Although farmers organized cooperatives to create a more balanced competitive environment, these organizations could be considered violations of antitrust statutes. 
So, Congress passed legislation that protected coops (and other societal sectors such as labor forces) from antitrust laws. Historians consider the 1922 Capper-Volstead Act as a cornerstone (or magna carta) of marketing coops. Barton (1989) describes that Act:

It simply provides that farmers can organize marketing cooperatives without violating antitrust laws, as long as members are agricultural producers, no member has more than one vote or dividends on equity are less than $8 \%$, non-member business is less than $50 \%$, and prices of products marketed are not unduly enhanced. Legislation has also been passed which provides for the single-tax treatment of patronage-based income, thus avoiding the double-tax treatment of IOF [Investor Oriented Firm] corporations (p. 17). In the worldwide economic context, many problems we face today result from inadequate planning and shortsightedness. Groves (1985) notes that past evolutions are a prologue to the future and that the United States is now in a world of equal competitors. This is in contrast to the mid-1950s post World War II global situation when the US had an enormous technological lead. Decisions are now made in an entirely different economic and philosophical climate than existed twenty, thirty or forty years ago.

Craft cooperatives have evolved for various reasons. Value added to resources is key to the idea of craftsmanship. Production is generally not perceived as a probleminstead it is usually considered as rather joyous, and is often accomplished at home with minimal facilities. Likewise, supply is generally not much of a problem for craftspeople that tend to use mostly indigenous materials for producing their wares. Also, contributing to the community or society is a natural positive by-product of craftsmanship. So, what is the problem? Making a living through the marketing of those wares! 


\section{$\underline{\text { Making Ends Meet }}$}

To survive, craftspeople must involve themselves in contemporary forms of business, while their modes of development follow more traditional patterns. Business is a form of survival in and development of the societal economic base. Development is the process of using known methods and procedures or creating new methods and procedures for the purpose of evolving an invention or innovation from initial idea or pilot to commercial application. For craftspeople, developing a form of marketing suited to present economic circumstances requires a modern business organization.

A business organization can be a proprietorship, a partnership or one of three types of corporations- regular (or 'for-profit'), non-profit, or cooperative. Coops differ from other forms of business organization. These differences are both legal and operational. Cooperatives are not to be confused with non-profit organizations since they are, in fact, oriented for profit (Cobia, 1989; Mancuso, 1992). The cooperative form of organization most nearly conforms to the practices, philosophy and lifestyle patterns inherent to the production of crafts.

In a cooperative, members are the owners, and as such have control over their organization: each person has one vote. Members join primarily to sell similar goods and/or services collectively. They may be either self-employed individuals or businesses (cooperative or otherwise).

Estimates from 1985 showed that there were 200 handicraft cooperatives in the United States with a total membership of 25,000 crafts people (Hoyt, 1989). Many of these coops existed in non-urban areas. While in a good position to deliver arts to the rural areas, matching products with urban markets requires considerably more planning. Coop members must be fully aware of costs and how they are to be covered. Expenses 
must be met either by the members themselves, community user contributions, special grant projects and/or government subsidies.

Employee-owned cooperatives are the country's oldest form of employee ownership (dating back to the 1770s), yet interest in them has fluctuated in cycles. A decline in their popularity took place for several decades until the late 1960 s when social instability set in and traditional notions of careers were questioned. By the 1980s, Hoyt reports employee ownership was effective as an alternative strategy to save jobs and retain local control of businesses. It has also become an attractive tool for community economic development. Therefore, leaders began to adapt parts of the US tax code to favor cooperatives (Hoyt, 1989).

Businesses exist for both economic and social purposes. The cooperative form of business is flexible and can be applied to nearly any business endeavor. Cooperatives must be careful not to fall into the same trap, as have IOF firms. In other words, the only test of success should not be whether or not the bottom-line figure on the operating statement is black. As Groves (1985) states, American businesses are often criticized for operating in the short run and ignoring

...the long run (i.e., looking for the short-range maximization of profit to pay shareholders rather than long-run gain for the corporation). A longrange outlook has been rated as a strength for businesses in other countries, and short-range outlook as a weakness of business in the US (p. 20). Rural and urban people alike engage in craftsmanship, some as a hobby and others for a livelihood. Yet there exists a great difference in access to markets between the two groups. Leary and Roy (1975) observed that rural craftworkers are at a disadvantage in marketing their products while urban craftworkers have a greater range 
of opportunities for marketing theirs. This difference is a vital consideration in the West Virginia context, where most craftspeople operate in a rural environment. Studying craftworkers' cooperative strategies, they pointed out eight dissimilarities between rural and urban settings that rural craftspeople must acknowledge:

- They have more limitations in choice of marketing outlets and alternatives.

- They might have to operate over wider areas to acquire sufficient membership.

- They might have lower break-even points of operation because of lower building costs or lower rentals on fixed facilities and lower labor costs.

- Coops could be capitalized with personal FHA loans, yet the typically lower average incomes might handicap rural craftspeople to contribute their own equity capital.

- Their outputs may differ given closer proximity to nature and relatively more time to explore diverse subjects.

- They may have fewer opportunities for formal training.

- They may have more familiarity with and knowledge of coops.

- They may be more inclined toward producing crafts as a way to supplement income.

While there exists a hindrance for craftspeople to market their work, marketing ventures undertaken cooperatively appear beneficial. Groves (1985) offers an example in favor of coops asserting that people are frequently at their best when economic conditions are at their worst. He states that:

It is always easier for businesses to grow in a period of economic expansion; yet cooperatives have experienced their most rapid growth in times of economic difficulty. It is during hard times that people have looked toward cooperation as one way of easing some of their economic problems and maximizing their limited income (p. 12). 
Even so, coops survive for only six to ten years, as circumstances change. For example, when a coalition of members can lower costs by forming a spin-off cooperative more economically, a cooperative becomes politically unstable because it fails to achieve minimum net price for members. This problem confronts not only marketing cooperatives, but also multi-purpose coops. As described by Schmiesing (1989),

If the members patronizing successful divisions do not patronize the losing divisions, internal conflicts will develop. Some will thus advocate divesting unprofitable divisions or forming a new, more profitable cooperative.

However, these strategies may be offset by cost savings in the function areas such as finance or marketing of the diversified cooperatives (p. 169).

\section{Types of Craft Cooperatives}

A common way to classify coops by function is to sort them into the following categories: manufacturing/production/worker, supply/consumer, marketing/advertising/promotion/sales, and multi-purpose or diversified (Greer, 1988; Groves, 1985; Halket, et. al.; 1985, Hoyt, 1989; Nash, 1976; Roy, 1981). While individual members of coops will have a whole range of aims and objectives, the existence of a common purpose for organizing is basic to the formation of a coop. The most appropriate structure depends on the common purpose of the individuals forming a coop (Roy, 1981). Each structure provides different benefits to members, as clarified by Greer (1988):

In a worker coop where the members of the coop are its workers, each individual worker is employed by the members. In contrast, neither the members of a marketing nor a consumer coop are employed by their cooperative. The members of a marketing coop 
are self-employed individuals, or businesses, and the members of

a consumer coop are the customers of the coop (p. 3).

In summary, a worker coop is intended to provide stable employment while a marketing coop is intended to provide stable markets.

Manufacturing/production/worker

Shared workshop space is the major reason most craftspeople establish a coop: to provide themselves with a facility in which to pursue individual production activities. The members are the workers. These coops exist where workers join primarily to conduct a business and enjoy the benefits of employment. Worker coops can be applied to most types of business activity (Hoyt, 1989). Production coops for craftworkers are normally plants, shops or studios that are owned and operated by the workers themselves. These may include a marketing operation where crafts items are produced individually but marketed cooperatively (Halket, et.al., 1985). Therefore, productive cooperatives may include both production and marketing activities, thus making them multi-purpose organizations.

\section{$\underline{\text { Supply/consumer }}$}

Consumer coops occur where members join primarily to provide themselves with goods, services and/or facilities consistently. Members do not enter into an employment relationship with the coop, but are rather the 'customers' of the coop. Supply/consumer coops for arts and crafts raw materials have proven to be an attractive idea to craftworkers because of price savings on bulk purchases and avoidance of middleman (or agent) costs for service. In one study, approximately 94 percent of Louisiana craftspeople stated interest in patronizing a supply operation, but only if prices were lower or competitive with buying at retail as individuals (Leary \& Roy, 1975). 
Marketing/advertising/promotion/sales

Supply coops and marketing coops differ in the theories used to explain their relationships with member-patrons. A patron's output is an input in a marketing coop's production process. Therefore, issues confronting the patrons, management and board of directors are also different (Schmiesing, 1989).

Craftspeople spend their time and energy to create products, and are typically not skilled at, nor very interested in, the marketing aspects of their work. The goal of a marketing cooperative, therefore, is to assist members to reach markets for sales of their work. The marketing coop is seen as a good method for reaching the marketplace with individually produced arts and crafts. This is due to the concentration of products together with a concentration of buyers. Craft outlets, such as local retail craft shops, are probably the most common forms of arts marketing coop (Greer, 1988).

Leary and Roy (1975) queried Louisiana craftspeople about their coop commission preferences. Percentage commission for the coop's selling function in the marketing of the arts and crafts as preferred by the craftworkers interviewed follow:

- About half of the craftworkers preferred that the coop receive from between 20 and 30 percent commission of the sales price.

- About 12 percent favored an 11 to 20 percent commission for the coop, and for another 12 percent, the percent commission was not ascertained.

- Nine percent were willing to allow the coop whatever commission the coop desired or needed.

- Six percent of respondents expressed no idea and six percent indicated no patronization of coops.

- The remaining 6 percent of the craftworkers wanted the coop to take either a 
1 to 10 percent commission or a commission of over 30 percent. The average percentage commission preferred was 24 percent (Leary \& Roy, 1975, p. 15).

The method of valuation used by craftworkers in setting a price for an art or craft item was also studied by Leary and Roy (1975). They found that:

- About three-fifths of the Louisiana craftworkers interviewed priced their wares considering material cost and some other factor (usually labor expended), demand for the item, selling price of competing items, and or desired selling margin.

- Over 18 percent of the craftworkers considered demand, or what the people would pay, as the basis for setting a price.

- Nine percent priced or would price on the basis of material cost only.

- The remainder, or about nine percent, either desired no patronization of the coop, or their method of valuation was not ascertained (Leary \& Roy, 1975, p. 14). Preferred retail selling arrangements of the Louisiana craftspeople in that 1975 study were found to be as follows:

- About 40 percent of those interviewed preferred a cash sale over any other type of arrangement. These craftworkers preferred selling their items outright to a coop, or to individuals, or to retail outlets for cash at time of sale.

- About 21 percent preferred a combination of sales arrangements which included cash sale, consignment sale, any coop sales policy, coop financing of raw materials, and/or commission sales.

- Eighteen percent had no preference as to the type of sales arrangement and would go along with any coop sales policy. 
- Only 15 percent preferred consignment selling, and the remaining six percent desired no patronization of the coop but preferred to sell individually (Leary \& Roy, 1975, p. 14).

The above Louisiana excerpts from interviews and statistics about coop commission preferences, while more than several decades old, are probably relevant yet today for this study because artisans in West Virginia share with craftspeople in Louisiana common stories and issues due to the proximal rural nature of the states in which they live. There are results to be considered as relevant to other rural areas. All southern Appalachian mountain areas share a relatively common economy, history, politics and culture. Therefore, a coop's success, in regard to the selling function in the marketing of crafts today, would likely be similar throughout this region of the United States. However, the most relevant research available happened to be conducted in the adjacent state of Louisiana, where issues may be said to overlap.

\section{$\underline{\text { Multi-purpose }}$}

A multi-purpose, or diversified, craftworkers coop could include a combination of workshop space, marketing activity, community access, and/or housing and/or supply. The activities of a coop set up by members to provide themselves with a joint production facility can be relatively simple and initial capital contribution from each member low.

Craftspeople may take advantage of their close association to undertake some joint marketing activities, as the members' wares may well be displayed jointly. This should provide little problem if the marketing activity is confined to the work of craftspeople who joined the coop to share workshop space. However, problems can arise if membership is extended to those who wish to use the space only for marketing and not for producing their wares. Problems may arise out of differing expectations that could 
undermine the coop's effectiveness. Likewise, providing non-profit community access to the facility has direct financial implications for that coop. Due to potential organizational problems arising out of the complexity of purposes, these types of coops are advised to research policy issues of incorporation and legislation (Greer, 1988).

Greer's (1988) research suggests the better viability of an organization that focuses its attention not on running outlets, but rather on operating and managing a network of marketing opportunities for its members. It's important to establish a well thought-out agreement between the members and the coop on matters of quality, continuity of supply and price setting. While the coop could run some outlets, the emphasis and resources might best be directed mostly toward developing and executing a strategy to penetrate a range of markets. The members might come from various places and be comprised of combinations such as: individual artists and craftspeople, craft outlets, galleries and agencies, production cooperatives, and other arts business organizations.

Another strategy Greer (1988) proposed exemplifies an arts worker coop comprising craftspeople, designers and art marketers to become a multi-purpose organization,

The designers' work could produce designs for the crafts people, who could develop the model and then pass it on to the worker cooperative, which would produce the work, which in turn would be carried to the market via the co-operative's marketing expertise. The circle would be completed by feedback from the market to the designers (p. 71). 
This cooperative strategy would create specialization, a shift from traditional independent craftsmanship. It is likened to a flexible production network, such as Appalachian By Design, which currently involves dozens of women weavers throughout rural West Virginia. Identifying some of the major strengths and weaknesses of these types of craftworkers organizations helps to clarify the purposes of conducting this study about cooperative marketing, advertising, promotion and sales of craft products utilizing electronic media.

\section{Characteristics and Organization of Cooperatives Relevant to Craftspeople}

All coop types share the cooperative principles, which establish a framework for a member-owned organization that is democratically controlled by its members. It is those principles that distinguish coops from other forms of organization, such as IOF and nonprofit organizations.

Coops can create economies of scale for acquiring supplies, sharing means of production, and procuring easier access to markets that all result in cost savings. In addition, shared risk is strength: initial capital contribution from each member is relatively low compared with other business options. Flexible application of the cooperative concept and multi-purpose combinations are possible. Coops can do bulk buying, share facilities and services, and enhance individual exposure by marketing together. Additionally, patron ownership and democratic control provide a sense of autonomy.

On the other hand, due to their non-hierarchical organization, cooperatives are relatively unstable. Inefficient operations are characteristic. Response to changing markets may be slow, client communications can be muddled, and on-going management can be anarchic or disorderly'. Depending on the coop, capital is relatively non-liquid, 
which can lead to inflexibility in the face of changing markets. The shared risk aspect of this policy can be considered a weakness by the more financially successful of the craftspeople at any given time. Members must be educated in the function of coops and individuals' roles. Differing expectations abound. This education costs time and money. A successful craftsperson that has an IOF can make more income than a successful coop craftsperson because of the limited dividends policy of cooperatives.

\section{$\underline{\text { Stability }}$}

Most coops dissolve within six to ten years, as circumstances change (Cobia, 1989). There are two interventions that can lead to greater stability: education and funding. In any democratically controlled organization, education programs are needed at all levels. Members need education for decision making in what are quasi-public policy making procedures. Members, directors, managers and employees all need continuous cooperative education to understand their responsibilities and to make sound decisions (Groves, 1985).

Where funding is concerned, the coop's viability will depend on the probability of attracting funds to cover costs, rather than the mere possibility of this occurring. From a game theory analysis, the internal decision-making process for marketing coops is a strategic one, not a game of chance. According to Staatz (1983),

Many cooperative choices involve group decisions that can be conceptualized as 'cooperative' games. These groups of individuals can gain from acting jointly. Successful cooperation, however, requires that the group members communicate and bargain, as well as compromise, in order to determine rules for the allocation of costs and benefits. Once they have agreed on allocation policies, the individuals must then make and keep binding commitments to 
follow these policies (p. 1084).

This situation would tend to require a longer reinforcement horizon than is necessary with an IOF, however research has shown that neither type of organization remains successful beyond five or six years, as circumstances change (Dodge \& Robbins, 1992). Coops and their principles are a means to the end of effectively meeting the needs of patron-members. Upon leaving a marketing coop, a member is entitled to his or her capital contribution, plus any limited return that the coop may have allocated but not yet paid.

Theoretical Concepts

Cooperatives, more than any other type of business, have tried to combine the theories of social and economic systems while designing a business. Theory, however, has been used much less than experience or belief systems to derive actual principles. The primary use of principles is to serve as guidelines for coop directors, managers and legislators (Groves, 1985).

Cooperative goals and interaction have been found to contribute significantly to successful networking (Tjosvold \& Weicker, 1993). People within organizations may assist each other and work together in solving problems without strong specific common goals because of generalized beliefs that they should contribute to the organization.

\section{Operational Rules}

All businesses operate under some rules and principles, whether well defined and written or only in the mind of the manager. All coops share the principles that establish a framework for a member-owned organization that is democratically controlled by its members. It is those principles that distinguish coops from other forms of organization. 
Financially, the contribution to owners' equity and distribution of net margins is proportional to use by current member-owners.

The latest known American revision of cooperative principles was written in 1984 by Ingalsbe (Director of Agricultural Cooperative Service Information and Education Staff), Jacoby and Simpson (members of the American Institute of Cooperation). Together they felt there were four principles and three practices relevant to the present state of coops. According to these authors, an organization must follow four key principles if it is to be a true cooperative. Those are: service at cost, ownership benefits in proportion to use, democratic control, and limited return on equity capital. They define a practice as an action that supports, complements, or carries out a principle. These practices are not distinctive to a cooperative, yet can make a difference between long-run success and failure. According to Groves, cited by Ingalsbe, Jacoby and Simpson, the 1984 practices of most importance were determined to be: continuing member education, cooperation among cooperatives, and operations on a sound financial basis.

Six principles of the philosophy of cooperation as adopted by the International Cooperative Alliance are outlined in Greer (1988) as follows:

1. Membership of a co-operative society should be voluntary and available without artificial restriction or any social, political, racial or religious discrimination, to all persons who can make use of its services and are willing to accept the responsibilities of membership.

2. Co-operative societies are democratic organizations. Their affairs should be administered by persons elected or appointed in a manner agreed by the members and accountable to them. Members of 
primary societies should enjoy equal rights of voting and participation in decisions affecting their societies. In other than primary societies the administration should be conducted on a democratic basis in a suitable form.

3. Share capital should only receive a strictly limited rate of interest, if any.

4. Surplus, or savings, if any, arising out of the operations of a society belong to the members of that society and should be distributed in such manner as would avoid one member gaining at the expense of others.

This may be done by decision of the members as follows:

(a) by provision for development of the business of the co-operative;

(b) by provision of common services; or

(c) by distribution among the members in proportion to their transactions with the society.

5. All co-operative societies should make provision for the education of their members, officers, and employees and of the general public, in the principles and techniques of co-operation, both economic and democratic.

6. All co-operative organizations, in order to best serve the interest of their members and their communities, should actively co-operate in every practical way with other co-operatives at local, national and international levels (p. 94). 
Membership

Because the purpose of a coop is to maximize member income, member relations are a challenge for these organizations. Profit maximizing decisions are not always the best for a given individual member. To many people, the idea of cooperation means equal treatment in regard to pricing, voting, time, etc. However, Schrader (1989) clarifies that:

Even though the principle of business at cost implies unequal prices when the costs of serving patrons vary; there is often a confusion of equity with equality. The need to distinguish clearly between equity and equality increases as the variety of patrons becomes more diverse (p. 426).

Because those who own, use and control the cooperative are the same people, members need skills and knowledge for decision-making. These members make selection of a director for the business. Since the board of directors, or half of the management team, is composed of volunteers, they do not really fit the definition of either 'inside' or 'outside' directors. Like non-profit managers, they occupy a unique position of being 'in' the cooperative yet, in many ways, not 'of' it. The board must be aloof from routine management decisions and be in a position to judge the performance of the organization from an objective standpoint. This is because it is legally responsible for management, and as such may not always be in harmony with the desires of the members (Groves, 1985). 


\section{Investor-Oriented Firms (IOF)}

Craftspeople are often entrepreneurs, assuming risks in hopes of making a profit by organizing and managing their own businesses. These are all small firms by any standard, based on sales volume and number of employees. Entrepreneurial craftspeople tend to be an independent group that has particular talents and trades. This implies a major focus on production of the wares, with a resulting lack of emphasis on marketing them.

Many small business people conduct their marketing quite informally. Friendly and convenient verbal exchanges with suppliers, distributors and potential customers characterize marketing for this group. Usually these craftspeople are quite aware of the marketing challenges of competing with large financially secure firms. They tend to find niche markets for their products.

\section{$\underline{\text { History and Background of IOF Craftworkers Firms }}$}

The dominant reason for an investor-oriented firm's existence is to generate income for its owner(s) or shareholders. Profit, or return on investment, is the major reason for becoming involved in this type of organization. Financially, the sole difference between a craftworker's coop and an IOF craft firm amounts to availability of capital. How money is organized (acquired, used, and redistributed) is the essential difference.

In terms of money allocated, IOF craft firms put marketing secondary to other business costs. Limited financial resources create problems in conducting quality marketing, expanding new markets, extending credit, and dealing with advertising costs. 
Furthermore, the owners do not actively or formally acquire marketing assistance through secondary or primary research.

Craftspeople have always had niche markets, and seldom have fit well with any mass marketing paradigm. Niche markets and target markets remain key to a craftsperson's IOF: particular classes of customers are targeted in an attempt to effectively satisfy their distinct desires. The success of target marketing by larger enterprises implies that successful small companies should also consider the strategy of market segmentation. In fact, even non-profit organizations have shown this segmentation strategy useful for the purpose of fund raising. Diverse applications of market segmentation methods have been shown effective by museums, performance arts groups and higher education institutions (Petersen, 1991).

\section{Types of IOF Craft Firms}

In general, an IOF industry deals with retailing, service, manufacturing or wholesaling (Petersen, 1991). Craftspeople primarily manufacture or produce their wares, yet also must usually involve themselves in sales activities to survive financially. To make sales usually requires some extent of marketing, advertising, and/or promotion.

A small crafts firm could be a sole proprietorship, a partnership or a regular corporation. Shared fiscal responsibility for these businesses evidences itself in the forms of investment, loans and interest. Traditional business equates membership priority as shares in stock. This means that individuals with more shares or capital contribution get more votes in the affairs of the organization.

Small businesses differ greatly, as do their needs. Very small firms, typical of craftspeople, appeal to local market niches that are relatively immune from competition with larger rival firms. Satisfaction with a method of marketing is a result of its inherent 
value as well as the manner in which it is employed. A marketing method that proves useful to one company may not function well for another (Petersen, 1991).

\section{Characteristics and Organization of IOFs Relevant to Craftspeople}

An IOF organization has its focus on profits, not sales per se (Petersen, 1991). In fact, many craftspeople are able to sell their wares, yet have difficulty making enough income from those possible sales to cover production expenses of material cost and labor expended. This implies that the company necessarily folds.

To identify some of the major strengths and weaknesses of these craftspeople's investment oriented firms helps to clarify the purposes of conducting this study about contemporary crafts cooperative marketing, advertising, promotion and sales of wares utilizing electronic media. This background information clarifies some of the inherent advantages and problems a craftsperson faces trying to market non-cooperatively. One of the advantages is that craft production generally shares the benefits of other small businesses in regard to flexibility. The weaknesses of these IOFs, however, are significant, and can be addressed by working together with other craftspeople in similar situations, sharing financial, human and information resources. Given widespread communication technology advances, and craftspeople's general lack of a competitive attitude, cooperative approaches to marketing that acknowledge new means of promotion seem logical.

Small firms have unique advantages over larger ones because of their size and flexibility. These strengths include the ability to make rapid changes in basic orientation, swift implementation of major decisions, proximity of markets and significant customer loyalty (Bergeron \& Raymond, 1992). An IOF can adapt rapidly to market changes due to streamlined decision-making inherent in those types of businesses. Economies of scale 
production are possible if a non-unique quality of item is to be produced for sale. Availability of liquid cash is possible, providing flexibility in response to changing markets.

On the other hand, small IOFs generally lack the required financial, human and information resources to thoroughly analyze the firm and its environment (e.g., markets, competitors and strategic position). These firms also tend to offer a limited number of products to a very specific market, which increases their vulnerability. They have little control over their extra-organizational situation, meaning they usually face greater environmental uncertainty than larger firms (Bergeron \& Raymond, 1992).

In an IOF, the workers' needs are often sacrificed to market demands. For those craftworkers unable to comply with these demands, unemployment results. Otherwise, labor is repetitive and thus tends toward alienation. Interests of investors hinder the autonomy of craftspeople (e.g., a new process or item may not be supported because the company decides it must continue producing only 'hot' items). Individual capital investment and risk is relatively high. Also, high taxes and expensive insurance costs are a problem for these small businesses. There loom lawsuit scares more and more frequently for IOFs. Additionally, failure rates are high for these entrepreneurs; businesses often fold within only one year.

$\underline{\text { Stability }}$

In an IOF the contribution to owners' equity and distribution of net margins is based on the money available to invest and proportional return on investment (Groves, 1985). A firm's stability therefore depends on its profitability to the owner(s) or shareholders. 
Development of any business organization tends to follow a predictable pattern of stages. The starting point is a struggle for autonomy in the creation and development of a viable enterprise. This is followed by expansion and then stability and institutionalization. Small firms face different sets of internal and external environmental variables from larger organizations as they follow patterns characterized by sequential and progressive stages. These variables cause problems that must be solved if the momentum of the business is to be maintained. It is apparent that those problems often are not effectively solved. It has been estimated that about 55 percent of small businesses fail within five years of inception, and 81 percent fail within ten years (Dodge \& Robbins, 1992).

\section{Theoretical Concepts}

Profit-minded competitiveness is the driving force in an IOF. Sales measures lead a firm to become sales-oriented, and perhaps less able to generate the necessary income to sustain growth. Therefore, goals should be defined in terms of profit rather than sales.

Policy-making procedures are often private affairs. Research and development requires information on events outside the organization in order to identify and interpret potential trends. Therefore, an owner, president or manager should be continuously scanning the environment for opportunities and threats in regard to the business venture (Meziou, 1991).

The managerial philosophy of many small business executives (particularly those who have attended courses or seminars on marketing) prioritize by 1) emphasizing customer satisfaction at all levels of the organization, 2) offering products that are perceived to truly satisfy customer needs or wants, 3) striving to achieve efficiency in 
producing goods, and 4) keeping customers in mind when pricing products. Most do not conduct formal marketing research and acknowledge that they need more research and development on three marketing aspects of their companies: a one-year marketing plan, long term plans and marketing segmentation. Segmentation identifies the concept that a firm must achieve customer satisfaction by providing the right marketing mix to the right group of customers. Meziou, 1991, clarifies further that a firm must offer one product to a specific segment (concentrated marketing) or several products to several segments (differentiated marketing).

\section{$\underline{\text { Personality }}$}

Among most craftspeople, the individual entrepreneur is the business. The craftsperson makes personal decisions and creates the business, yet (s) he does that within a context of working with many other people. Therefore, in order to succeed in business, it has been found that personality characteristics of an entrepreneur to network and cooperate are very important. Networking relationships tend to be less structured than those within an organization. That networking context, however, may be appropriate for these individuals who might be characterized by motivation and skill in developing mutually rewarding relationships. Recent studies show that goal interdependence among small IOFs highlights the importance of networking and suggests that entrepreneurs need skills to develop cooperative goals and proficiencies. Entrepreneurs are advised to be open-minded, considering different points of view and to persist through adversity. Negotiating differences becomes important, as well as responding to both the encouragement and the criticism of others appropriately (Tjosvold \& Weicker, 1993). 


\section{$\underline{\text { Operational Rules }}$}

The decision making process is such that a person receives one vote per share of common stock. Director selection can be from inside and/or outside the business, yet top-down decision-making is characteristic of any IOF.

Few, if any, crafts companies have a formal marketing department headed by a marketing executive. Because of this fact, the owner, president or a manager typically makes marketing decisions. This decision-making power can be defined as capacity to affect goals or, as control over valued resources (Tjosvold \& Weicker, 1993).

It has been shown by Tjosvold \& Weicker (1993) that entrepreneurs can develop a useful network by strengthening their cooperative goals with network members, showing that the relationship can be win-win for various players. A loan officer, for example, could build up a portfolio and an entrepreneur could receive the equipment needed to be productive and repay the loan. One entrepreneur formed a mutually beneficial relationship with a retailer of her glass crafts. The retailer suggested, for example, that she sell her products in boxes, advice that boosted sales in that shop as well as opening other marketing avenues. Knowing people within the target market before the need to sell craftwork helps. Friends also help entrepreneurs with cooperative links. An accountant friend might provide services of experience and advice to the craftsperson that later result in more business and referrals for the accountant.

\section{$\underline{\text { Membership }}$}

It is popular to think of an entrepreneur in isolation overcoming obstacles and fending off dangers all alone. Although compatible with the myth of being a rugged individualist, this notion doesn't take into account the critical importance of developing a network of people. A network becomes essential for individual IOF craftspeople because 
they need people to turn to for ideas about new ways to look at a given issue and for expanded knowledge in general (Tjosvold \& Weicker, 1993).

The purpose of membership in an IOF is to maximize returns to stockholders. Membership and shares are synonymous, so people with more shares or capital contribution get more votes in the affairs of the organization. To reiterate, the structure is such that those who own, use and control the business may be different people. A major difference for a craftsperson marketing wares in a cooperative and marketing as an IOF amounts to the personal availability of liquid capital.

\section{Communication and Information Systems (CAIS)}

Most organizations use information in all their daily activities, and communication in any of its various forms is essential to functioning. These forms have evolved exponentially in the past several decades, with recent changes impinging significantly enough on marketing to warrant their inclusion in this study on craft marketing.

Contemporary technical communication systems are comprised of four subsystems: visual, acoustical, telecommunications and computers. Three overall trends characterize these systems in the 1990s. First, increased speed, capacity, throughput, system complexity, device intelligence, hybridization and interfacing are ever evolving. Second, decreases in size, user skill required and component costs are evident. Third, there is a shift in sources and methods of development, in forms of symbols and signals, and in plateaus of activity.

Different methods have been proposed to identify opportunities for usefully employing communication and information systems in organizations. However, they all basically address needs and experiences of large enterprises. Adaptations of methods are 
required for appropriate applications in small firms (Bergeron \& Raymond, 1992). In this section is a discussion of the history of CAIS use and access for cooperatives and IOFs.

\section{$\underline{\text { History and Background of CAIS Access and Use }}$}

\section{by Small Organizations for Operational Purposes}

Certain characteristics of small enterprises often create important challenges for development and implementation of computer-based information systems. Some of these are described by Bergeron \& Raymond (1992) as “...their resource 'poverty', the intuitive as opposed to analytic nature of planning and decision-making, the rapid evolution of the firm, and the firm's dependency on a few key individuals" (p. 23), which shape the methods by which CAIS are employed. Nevertheless, potential for using communication and information systems in small firms exists not only at the operational level, but also at the administrative and strategic levels.

Communication technology itself has not created existing patterns of uneven development, nor will it create equality between different locations. The idea that availability of a more sophisticated version of voice telephony, for example, will equalize opportunity is a misconception. The role of communication technology in urban and regional development can only be usefully conceptualized within the much broader set of economic and social relations, which are responsible for the structuring of space. The research report of Gillespie, et al. (1989), concludes that competitiveness will increasingly derive from the ability to generate and commercially exploit information. Using a historic parallel, they state:

Those communities, regions and their elected representatives, which fail to 
grasp the economic significance of advanced telecommunications, as part of computer network innovations, will find themselves in a rather similar position to those towns which, in the nineteenth century, rejected a railway connection in order to preserve jobs and sources of wealth-creation which were based on the horse. The only difference is that in the present information society context the 'rude awakening' will come rather more rapidly (p. 106).

A new perspective on regional development is therefore needed for the stability of not only cooperatives, but also all small businesses: the existence of a set of structural changes must be acknowledged. This is because we are experiencing the emergence of an information economy that is accompanied by the rapid diffusion of information and communication technologies.

Flexibility as well as social and cultural attitudes of members within an organization was found to be key issues in successful adoption of information technology (Cowan, 1995). Its widespread diffusion has encouraged the emergence of new ideas and paradigms. Organizations of all kinds have been able to improve strategic management by their abilities to process information more quickly and to have the ability to respond more effectively to changing markets.

Regarding the use of information technology, recent research reveals differences between very small (less than ten employees), relatively small (10-19 employees), and medium-size and large companies' use of information technology. One study identified that relatively small (10-19 employees), highly specialized companies exploit microelectronic applications to significant benefit. As a result of the analysis, Jaakkola (1993) concluded that any bottleneck to adoption was not the availability of technology resources, but instead a lack of strategic planning. Piecemeal adoption has resulted in 
difficulties integrating different subsystems, or a situation in which an installed subsystem dominates subsequent adoptions. These data indicate that cooperatives, as other business organizations, have in common today the need for strategic, long-range plans and policies that include utilization of communication technology.

Because communication and information systems (CAIS) are part of a larger infrastructure, the appropriateness of electronic media for marketing applications by craftspeople depends on the maturity of all areas that make up an infrastructure. For organizations to be successful, a critical mass of limited resources must be mature throughout five major areas: human skills, technical communication devices, all networks and systems, policy and law, as well as the budget and economy. It is the interaction between all these areas that determine how environmental situations beyond an organization affect it, and how use of CAIS by an organization impact other areas of the larger infrastructure. The following sections examine these major areas as they impinge on cooperatives and on IOFs.

\section{$\underline{\text { Cooperatives }}$}

Cooperatives face three key issues. First, they must determine whether to serve members whose productions are both large and small (patrons with very different needs). Secondly, they must come to grips with what degree the coordination function can be performed cooperatively. Thirdly, coops now must decide how to deal with communication and information systems (Schrader, 1989). While the first two issues are age-old, the third is a very important, newer phenomenon. This study focuses on the third group of CAIS issues.

Business transactions are increasingly conducted by way of technical communication devices, only one element of five that comprise an overall perspective of 
an infrastructure. For this reason, four other considerations abound in the categories of human skills, networks and systems, budget and economy, as well as policy and law. Elements Required for a Mature Infrastructure of Cooperatives

A communication infrastructure is needed for reliable functioning of systems to provide information transfer, storage/retrieval and processing. A set of human-made entities of hardware, software, applied theory and re-configuration of functional parts defined within an environment is required. There are five elements of overlapping infrastructure considerations necessary to the success of any type of business. The interests and capabilities of cooperatives, however, may focus more on one area or another (skill, devices, networks, money and policy) with less or more emphasis than would a non-coop firm. Each of these areas is addressed in this study, and to clarify the essential inclusion of each category is presented as a Communication Infrastructure Diagram in Figure 1 of the Appendix.

\section{Human Skills}

Because the benefits of cooperative membership are often obscure, they are here reiterated. This unique need for education programs in coops requires skilled leaders. These leaders must research the needs and concerns of members as they plan organizational strategies. Developing a structure that suits the situations and types of crafts marketing activities is a challenge. Realizing the benefits of a cooperative structure depends on the existence or acquisition of a range of communication skills by its members. The need of winning commitment from members requires high levels of understanding. While the most effective form of communication is one-to-one personal contact, small group discussions are also effective because in both cases there is an opportunity for instant response. 
Technical Communication Devices

Physical distance is often a barrier to essential meetings, and therefore Vilstrup, et. al., (1989) suggest that cooperatives need to use modern communications technology and methods to compete successfully. The availability of video, satellite, VCRs, teleconferencing, and computers provide new opportunities for cooperative communicators as they combine them with successful conventional communication techniques. Internet access and use, which require installed devices, are becoming increasingly a norm in many business endeavors. Where small firms and cooperatives fit into the Internet is worth considering.

\section{Networks and Systems}

The unique structure and ownership of the cooperative requires effective communication with member owners and users of the cooperative. The evolving business environment and growth of coops have made the need for timely information more urgent. Because member education and member feedback are so interdependent, a skilled staff and an adequate budget allocation are prerequisites for a successful cooperative. Communicating with new members, potential members, government agencies, financial and business institutions, and the public is an ongoing challenge and a major responsibility for boards of directors and managers of coops. Therefore, building a database of information about the cooperative's members, market, competition, and general economic situation is important as a basis for strategic planning.

\section{Budget and Economy}

It is typical in the arts and crafts business to sell merchandise on consignment, yet retail outlets do not usually want to adhere solely to commission selling. Therefore, any craftworkers' marketing cooperative needs to consider some combination of sales 
arrangements in dealing with retail outlets. The type of buying arrangements preferred by retail outlets showed through interviews that 35 percent preferred handling arts and crafts on a consignment basis. Another 35 percent were partial to a combination of cash buying, consignment, and/or commission basis. About 24 percent preferred buying the merchandise outright for cash. Some wanted sales arrangements in a combined manner and only one interviewed desired no patronization of the cooperative (Leary \& Roy, 1975).

Purchasing services requires that one has an idea of what is desired. One should therefore have constructed some kind of matrix for comparison-shopping, as well as some basis for constructing a bid for services as an option.

\section{Policy and Law}

In a coop, each person is a member as a person and as such has one vote in the policies adopted regardless of how much capital that individual has to offer. The rights of the membership are separate from the capital contribution of each member. To facilitate membership, the coop may have to adopt a system whereby the amount required to join can be paid off over a period of time. In regard to leaving a coop, a member is entitled to his or her initial capital contribution, plus any limited return that the coop may have allocated but has not yet paid. As discussed earlier, the members should adopt a policy that covers the eventuality of the coop winding up. Because the concept of a coop is to continue its service to members, rather than working towards selling out and reaping financial benefits, a coop might decide on a policy that bequeaths net assets to another coop with similar aims. Cooperative development funds are an additional possibility that some discontinuing coops consider (Greer, 1988). 
Capacity of Cooperatives to Develop and Use CAIS Infrastructure

In a marketing coop one must consider a developing democratic structure that suits the personal situations and types of craft activity involved. According to Tjosvold and Weicker (1993), each entrepreneur needs "skills to develop strong cooperative goals, to discuss their controversies constructively, and in other ways to work together" (p. 18).

The benefits of a coop structure depend on the existence or acquisition of a range of communication skills of its members. On-going education and training in the use of communication devices and systems would seem essential for some, if not all, coop members. The members' ability to act as a cohesive unit and to resolve conflict successfully is vital for reaping the possible benefits of a cooperative.

\section{$\underline{\text { Investor-Oriented Firms (IOF) }}$}

Craftspeople tend to make use of a combination of marketing opportunities.

Retail outlets have been perceived as a sales method of last resort. One of the reasons for this lack of a relationship is the inventory required by outlets. The personal concern about high commission charges and lack of desire or ability to engage in high-volume production of the same item may account for this. Observed bias of craftworkers has shown that they are conditioned against selling methods that yield less than the full sales proceeds and that they favor greater sales volume of a given item (Leary \& Roy, 1975). Elements Required for a Mature Infrastructure of IOFs

The five elements of overlapping infrastructure concerns (abbreviated here as skills, devices, networks, money and policy) for any business are basically the same for an IOF as for a cooperative, with some exceptions to be illuminated by this study. Certain considerations are specific to IOF firms, while some are the same as for coops. 
Table 1 in the Appendix points up some of the various considerations for craftspeople or artisans: terms, which are interchangeable in regard to this study.

\section{Human Skills}

The owners of an IOF know why they have made their investment- to maximize the return on their investment. Achieving this goal requires on-going financial planning, a learned skill. The management style of the owner-manager must be recognized in assisting him or her to examine the goals and strategies of the firm. This will often imply the intervention of an outside consultant with the expertise required to help managers to focus on the critical aspects of their enterprise (Bergeron \& Raymond, 1992)

\section{Technical Communication Devices}

The advent of powerful, low-cost mini- and micro- computers, coupled with userfriendly software, has allowed a greater number of small enterprises to implement information systems in recent years. Computer based information systems not only reduce costs and provide better information to managers, but also have the potential to increase organizational effectiveness (Bergeron \& Raymond, 1992).

Internet access and use, which require installed devices and services, are becoming increasingly a norm for many types of organizations. Where small firms fit in is worth considering.

\section{Networks and Systems}

CAIS can be designed to help an organization produce at lower cost, to differentiate itself from competitors, and/or to identify and concentrate on a particular market segment. Therefore, building a database of information about all aspects of business functions is important as a basis for strategic planning. 
Bergeron \& Raymond (1992) suggest a five-step method for planning information systems for competitive advantage of small firms derived from studies (on the value chain and the theory of strategic thrusts) conducted for large enterprises. The contribution of their adapted methodology resides in its explicit approach to the generation of CAIS for competitive advantage. Their criteria for small enterprises were based on the US Small Business Administration definition of a firm that has less than 250 employees. The methodology consists of the following steps: creating a working group, familiarization with the concept of using information systems for competitive advantage, analysis of the organization, identification of opportunities related to using information systems for competitive advantage, and evaluation of the opportunities.

\section{Budget and Economy}

Small business loans and shareholder investment fund these IOFs. The US Small Business Administration offers seminars and workshops for entrepreneurs about the latest issues on taxes and other concerns. In terms of sales, consignment, commission arrangements or cash merchandise purchases (all possible in an IOF); some kind of matrix for comparison of these would be helpful.

\section{Policy and Law}

Policy issues obviate the capability of telecommunications-based innovations to re-define the nature of relationships based on spatial location, particularly significant for peripheral regions of national and international economic systems. Equal access, a requirement for 'universal service' provisions, is at the heart of policy decisions. Because telecommunications networks are by their very nature spatial systems, both threats and opportunities associated with the same set of structural changes make the role of public policy vital for these regions. 
The expansion of government's role in the economic and social issues of public policy requires that small business people not be complacent. They require collective action for resolution. Business people, regardless of their political sentiment, are advised to develop a proactive and constructive position for incorporating new knowledge into national policy (Cook \& Barry, 1993).

\section{Capacity of IOFs to Develop and Use CAIS Infrastructure}

According to Fitzgerald (1993), small business has become the hot spot of the 1990s in the fast evolving telecommunications industry. This is partly due to a boom in home offices. Television, radio, print and direct-mail ad campaigns by and for these organizations also have increased.

Successful adoption of communication and information systems by private sector business people culminates in difficulties of evaluation. Ignorance about how to evaluate the ever-evolving changes within communication technology has become a huge hurdle that looms far beyond requirements of the specific enterprise itself. Questions about copyright and how to make money are typical concerns of artists and craftspeople that might use the Internet to market their wares from a web sight. Photographic art critic A.D. Coleman (1996) considers these questions naive or marginal as initial responses to the opportunities afforded by a new, radically innovative, medium of mass communication. -He considers communication systems (such as the Internet) as potentially a locus of our ongoing national debate over freedom of speech. With sales issues aside, a competitive advantage is created when a firm increases its comparative efficiency or its bargaining power. This suggests that what a firm offers is more than the physical product or service itself and that CAIS is part of the firm's total offering (Bergeron \& Raymond, 1992). 


\section{Contemporary Marketing Efforts of Small Organizations}

Marketing orientations of small and large firms are different, and most of the literature addressing marketing and advertising comes from a big business perspective. Looking at the future of marketing in general, Georgescu (1997) points up five governing rules. The rules he identifies involve brand names, interactive media, creativity that turns marketing insight and knowledge about brands into business results, and more than 30second TV ads. When measuring advertising results, marketing communications is considered an investment rather than an expense for large firms.

Limited financial resources for marketing characterizes small organizations as well as cooperatives, which simply cannot operate by those same rules that apply in the bigger business world. Additionally, marketing coops contrast with IOFs in the way they do business and in the way their performance is affected by differences in market structure and specific cooperative objectives or group choice issues.

The previously-mentioned cooperative strategy proposed by Greer (1988) for an artist or crafts coop deserves further consideration here: an organization might best focus attention on operating and managing a network of marketing opportunities for its members. A well thought-out agreement between the members and the coop on matters of quality, continuity of supply and price setting would require cooperation. A competitive stance would be a deterrent for this population.

While the coop could run outlets, its emphasis and resources might best be directed mostly toward developing and executing a strategy to penetrate a range of markets. The members might come from various places and be comprised of combinations such as: individual artists and craftspeople, craft outlets, galleries and agencies, production cooperatives, and other arts and crafts business organizations. 


\section{$\underline{\text { Readiness }}$}

Readiness, the state of being prepared or equipped for immediate action to achieve an identified goal, depends on past experience and current potential. Besides business factors, the wares must also be ready for the marketplace. Before beginning a promotion, an artist or a craftsperson should address the following considerations according to Smith (1997):

- Are you able to produce artwork of a consistent quality and style?

- Is the quality of your work up to the standards of the market?

- Do you have a body of work ready to sell (i.e., 20 or more pieces)?

- Are you able to produce enough pieces per month (an average of 5 for a full-time artist) to keep up with future supply and demand?

- Are there legal considerations in selling your product?

- Are you psychologically ready for the possible onslaught of criticism?

- Are you willing to part with your work?

- Do you consider the price you calculated an agreeable price at which to start selling your work? (p. 154).

These are all essential marketing considerations, relevant to product, price, place and promotion. In this study, readiness refers more specifically to the skills that are available to an individual or organization to establish and utilize electronic media for the marketing of their craft products.

\section{Description of Current Efforts}

To locate a target market requires research. Reference guides and directories, available in libraries, are compiled annually for this purpose. Additional efforts include a variety of promotional involvement. Using relevant categories, a craftsperson is advised 
to keep a mailing list on index cards, a Rolodex-type system or on computer. Using a computer can add the advantage of being able to produce mailing labels efficiently and to create a database. Coding information by number and color has proven viable.

Postcards, newsletters and brochures sent by direct mail are often appreciated when they include a good quality reproduction of an art or craft work.

Informal verbal exchanges lead to a great deal of art and craft information useful to the craftsperson, yet a systematic approach to seeking marketing help and developing marketing plans is advised by the Journal of Small Business Management authors. Types of marketing assistance include magazines and trade show materials, library materials including business books, sales training manuals, subscription newsletters, educational tapes, telephone surveys, personal interview surveys, mail surveys, complaint forms and focus groups (Peterson, 1991, October).

Telephone services are the first crucial link to almost every small company. A business today cannot be run without a telephone, and it permits a great deal of research besides contacts. Use of a client status sheet during daily calls proves helpful. Use of an answering machine or service is also essential. Local networking is highly recommended, and treating customers as lifelong clients is paramount for the artist or craftsperson. Word-of-mouth publicity has been, and always will remain, a very effective marketing avenue. Word spreads fastest in smaller niche markets than in larger ones. Searching out a target market often begins here.

In addition to traditional advertising, Fitzgerald (1993, March) notes that, telecommunications companies are providing information and education services to small business owners, including free consultations and seminars explaining how to set up a home office and how to maximize efficiency with minimal personnel. In thus providing 
basic small business phone service, the telecommunications company is in a position to suggest a variety of add-on services. Some of those include mobile and cellular phone service, additional office phone lines for computers, modems and faxes, plus 800 numbers and custom-calling features such as paging, voice messaging, call routing and tracking services.

According to a 1991 Journal of Small Business Management, yellow page ads have become the leading advertising medium for many small businesses, often consuming a significant portion of a firm's promotional budget. If one invests in an ad in one of the many other directories or magazines, it is advisable to purchase reprints of that page. A reprint is an exact duplicate of the page and is usually relatively less costly than a normal full-color flyer.

According to Smith (1997), the golden rule of advertising is repetition, so one should budget for a three-time magazine or newspaper advertisement rate. If one starts to advertise, it must be with plans for a long-term investment. Smith advises to concentrate all one's promotional activities on the 25 percent of people who like you and your work. Also, ads in public transport areas, such as visuals on monitors in subway stations, can be effective, and require only a photographic slide, print or digital file plus cost of the service (p. 196). A 30-second local cable TV commercial does not lead to direct sales, but provides local notoriety. From that, one can market further with business cards as people recognize the craftsperson on $\mathrm{TV}$, and can then be given a personal invitation to view the craftwork.

Cross merchandising is getting images of one's creative products printed on calendars, T-shirts, mugs, etc., out for purchase to the public. It is a very popular medium for contemporary marketing. Reproductions representing work can be had on 
compact disk. This medium necessarily reduces visual quality from the original, but it is archival, meaning that the image captured does not fade over time. Eight hundred images fit on a CD-ROM, and can be toured by categories. A computer's monitor can display nine thumbnails at a time, and then allow the viewer to zoom in and enlarge one image at a time.

Nonprofit organizations and craftspeople frequently work together in their promotional efforts. This type of community involvement is a win-win situation if the craftsperson finds the right organization for his/her type of product. Donating to every charity that asks can quickly become unprofitable. No tax benefit is allowed the craftsperson under present federal tax law. While the creator/producer can deduct only material costs, a collector who purchases the work and then donates it to a charitable cause can deduct the full market value.

\section{The Internet}

Although there is currently a great deal of hype about the usefulness of the Internet for marketing, its viability does deserve more than simple mention in this review of the recent literature. Highly cooperative in nature, the Internet is a voluntary undertaking. There are groups and committees that work toward this cooperation, getting networks to agree on certain communication protocols regarding how packets are sent and received, for example. A network joining the Internet becomes part of the Internet, but retains control and ownership of its own network. Control was therefore shared among 45,000 networks as of 1995 (Ellsworth \& Ellsworth, 1995).

Businesses joining the Internet find that this cooperative venture is different from any other organization with which they work. It has an unusual history, and is not governed in the way that other organizations are. On the Internet, there is a significant 
community culture of cooperation, sharing data, and providing services and information without cost.

By 1994 the commercial aspect of the Internet was the sector with the most domain names. The commercial sector of the Internet is now the most rapidly growing sector of all existent areas of commercial, government, networks, education and organization domain registrations. Additionally, the World Wide Web has become the fastest growing protocol. (Ellsworth \& Ellsworth, 1995)

Integrated Services Digital Network (ISDN) is a digital telephone line between individual telephones and the telephone company's central switching station. It has been available since the mid 1960s, but only now is becoming widespread, especially in metropolitan areas. In Europe this service has been easily available for many years. The installed base for small towns and rural areas in the US is not yet extensive, however. This lack of access to ISDN service beyond cities is problematic for many rural craftspeople who might otherwise make use of applications on the Internet for multiple or specific purposes.

While not available everywhere, some telephone companies are providing dial-up digital ISDN services. This means that the user does not pay for full ISDN services, but rather, uses the connection through access servers called ISDN devices, bridges or routers (similar to modems) on a part-time, on-demand basis. These situations are typically cheaper than standard full-time dedicated ISDN services, and can be used over normal voice phone lines. This kind of configuration allows for small business LANs or homes to connect at higher speeds to the Internet.

The whole arena of Internet service providers is dynamic, with various systems evolving daily. Using the Internet, a fast modem is recommended for the sake of 
efficiency and cost savings of telephone use time. Also, a VGA graphics-compatible monitor, and appropriate software beyond a graphical user interface (GUI) are essential hardware and software devices. As of 1998, there are three common types of Internet access: nodes, SLIP, and dial-up shell accounts. Dial-up shell accounts are very low cost and yet can be powerful marketing tools. They are a good choice for a small business or cooperative (Ellsworth \& Ellsworth, 1995).

The World Wide Web (WWW) is a system on the Internet that allows 24-hour-aday 'presence'. Specially written files are placed on a computer connected to the Internet. Others on-line can view these files by using a GUI browser program. Viewers indicate their choices by pointing and clicking with their computer's mouse. Marketing and sales can be accomplished using full-color catalogs with formatted pages of text and pictures. These can be easily updated, with changes visible to others immediately. Onscreen order forms, as well as customer feedback, requests and survey forms are possibilities. These data are collected in files for the originator to use at any point. Online customer support with text, graphics and even sound can be designed, with no extra maintenance after the initial materials are prepared. Because millions of people worldwide browse the Internet, wide distribution of product and other business announcements can be accomplished with ease. Cost, however, is no small concern.

The Internet's phenomenal growth is attributed partly to the development of an open standard protocol (TCP/IP), and the open HTTP/HTML protocols. Other protocols also allow new types and greater quantities of information to be transferred in standardized formats. These have allowed additions and improvements to be added to the system without having to remake it. Also, new GUI browsers are attracting more users to 
the Web. Access is becoming less expensive and more widely available on a monthly basis.

One example is Kaleidospace, a marketplace where independent artists can sell their work. This Web page contains links to a variety of artists' homepages, and a set of icons used to get information on announcements, consulting, ordering and enrolling. It has a graphically interesting page showing a kaleidoscope with choices for going to the tool shop, art studios, Cyberfaire, news, etc. (Ellsworth \& Ellsworth, 1995).

Some forward thinkers believe that Web-based marketing should become an integrated part of a marketing plan that encompasses the Web, the larger Internet, and non-Internet strategies. The key to on-line marketing success using the WWW is to integrate the Web presence with other on-line activities, and with traditional advertising and marketing efforts (Ellsworth \& Ellsworth, 1995).

On the Internet, those four 'Ps' of marketing (product, price, place, and promotion) are being played out quite differently than they are off-line. A 'product' marketed on the Internet can now be most any goods or services, represented by information, images and sound files. 'Price' on the Internet can bring some savings to companies that find they can adjust prices for greater competitiveness by marketing through the Web. 'Place' becomes international, and is about creating methods for using the Web to market and sell. 'Promotion' on the Web can include advertising, sales, marketing and public relations by adapting off-line promotion modalities. There is a WWW Yellow Pages Directory that lists a site, its URL as well as a brief description of the site. That directory is available in print accompanied by a CD-ROM.

In regard to new Internet skills, it must be recognized that the Web does not function in a linear fashion. Therefore, the construction of a Web site and pages for 
marketing requires nonlinear thinking and activity. Writing documents for use on the Web is very different from writing linear, top-down documents. Instead, much of the control over the order of access is in the hands of the reader as opposed to the writer (Ellsworth \& Ellsworth, 1995). These marketing and advertising approaches require skills and knowledge most probably obtainable through specific, private consultation sessions. Personal use by a craftsperson for other reasons would surely aid in his/her understanding of what a reader encounters on the Internet, and could thus assist in designing a marketing site appropriate to the culture as regards downloading images. Many businesses have an automated mail reply feature that can automatically return a message to someone requesting information. When an e-mail message is being requested, one is more free to respond with less subtle advertising than normal as long as it is related to the topic the user was led to expect.

Having a Gopher site in addition to a Web site increases the chances that Veronica, a powerful Internet search tool, can find one's site. Gopher can be used to develop interest and then point a visitor to the Web site, where the use of images and interactive activities is much easier (Ellsworth \& Ellsworth, 1995).

The cross-fertilization between a Web site and traditional marketing media is considered to be very important to the success of a Web site. Web site marketing can be accomplished by gaining visibility as a 'virtual corporate headquarters'. A Web page is a document designed to be displayed on a browser, with a 'homepage' as the main introduction. On that first screen are listed choices that lead to all of the other pages being offered or suggested. Making a page an attractive place to visit on an ongoing basis is the best Internet advertisement. From there one can market and sell products and services. Some questions that ought to be considered follow: 
- What plans does one have for WWW marketing strategies?

- What hardware and software does one have or is one prepared to purchase?

- What kind of personnel does one have, or are there plans to hire?

- Are there limitations on what services are available?

- Does one want to create and maintain a Web site or to contract for Web and/or HTML services? (Ellsworth \& Ellsworth, 1995).

Web-based marketing provides an opportunity to be a good net citizen. The tradition on the Internet called 'giving back to the Net' (or as Internet founder, Vinton Cerf, calls it a 'gift economy of the Internet') can also make a Web-based marketing strategy work better. In planning a Web site, businesses are encouraged to include consideration of what value to add in that milieu. The tradition of giving back, or gift economy, is very strong, and any business using the Web for marketing is well advised to heed that expectation. The range of services, products, and information used to add value to a Web site is almost limitless. Some companies offer links to related sites; some maintain directories of businesses or resources, and some offer free copies of their software or news feeds. The homepages of Downtown Anywhere, EUnet, and Quadralay exemplify this kind of value-added activity (Ellsworth \& Ellsworth, 1995).

Cable TV companies are looking at the delivery of Internet connectivity to enable interactive video and shopping. Some companies are looking into the use of microwave equipment and repeaters for the delivery of Internet services. Some of the telephone companies that already own the towers and systems are interested in starting services or leasing equipment to others. RadioMail is already delivering e-mail using wireless technology. Several companies are attempting to gain access to portions of the radio spectrum in order to provide Internet and other services to consumers. Additionally, use 
of small digital satellite dishes (similar to those already delivering cable-like TV) is predicted to be including Internet connectivity (Ellsworth \& Ellsworth, 1995).

Internet culture includes a type of policy. For example, because larger documents take longer to download, it is a poor practice to include very large pictures as in-line images since they are very memory-intensive, taking minutes to download. Instead, a Web visitor should be given the choice of whether it is worthwhile to view a picture by using a miniature in-line version of it. That way it can be used as an anchor for loading the larger version as an external image that can be displayed later, when desired. A long document should include many internal links to these images. Original graphics and picture files can be made using computer screen captures, scanned images, and computergenerated graphics. Two of the many dozens of graphics file formats are most likely to serve across platforms: GIF and JPEG (Ellsworth \& Ellsworth, 1995). To be sure, copyright issues become more complicated and unprecedented when images are involved- something very important for craftspeople to consider. A reproduction available for free can definitely compromise the creator's sale of an original 2dimensional image, and can even provide theft opportunities of 3-dimensional designs.

The concepts of marketing and advertising are distinct, as becomes obvious in the context of using the Internet. In traditional media, advertising is everywhere- on TV, in the newspaper, on the sides of buses, on the radio, through direct telephone marketing, etc. On the Internet, however, it is said that intrusive advertising is not to be permitted and is strongly disliked by the citizens of the network. Sending unsolicited e-mail or posting inappropriate ads to newsgroups or mailing lists can result in immediate damage to a company’s reputation (Ellsworth \& Ellsworth, 1995). 
Security and privacy are important policy issues on the Internet. OpenMarket is one example of a business that has a system of payment verification that uses a payment URL. That encodes the details of a sale and tracks electronic documents using a fingerprint system. A URL assigns random, unique numbers to each document. In addition to creating a Web browser called Netscape, Netscape Communications has created a system for a secure commerce Web server, called the Netsite Commerce Server. When using Netscape for browsing, one can connect to a secure server and transact business. It supports document protection, data encryption, server authentication and digital signature verification for use with credit cards.

Many page owners log the access to their pages. This can include information about your login site and your user name. From a marketing perspective this is very useful data. Anyone can find out who is visiting one's page, what domains they are from (.edu, .com, etc.), what time of day they hit the page, or how many people visited after a big 'ad' campaign (Ellsworth \& Ellsworth, 1995).

The contemporary question of when to add the Web to a business' media mix is still difficult to answer for most. Tools for usefully measuring Web advertising effectiveness don't yet exist, and companies want to know whether their money spent this way is actually generating purchases. Klein (1997, May) analyzes considerations for making Internet advertising accountable. Rather than knowing only how many times a site has been seen, what advertisers want is, "the ability to track a user's Internet habits, including all the sites they've been to and their behavior on those sites before coming to your site" (p.14). Additionally, advertisers are beginning to demand lead generation and on-line purchases from their participation on-line. Klein concludes that the obstacles to meeting these objectives are threefold: reaching an industry standard on banner-to-sale 
measurement, software and human resources to implement measurement, as well as privacy issues.

While one does not have to create one's own home page, nor even own a computer to advertise on the Internet, caution is voiced. Smith (1997) reiterates Klein's concerns about Internet hype. She advises artists not to fall for it. She believes that displaying visual work on-line is mostly a waste of money better spent aimed directly at collectors. Numbers of 'hits' on a Website is not the reason that companies market on the Internet. While a large quantity of casual visitors is not what an artist needs for marketing work, craftspeople typically have less of a collector's market than does a fine artist. Therefore, the target markets can differ between the two types of producers. This study, to reiterate, concerns only a sample of those West Virginia individuals who consider themselves craftspeople.

\section{Summary of Literature Review}

This literature review focused strongly on cooperative organizations and investororiented firms, and how they can be organized to utilize communication and information systems to promote and enhance their functions. This background lays a context for the present study. Craftspeople have needs that could be well served by stronger business organization, division of labor, especially to market their products, and communication systems that expand their reach. The present study investigated features of West Virginia craftspeople and how these features may influence the extent to which they participate in cooperative organizations and employ electronic marketing strategies supported by CAIS. 


\section{CHAPTER THREE: RESEARCH METHODS AND PROCEDURES}

The purpose of this chapter is to describe the methods and procedures used to carry out this research. This study was designed to identify the perceived readiness of West Virginia craftspeople to apply their skills and resources toward marketing their products cooperatively using electronic media. The following procedure was used for this study: (1) identifying the problem and research questions, (2) reviewing the literature, (3) developing the survey instrument, (4) identifying the study population, (5) pilot testing the survey instrument, (6) administering the instruments and collecting the data, (7) analyzing the data, and (8) drawing conclusions.

The pilot survey instrument obtained usable responses for designing the final survey of this representative population. The pilot study analyzed 6 subjects and focused on design of an improved survey. Although a SPSS statistical analysis of this small group was done, it is given less emphasis in this document than the quantitative results of the final survey. The change from SPSS to SAS was made because the researcher had more access to resources using the SAS statistical analysis program.

\section{Identification of the Problem}

The researcher was interested in investigating issues associated with marketing handcrafted work created during the late 1990s. The researcher reviewed the literature, viewed exhibits, attended seminars and conferences, and conducted discussions with individual craftspeople. It became apparent that the degree of experience and potential (readiness) of West Virginia craftspeople for using electronic media to market their products in a cooperative manner was not known.

Therefore, the following research questions were identified: 
1. What are the skills and knowledge a sample of individual West Virginia craftspeople have used to market their products utilizing electronic media?

2. To what degree can existing individual readiness (experience and potential) of a sample of West Virginia craftspeople fulfill the objectives of establishing and using electronic media for marketing their products?

3. What is the maturity of the existing infrastructure from the perceptions of a sample of individual West Virginia craftspeople?

4. What is the perceived degree of access to electronic media by a sample of individual West Virginia craftspeople for marketing their products?

\section{Review of the Literature}

A review of the literature, presented in chapter 2 , was conducted in the content areas of cooperatives; investor-oriented firms; communication and information systems; and contemporary marketing efforts of small organizations. Additionally, reviews of the literature on mail survey design, development, administration and analysis were conducted. Statistical methods were analyzed, with attention to research on sampling strategies.

The literature search was partially conducted using computer databases. Educational Resource Information Clearinghouse (ERIC), Infotrak and Infomine database systems were searched to identify documents such as journal articles related to the selected content areas. West Virginia University's MountainLynx, an on-line (card) catalogue identifying library holdings (books, journals, etc.) was searched for relevant books and periodicals. Dissertation Abstracts International and Master Thesis Abstracts identifying recent research conducted in the relevant areas were reviewed both in hard copy and electronically on-line. Data sources included books and journal articles on 
cooperatives in agriculture and arts organizations, books on marketing, communication technology and statistics. Journals of Small Business Management and Advertising Age, United States Department of Agriculture (USDA) reports, Small Business Development Office (SBDO) articles, and dissertations were part of the research. The West Virginia Commission on the Arts, a state agency in Charleston, provided insight and support for aspects of this research. The Commission's Long Range Plan for Fiscal Years 1998-2000 was made possible by the participation of 140 West Virginia citizens through interviews, public meetings, focus groups, correspondence and response to a survey. The quarterly ArtWorks Publication of the West Virginia Commission on the Arts provided relevant current information, as did the Arts Commission's Peer Assistance Network Advisors Directory. Additionally, correspondence in person with experts in the field by telephone and Internet provided guidance to the researcher in the various literature searches.

\section{Development of the Survey Instrument}

Based on existing research about questionnaires, a review of the literature and discussions with experts in the field resulted in a number of decisions affecting this survey instrument. Use of explicit models on the conduct of surveys aided the researcher.

Concerned with gathering facts about 'what is?' rather than the manipulation of variables (experimental), surveys are the most commonly used approach in educational research (Wiersma, 1980). This study employed a non-experimental survey research design. Wiersma (1980) defines a questionnaire as a "list of questions or statements to which the individual is asked to respond in writing" (p. 142). Response options may range from a checkmark to an extensive written statement. The items included in a questionnaire should be structured to address the research questions, and be worded to elicit the required information. Items can be either open-ended, eliciting a constructed 
response, or forced-choice, requiring the selection of one choice among two or more alternatives. Forced-choice items increase the consistency of response across respondents and contribute to the ease of data tabulation (Wiersma, 1980). However, open-ended questions may elicit relevant information not previously identified by the researcher. Thus, open-ended questions were included in the present survey.

The purpose of the questionnaire in this study was to gather data that identified five general areas relevant to a stratified sample of individual craftspeople, craftspeople involved in cooperatives, and craftspeople involved in investor-oriented firms. The stratification was obtained using a random table of numbers to select from a mailing list compiled alphabetically. Those five areas of questions include demographics as well as questions aimed at answering the four research questions listed on page 70 and included in Appendix G, as each concern is addressed by the survey questions. Care was taken in deciding survey question order, writing transitions and formulating page layout. Working these out together was required to achieve a reasonable balance among the objectives to maximize response (Dillman, 1978).

The researcher examined responses to the survey questions as they addressed themes derived from the four research questions. Demographic responses were perceived as important components of the questionnaire in order to assist the researcher in describing and explaining the West Virginia craftspeople population. The survey instrument was designed to elicit quantitative and open-ended qualitative data in order to obtain a useful combination of information leading to analysis and synthesis. Comments evoked by the survey are listed in Appendix F. 


\section{Identification of the Study Population}

The population was identified from an Artist's Register mailing list of 946 craftspeople active in the state as of 1996. The West Virginia Division of Culture and History Communications Division made that list available to the researcher for one-time use. The researcher was provided with options as to how the list would be printed onto mailing labels: organized by zip code, medium, alphabetically by last name, etc. Although labels printed by zip code would have been more expedient and economical, the researcher requested and used a printout of alphabetical mailing labels in order to maximize randomness of variables such as craft medium employed, age, gender, and location in the study.

Motives of craftspeople for submitting slides to the register representing their products was partly for inclusion in a bi-annual Juried Award Competition sponsored by the State Agency in Charleston, WV. Criteria for being on the State lists included subjective decisions about product quality (juried by a small group of professionals), perceived needs of the marketplace, and the craftsperson's motivation to be juried. Motivation was required to produce photographic slide images of the art or craftwork, to travel, to make submissions of actual products, and to complete the necessary forms requesting to be considered. Opportunities for participating in exhibits arose from inclusion in the Artist's Register.

In order to obtain a representative sample of West Virginia craftspeople, a random sample of names with mailing addresses from this Artist's Register was selected. It is a database organized by medium employed in construction of the craft (i.e., clay, fiber, glass, leather, metal, paper, plastic, wood and mixed media). These general craft categories comply with the Information System Project of the National Assembly of State 
Arts Agencies, a system designed for organizing and labeling information used by public arts agencies. Of course, additional and mixed media are frequently used, but not easily categorized for statistical purposes.

An adequate sample from the mailing list was selected to receive a questionnaire by postal mail to arrive at an acceptable number for analysis of the survey instrument. Sampling was based on random selection from the alphabetical list of the database of craftspeople, accomplished by choosing names correlated with a table of random numbers. This technique enabled the researcher to select from the total population of 946 a random sample of 190 craftspeople (20\%). Of that 20\% sample, 60 surveys were returned, or more than $30 \%$ of those mailed out. Of the 60 surveys returned 46 (almost $80 \%$ ) were usable. Fourteen of the 60 returned surveys were too late for inclusion, had moved out of the state, or indicated that the craftsperson was now retired, answering few or none of the survey items.

According to other researchers (Pawlowski, 1994; Fallon, 1995; and Lewis, 1998), one fifth of the population, or 190 craftspeople, should render an adequate sample for this study. It was also suggested that a researcher can expect only a $25 \%$ return, and therefore 800 (or approximately $75 \%$ of the population) surveys should be mailed to expect between 100 and 200 responses (Walls, 1998). Ideally, one would survey the entire population of 946 on the mailing list (already just a sample of the true population of West Virginia craftspeople) for a fair geographical representation throughout the state, yet this was not feasible given limits of resources available to the researcher. 


\section{Pilot of the Survey Instrument}

The survey instrument was piloted to confirm its readability and comprehensibility, as well as to determine strategies for audience analysis. The pilot was conducted with participants who had characteristics similar to those in the larger study, an approach that is recommended in the literature (McMillan \& Schumacher, 1989). Data were collected using a self-administered questionnaire, which was mailed to respondents. The six participants included three women and three men working in diverse craft media, half living in Monongalia County and half in other counties of the state. The primary criteria for participation in the pilot study were that the participant be likely to respond. The researcher determined that a minimum of four of the six pilot respondents was essential for detection and correction of weaknesses in the instrument. An ad hoc frame-of-reference probing approach assisted the researcher in determining respondents' understanding of the intent of survey questions, and the researcher's understanding of the meaning of pilot participants' responses.

The pilot utilized five types of questions: yes/no or forced choice, Likert scale, open-ended, continuum, and list choice. Fifty-three questions were presented as forced choice (yes or no), a 5-point Likert scale was used for forty-one questions, nineteen were open-ended questions, eleven questions were presented on a continuum and four questions were list-choice. Appendix A, a copy of the Pilot Survey Instrument includes definitions of terms deemed important by the researcher.

\section{Administration of the Survey Instrument and Collection of Data}

The pilot questionnaire was organized to facilitate ease of self-administration and to encourage responses to all items. Items addressed aspects of the four research questions as well as demographic information. Those items were designed to collect 
related identification and categorization data and data of professional interest to the researcher. Because these items are sometimes sensitive, the literature suggests including them after the responses to other items have already been supplied. In this way one has earned the dedication of respondents to follow through (Dillman, 1978; Mangione, 1995). Initially, each participant was contacted by telephone, informed about the nature of the survey, and asked to participate in the pilot test of the questionnaire. All agreed to participate. Each participant was asked to read a letter of introduction to be sent to the larger sample, as well as a cover letter specifically for pilot participants that outlined the researcher's study questions (not to be included in the final survey packet). Survey data were collected by postal mail using West Virginia University as the return address on self-addressed stamped envelopes. According to the literature, this use of an institutional affiliation establishes credibility and respect with the respondents (Mangione, 1995). An identification number was hand-written onto the cover of each questionnaire in order to track responses. A cover letter accompanied the survey instrument, which had an attractive marbleized colored cover to the $81 / 2^{\prime \prime} \times 11$ " size pages of questions on white paper with plenty of space around and between survey items. Experienced advice indicates that the unique location of the questionnaire's front and back covers puts them in a position of giving both the first and last impression of a study's worth (Dillman, 1978). The return date deadline was in large, bold print on the back cover.

Given the propensity of both the researcher and the population to be influenced by aesthetic considerations, presentation was deemed very important. Pricing concerns, however, prompted the researcher to fold the survey instrument in half so that it would fit into a $6.5 " \mathrm{X} 9.5 "$ white envelope. The cover letter encouraged the respondent to relax over a cup of tea while completing the survey, suggesting a half-hour commitment. A 
foil-sealed decaffeinated tea bag and a return envelope with a decorative postal stamp were enclosed as enticements to complete and return the questionnaire. Reminder postcards (printed on the same marbleized paper as the survey's colored cover) were mailed a week after having mailed the survey packet to encourage high response rates by the two-week due date. A second set of identical address labels was therefore required. The decision to print reminder postcards to be mailed on 4.25 " X 6 " paper rather than the intended 8.5 " X 5.5" postcard was also a financial decision, given that the smaller was priced as a postcard while the larger would cost the price of a letter. The researcher summarizes the above details as essential considerations for such a study.

\section{Analysis of the Pilot Study}

The analysis of pilot study data led to many adjustments in the final survey instrument. Given advice from the doctoral committee at the prospectus meeting, approximately $75 \%$ of the questionnaire items were eliminated because the instrument was deemed too extensive and overwhelming. While statistical analysis was done on the pilot data to parse out other data, these are not presented as valid products of standard statistical analysis. However, in the following section on findings, relevant statistics are presented and analyzed.

One result of the pilot study assisted the researcher in determining that definitions of terms used in the survey instrument should be included within the question they are meant to clarify, and not to be listed all at the beginning, as was done in the pilot. Frustration and confusion about the meaning and relevance of certain words including technical terms and acronyms used in the survey instrument were evident, yet due to the nature of the research, use of these terms was deemed necessary. Some questions about access to devices and networks, policy and law as well as other infrastructure questions 
were altered in hopes that the responses evolved would more clearly match the intentions of the researcher during analysis. Others questions were eliminated because they were determined to be vague or out-dated.

The final survey instrument had questions re-organized from their locations in the pilot to assist the researcher in addressing the four research questions more readily. Some of the Likert scale questions were converted into forced-choice items in order to enhance the final clarity of responses, thus assisting the researcher in analyzing data related to budget, policy, and use of communication technology. Many of the openended questions were eliminated or converted to forced-choice items because of the difficulties encountered in reporting those results. However, some of the non-statistical questions were left in the final survey because they were to provide a context for the many forced-choice answers.

\section{Findings from the Pilot Study}

Responses across the six pilot participants' surveys were relatively consistent in regard to the majority of questionnaire items that were presented as forced-choice. Those yes/no responses contributed to the ease of data tabulation, as suggested in the literature.

The Likert scale questions were useful to the researcher in finding polarization, or in gaining confidence that questions were discriminating. Those results were analyzed by means and standard deviations using the SPSS computer analysis system. The mean scores showed that among the six pilot participants, each had different experiences.

Open-ended and list-choice questions led to high numbers of missing counts on the SPSS computer analysis, yet those who did respond to those questions with answers beyond the options listed gave the researcher useful demographic data. Additional demographic data, gained through questions presented on a continuum, assisted the 
researcher in identifying the level of sophistication of participants' communication technology devices.

At the prospectus defense meeting, statistical descriptive analysis of data was presented, based on frequency counts and the standard random sample percentages of homogeneous groups utilizing the SPSS system. Frequency distributions were displayed using tables to show categorical data collected in this pilot study. Appendix B provides a Frequency Distribution of Pilot Survey Scores as recommended in the literature by Gravetter \& Wallnau, 1992.

\section{Data Analysis Procedures}

The method of statistical analysis used in research to analyze data is usually determined by the way in which data are expressed. Borg and Gall (1989) write that in educational research, data are typically expressed in five forms: "the continuous score, the rank, the artificial dichotomy, the true dichotomy, and the category" (p. 338). When data are expressed in the form of categories, an appropriate way to summarize the data is by use of frequency counts or frequency distributions (Borg \& Gall, 1989). This study uses only two of these forms: the continuous score and the category. Continuous scores refer to "values of a variable that have an indefinite number of points along its continuum" (Borg \& Gall, 1989, p. 338). The designation of category refers to "values of a variable that can yield more than two discrete, non-continuous scores" (Borg \& Gall, 1989, p. 341). The continuum questions provide useful demographic data as well as to help identify the level of sophistication of participants' communication technology devices. The category questions provide more specific statistical data.

The pilot survey instrument was based largely on forced-choice and 5-point Likert scale items. List-choice, continuum and open-ended questions were included to gain 
professional information relevant to finding themes and for insight to future research. Results from that study led the researcher to changes in the final questionnaire. Some of the Likert scale questions were converted to forced-choice items because the pilot study data were difficult to analyze. These questions about budget, policy and use of communication technology proved most troublesome leading the researcher to determine that the clarity of those questions needed improvement in the final questionnaire.

A descriptive analysis of data was presented, based on frequency counts and the standard random sample percentages of homogeneous groups. Frequency counts can be graphically displayed in a frequency distribution table or in a graph that visually depicts the distribution of scores (Gravetter \& Wallnau, 1992). Categorical data collected in this survey were displayed using tables, as graphs were considered more complex than this study requires. All percentages were rounded up. Several of the open-ended responses do not comprise part of this dissertation 's data analysis, but are considered relevant to follow-up research.

\section{Determination of Conclusions}

Looking for meaningful relations among and between responses to the pilot questionnaire items produced information relevant to designing a better survey instrument for the larger target population. Discovering polarization in the answers to sub-questions of the major research questions, statistical frequencies obtained using the SPSS program showed the researcher that the questions were, in fact, discriminating. The mean scores increased the confidence that results from the pilot study revealed useful information to create a final questionnaire that would facilitate designing appropriate training for West Virginia craftspeople about strategies for cooperatively marketing their wares using communication technology. 
The study addressed individual West Virginia craftspeople as well as craft cooperatives and investor-oriented craft firms concerning four areas: skills and knowledge, readiness (experience and potential), perceptions about the infrastructure and perceptions about access to electronic media. The pilot study indicated that further research was needed to determine the perceived degree of readiness of this population to utilize communication and information systems for cooperatively marketing their products.

This study assumed a need for training about technological means, cooperatives, craft production decisions, as well as a need for policy and marketing education. These concerns determined the final formulation of the four research questions.

The pilot study indicated that further research was needed to determine the need of further researcher regarding individual West Virginia craftspeople as well as craft cooperatives and investor-oriented craft firms concerning four areas: skills and knowledge, readiness (or experience and potential), perceptions about the infrastructure and perceptions of access to communication and information systems (electronic media). Each research question was analyzed by grouping survey responses as they addressed those four research questions. Some survey questions addressed more than one of the four study questions because, by nature, those issues overlap. Open-ended survey data complemented the statistical data, clarifying or parsing out, the individual concerns and comprehension of this instrument. Those comments are listed in Appendix F. There were limitations to the conclusions drawn from this quantitative study because the survey instrument was mailed to only a sample of the West Virginia craft producer population. There were numerous craftspeople working in the state that were not registered on the 
mailing list from which this sample was drawn. These limitations should be kept in mind throughout the study's analysis and synthesis. 


\section{CHAPTER FOUR: ANALYSIS, FINDINGS AND SUMMARY}

The problem investigated in this study is the perceived degree of readiness of West Virginia craftspeople to cooperatively market their wares utilizing electronic media. Their levels of experience and potential (readiness) to participate in this major marketing medium are unknown. This study was undertaken to determine the degree of readiness of that population to use electronic media for cooperative marketing.

The following is a presentation of the analysis of a survey sent to one hundredninety subjects randomly selected from nine hundred and forty-six West Virginia craftspeople active since 1996. Forty-six usable surveys were returned. Table 2 is a representation of survey return percentages. These returns are deemed appropriate as a statistically representable sample of the number of participants.

Table 2: Number of Participants Responding to the Survey

\begin{tabular}{lcccc}
\hline $\begin{array}{c}\text { Population } \\
\text { Surveyed }\end{array}$ & $\begin{array}{c}\text { Usable } \\
\text { Surveys }\end{array}$ & $\begin{array}{c}\text { Surveys } \\
\text { Returned }\end{array}$ & $\begin{array}{c}\text { Surveys Mailed } \\
\text { to a Random } \\
\text { Sample }\end{array}$ & $\begin{array}{c}\text { WV Commission } \\
\text { on the Arts } \\
\text { Mailing List }\end{array}$ \\
\hline Numbers & 46 & 60 & 190 & 946 \\
\hline Percentages & $77 \%$ & $31.6 \%$ & $20 \%$ & $\begin{array}{c}\text { Unknown \% of } \\
\text { Entire Population }\end{array}$ \\
\hline
\end{tabular}

The collected data was recorded and analyzed employing the Statistical Analysis Systems (SAS) software and Microsoft Excel statistical software. The analyses of findings of this study have been grouped as they address four research topics: marketing skills and knowledge; experience and potential to establish and use electronic media; perceptions about the infrastructure of; and the perceived degree of access to electronic media craftspeople have to market their products. The analyses are presented for the most part quantitatively, although some non-statistical data is included. Some 
percentages in this study exceed one hundred due to rounding. Some questionnaire items offered the respondents an "Other" option that, while not amenable to statistical analysis, was frequently selected by subjects and added interesting and important detail. Open-ended survey questions and demographic information were included to complement and enhance the statistical data. Some of the survey questions address more than one of the four research questions, and thus may be referred to more than once. The statistical analyses are presented here. The Findings section follows and includes an interpretation of the statistical analyses and presentation of relevant nonstatistical information. Table 3 presents the twenty-two survey questions, as they are relevant to the four research questions under study. The survey instrument is represented in Appendix $\mathrm{C}$, and the cover letter sent to accompany that questionnaire is reproduced in Appendix D. Appendix E is a reproduction of the postcard reminder sent to survey participant. 
Table 3: Survey Questions Relevant to Research Questions

\begin{tabular}{|c|c|c|c|}
\hline $\begin{array}{l}\text { Research } \\
\text { Question }\end{array}$ & $\begin{array}{l}\text { Survey } \\
\text { Category }\end{array}$ & $\begin{array}{c}\text { Survey } \\
\text { Question } \\
\text { Number }\end{array}$ & $\begin{array}{c}\text { Description of } \\
\text { Survey Question }\end{array}$ \\
\hline $\begin{array}{l}\text { 1. } \\
\text { Skills and } \\
\text { Knowledge to } \\
\text { Market Using } \\
\text { Electronic Media }\end{array}$ & Demographics & $\begin{array}{l}8 \\
9 \\
10 \\
5-\mathrm{A} \\
5-\mathrm{B} \\
1\end{array}$ & $\begin{array}{l}\text { - Extent of use of marketing skills } \\
\text { - Levels of electronic media skills } \\
\text { - How electronic media skills were developed } \\
\text { - Means of marketing } \\
\text { - “ } \\
\text { - Primary craft media }\end{array}$ \\
\hline $\begin{array}{l}2 . \\
\text { Readiness } \\
\text { (Experience and } \\
\text { Potential) to Use } \\
\text { Electronic Media }\end{array}$ & Demographics & $\begin{array}{l}2 \\
3 \\
4 \\
6 \\
7 \\
22\end{array}$ & $\begin{array}{l}\text { - Years practicing craft } \\
\text { - Reward for involvement in a coop } \\
\text { - Reward for involvement in non-coop group } \\
\text { marketing efforts } \\
\text { - Number of products sold } \\
\text { - Plans to continue practicing craft } \\
\text { - Sales via Website advertising }\end{array}$ \\
\hline $\begin{array}{l}\text { 3. Perceptions } \\
\text { About the } \\
\text { Infrastructure of } \\
\text { Electronic Media }\end{array}$ & $\begin{array}{l}\text { Budget/ } \\
\text { Economy }\end{array}$ & $\begin{array}{l}11 \\
12-\mathrm{A} \\
12-\mathrm{B} \\
14 \\
13 \\
15 \\
16 \\
17\end{array}$ & $\begin{array}{l}\text { - Degree of favorability for marketing } \\
\text { - Financial expense of marketing } \\
\text { - Time expense of electronic } \\
\text { - Business plan for Internet services } \\
\text { marketing } \\
\text { - Existence of policy on use of electronic marketing } \\
\text { - Regulation of electronic marketing information } \\
\text { - Knowledge of electronic marketing policies } \\
\text { - Usefulness of rules and guidelines }\end{array}$ \\
\hline $\begin{array}{l}4 . \\
\text { Access to } \\
\text { Electronic Media }\end{array}$ & Access/Use & $\begin{array}{c}18 \\
19 \\
20 \\
21-\mathrm{A} \\
21-\mathrm{B} \\
21-\mathrm{C} \\
21-\mathrm{D}\end{array}$ & $\begin{array}{l}\text { - Hours per week using the Internet } \\
\text { - Potential to use the Internet } \\
\text { - Website representation for marketing } \\
\text { - “" } \\
\text { - “ } \\
\text { - “ } \\
\text { - “ }\end{array}$ \\
\hline
\end{tabular}

Research Question 1: What are the skills and knowledge individual craftspeople have used to market their wares utilizing electronic media?

Research question one is addressed by analyzing responses to the marketing and electronic skills questions (8, 9, and 10); marketing strategy questions (5-A, 5-B); and a demographic question (1). 
Survey question 8 presented the respondent with a list of personal skills and asked him/her to gauge, on a Likert scale of 1 to 5 , how much s/he used each skill to market products during the past decade. Number 1 on the scale represented "Little Used" and number 5 "Much Used". These marketing skills data are presented in Table 4.

Evaluating means of Likert scale responses for the skills questions, the skill most used by respondents to market their products was price setting, with a group mean of 2.95 . The skills least used were negotiation and website advertising, with a common mean of 1.68. The means of the remaining eight skills fell between 2.93 and 1.93. The mean scores increased the researcher's confidence that results revealed useful information, and showed that most skills were skewed to the lower end of the scale.

Table 4 (Survey Question 8)

$\underline{\text { Mean Scores for Marketing Skills }}$

\begin{tabular}{lccc}
\hline \multicolumn{1}{c}{ Skill } & Mean & S.D. & N \\
\hline Price Setting & 2.95 & 1.30 & 41 \\
Visual Production & 2.93 & 1.40 & 43 \\
Budgeting and Forecasting & 2.63 & 1.23 & 43 \\
Computer Software Skills & 2.44 & 1.34 & 41 \\
Bookkeeping & 2.30 & 1.27 & 41 \\
Internet Searching & 2.24 & 2.24 & 41 \\
Writing & 2.20 & 1.17 & 41 \\
Audience Analysis & 2.14 & 1.33 & 41 \\
Market Analysis & 1.93 & 1.00 & 40 \\
Website Advertising & 1.68 & 0.94 & 40 \\
Negotiation & 1.68 & 1.09 & 38 \\
\hline
\end{tabular}

Survey question 9 presented respondents with a list of electronic media skills and asked them to gauge their personal skill levels on a 4-point Likert scale representing beginner, intermediate, advanced and expert. A fifth option was labeled as "Not Applicable", which may help explain the wide distribution of standard deviations. 
From a business perspective, these skills might include using the Internet for advertising, and using databases and spreadsheets for target/niche marketing purposes as well as for accounting and inventory. Statistically, the highest rated skill was that of "Word Processing" with a group mean of 2.60 and a standard deviation of 1.12 . The skill least used was "Web-based Creation" with a group mean of 1.39 and a standard deviation of 0.72 . The means of the remaining seven skill categories fell between 2.54 and 1.63 , a cluster that fell mostly below mid range. Table 5 presents the array of data regarding respondents' electronic media skills, which were low.

Table 5 (Survey Question 9)

Mean Scores For Electronic Media Skills

\begin{tabular}{lccc}
\hline \multicolumn{1}{c}{ Personal Skills } & Mean & S.D. & N \\
\hline Word Processing & 2.60 & 1.12 & 35 \\
E-mail & 2.54 & 1.02 & 39 \\
Internet Searching & 2.37 & 1.09 & 35 \\
Desktop Publishing & 2.21 & 1.05 & 33 \\
Graphics Programs & 2.00 & 1.00 & 33 \\
Databases & 1.94 & 0.77 & 31 \\
Spreadsheets & 1.88 & 0.87 & 32 \\
Hardware Configuration & 1.63 & 0.88 & 27 \\
Web-based Creation & 1.39 & 0.72 & 31 \\
\hline
\end{tabular}

Choices of "Other" and "Not Applicable" were also offered. Skill levels in the category of "Other" were reported by two out of forty-six respondents at a group mean of 1.50 with a standard deviation of 0.72 . Respondents who selected the "Other" category were asked to list those additional skills. One respondent selected "Not Applicable" to all skill categories listed, and under the "Other" option specified the skill of using the telephone. Another respondent wrote that $\mathrm{s} / \mathrm{he}$ employed someone else to handle all electronic media work, analyzing the information, as would a supervisor. 
The optional open-ended survey question simply provided opportunities to enhance the statistical data. Response to the open-ended question helps the researcher make connections between the quantitative data and respondents' perceptions about potential limitations of the survey instrument. For example, the skill category of “Graphics Programs” included from the researcher's perspective tasks such as scanning, layout and typography. However, several answers suggested that the questionnaire wording was vague in survey question 9, implying respondents' unfamiliarity with computer terminology. Comments of respondents are in the Findings section of this chapter.

Survey question 10 presented the respondents with four methods by which they may have developed skills using electronic media, asking that they circle all that apply. Thirty-five $(80 \%)$ of the respondents indicated having taught themselves skills using electronic media. Nineteen (43\%) of the respondents reported having developed skills through courses or workshops. Fifteen (34\%) of the respondents identified one-on-one coaching as a way of having developed skills. Only eleven (25\%) of the respondents chose computer-based tutorials as a method of having developed electronic media skills. Table 6 presents the data about electronic media skills that indicate a large gap between self-taught skills and the remaining three skill development methods.

Table 6 (Survey Question 10)

Frequency Distribution for Electronic Media Skill Development $(\mathrm{N}=46)$

\begin{tabular}{lcc}
\hline \multicolumn{1}{c}{ Method } & Frequency & Percent \\
\hline Self-taught & 35 & 80 \\
Courses / Workshops & 19 & 43 \\
One-on-one Coaching & 15 & 34 \\
Computer-based Tutorials & 11 & 25 \\
\hline
\end{tabular}


Open-ended comments clarify that self-taught usually meant transferring one's knowledge about use of one program when experimenting with a new one. A majority of respondents indicated having been self-taught in developing skills using electronic media rather than utilizing computer-based tutorials. One-on-one coaching was often conducted at home, within the family. Responses indicated that college and county school classes were more useful than computer-based tutorials.

Survey questions 5-A and 5-B illuminated the various ways these craftspeople market their products. Respondents were asked in question 5-A whether they presently market their products by methods other than participation in fairs and festivals. Fortyfour $(96 \%)$ of the respondents indicated that they use additional modes of marketing. Those respondents who answered yes to question 5-A were asked to circle the major marketing strategies besides fairs and festivals that they use to sell their crafts. Table 7 presents that array of demographic data about marketing strategies.

Table 7 (Survey Question 5-B)

Frequency Distribution for Additional Marketing Strategies ( $(N=46)$

\begin{tabular}{lcc}
\hline \multicolumn{1}{c}{ Medium } & Frequency & Percent \\
\hline Word-of-Mouth & 24 & 52 \\
Gallery & 20 & 44 \\
Retail Outlet (Consignment) & 13 & 28 \\
Internet World Wide Web & 11 & 24 \\
Cooperative & 8 & 17 \\
Barter System & 6 & 13 \\
Print Advertising & 4 & 9 \\
Other & 19 & 41 \\
\hline
\end{tabular}

Of the number who answered question 5-B, twenty-four respondents (52\%) indicated that they used "Word-of-Mouth" while twenty respondents (44\%) circled using 
Galleries. The gap in frequency between responses to the first two strategies and the next two listed strategies of "Retail" and use of the "World Wide Web" indicates that more craftspeople market through "Word-of-Mouth" and "Galleries" than in any other single way. "Retail" was used by about a third and the "World Wide Web" was used by about a quarter of the respondents. The least used method of marketing listed was "Print Advertising" with only four (9\%) respondents. Overwhelmingly, as presented in Table 7, additional marketing avenues beyond fairs and festivals were used. Both methods of interest to this study, the "Internet" and "Cooperative" involvement were infrequently used as marketing strategies.

Because nineteen craftspeople (41\%) wrote comments in the "Other" category, it appears that this survey instrument may have excluded some important marketing strategies used by this population. Respondents described their marketing strategies, specifying mixed marketing avenues and listing additional methods they use to sell their products. Eight respondents wrote about various kinds of involvement with wholesale agencies, including the use of a representative, retail to wholesale and wholesale to retail arrangements. Involvement with Tamarack as well as state and national parks and museums was noted by five of the respondents. Four respondents added other information about their uses of non-consignment retail arrangements. These included gift shops and personally owned view spaces listed as a studio, a shop, a store and a bed and breakfast location. Three respondents noted uses of commissions and repeat business, and making donations or gifts to promote their products. One person indicated that $\mathrm{s} / \mathrm{he}$ would use the Internet for marketing if the Mountainmade.com site becomes operational, and $\mathrm{s} /$ he stated that one of the most overlooked assets for marketing by craftspeople was the telephone. Face-to-face or hands-on marketing were noted to be useful, as opposed to 
catalogue or Internet marketing. The more impersonal methods for sales might necessitate a shift to mass-production, which is not attractive to crafters, especially if the marketing is managed by non-crafters.

Survey question 1 asked subjects about their craft media. Respondents were asked to circle the one primary medium they employ in the construction of their craft. A list of nine options determined by a database used by the United States' National Information System Project of the National Assembly of State Arts Agencies facilitated the ease and contemporary appropriateness of this questionnaire. This demographic information, presented in Table 8 , is relevant to the study because the craft media used in this particular geographic area reflect aspects of the Southern Appalachian mountain state's resources and rural nature. Nineteen respondents $(41 \%)$ reported that they work with wood. That response contrasts, for example, with the category of plastics, reportedly used by none of the respondents. Six respondents circled fiber (13\%) as their craft medium. The media of clay, metal and glass each were selected by five respondents $(11 \%)$ as their primary medium. Only one person $(2 \%)$ selected leather as a primary medium. Many respondents work in various media and therefore selected more than one medium. Some chose the "Other" and/or the mixed media category. Two of the forty-six respondents selected only the "Other" category. Respondents were asked to describe those additional media (documented in Appendix F: Comments Evoked by the Survey) because of possible significance to this study. 
Table $8 \quad$ (Survey Question 1)

Frequency Distribution for Primary Media Used by Craftspeople $\quad(\mathrm{N}=46)$

\begin{tabular}{|c|c|c|}
\hline Medium & Frequency & Percent \\
\hline Wood & 19 & 41 \\
\hline Fiber & 6 & 13 \\
\hline Clay & 5 & 11 \\
\hline Metal & 5 & 11 \\
\hline Glass & 5 & 11 \\
\hline Paper & 3 & 7 \\
\hline Leather & 1 & 2 \\
\hline Plastics & 0 & 0 \\
\hline Other & 2 & 4 \\
\hline
\end{tabular}


Research Question 2: To what degree can existing individual readiness (experience and potential) fulfill the objectives of establishing and using electronic media for marketing West Virginia craft wares?

Research question two is addressed by analyzing responses to the survey questions that address the potential of respondents to promote and establish the use of electronic media for marketing $(2,3,4,6,7)$. All of those questions are grouped under demographics except for one (22), in the survey category of Access/Use. The demographic information is included to provide background for other data addressing readiness to use electronic media for marketing crafts.

Survey question 2 asked respondents to circle a range of years grouped into fiveyear spans reflecting the length of time they had practiced their crafts. These time-span data are presented in Table 9. Frequencies obtained using the SAS statistical analysis program showed the researcher that the questions were discriminating. All respondents had practiced their craft for at least five years; three had practiced for more than 34 years. A quarter of the respondents reported that they had practiced their craft for 10-14 years. Forty of the forty-six respondents had practiced their craft for about a decade or more, and fifteen had worked 20 years or more. It must be inferred that plenty of experience in craft production exists in this population, a positive factor in the overall equation. 
Table 9 (Survey Question 2)

Frequency Distribution for Length of Time Having Practiced Craft $(N=44)$

\begin{tabular}{ccc}
\hline Span of Years & Frequency & Percent \\
\hline $5-9$ & 6 & 13 \\
$10-14$ & 12 & 26 \\
$15-19$ & 7 & 15 \\
$20-24$ & 6 & 13 \\
$25-29$ & 8 & 17 \\
$30-34$ & 4 & 9 \\
$35-39$ & 1 & 2 \\
\hline
\end{tabular}

The survey presented two questions about group marketing efforts: cooperative and non-cooperative. Respondents were asked to answer Yes or No to survey question 3 about the rewards of involvement in a craft cooperative. Seventeen (46\%) perceived benefits of coop involvement during the past decade. In question 4 respondents were asked about the rewards of involvement in any non-cooperative group marketing efforts. Twenty-two $(63 \%)$ of the respondents who indicated that they were, or had been, involved in some non-cooperative (i.e., commercial, commissioned, guild for profit) group marketing effort indicated that they perceived benefits.

Un-solicited comments to survey questions 3 and 4 indicate respondents' concerns about the fiduciary definition of "Rewarding". The wording was judged to be unclear by several respondents in regard to these two survey questions. One comment stated that the wording of survey question 3 was misleading because cooperatives always take a percentage to cover costs, and this survey question defines it as an organization through which all money from product sales is returned to the individual craftsperson. 
Overall, the comments indicate a lack of familiarity with ideal cooperative practice, a conclusion further discussed in Chapter 5.

In regard to the "Yes/No" survey question 4 about rewards for non-cooperative group efforts, several un-solicited comments were written. To summarize those statements: state parks and turnpike shops buy crafts to sell, but given their high markup prices, product sales are poor. West Virginia is a rural state with businesses closing down or moving to more prosperous areas; craft shops are negatively affected; and potential customers won't exit the interstate to visit an isolated shop. To clarify the apparently confusing wording of survey question 3 regarding calculated shares, I quote Barton (1989) on one of the Rochdale principles considered timeless and universal, characterizing all types of coops, at all times, in all places: "business [is] at cost, which requires net income to be distributed pro rata to patrons based on patronage" (p. 28). In other words, to assess and divide costs and income proportionally to each individual member is the business strategy.

In response to survey question 6 , respondents were asked to circle a range of numbers indicating how many craft products they sold during the year 1999. The researcher assumed that asking for the quantity of products sold would result in a higher response rate than if a question about income was included. The response rate was in fact high but the information obtained was not statistically useful. While a question about income may have hindered responses, the data obtained from the question as stated was relatively inadequate due to confusion among respondents about how to quantify sales.

Eight respondents wrote un-solicited comments that survey question 6 was unclear, irrelevant or inadequate to reflect the craftsperson's situation or views on the subject. As examples, three respondents implied that money value was more relevant 
than quantity of products sold. One respondent did not circle any product quantity, but wrote, "\$80,000". A second respondent who circled $100+$ products wrote, "This is not a relevant question. Quantity is not important but value: how many dollar's worth did you sell." A third respondent circled 10-49 and clarified that for them it meant "different [unique] items [not mass-produced kinds]: we sold approximately $\$ 15,000$ worth last year." A fourth respondent circled $100+$ products and wrote, "Do you mean product lines or individual items? I made about a dozen types of pots, plus two special designs for a customer in 1999." A fifth respondent did not circle any range of numbers and instead wrote, "We produce approximately 200 pots per month X 10 months $=2000$ annually." A sixth respondent circled 10-49 but wrote, "I only had one table [sell] in May." A seventh respondent circled 50-99 and asked whether I was requesting information about "How many different items or how many individual sales?" An eighth respondent circled 10-49 and then clarified, "[That is] if you mean variety of products not actual pieces sold. If [you are asking about] actual pieces sold, then over 1000." In summary, the comments indicate differentiations among sales events, sales totals, and mass versus unique productions made by craftspeople that were not represented in the survey question as it was written.

The statistics for survey question 6 follow in Table 10, although presented with the caveats implied by the above-unsolicited comments. Twenty-seven respondents $(59 \%)$ indicated that they sold 100 or more craft products. A large gap in frequency occurs between the $100+$ and the 10-49 items sold categories. Very few craftspeople sold other quantities of products during 1999. The two most-selected categories of number of items sold may reflect the differences in the amount of labor required to produce a craft item, or the marketing of unique versus mass-produced items. 
Table 10 (Survey Question 6)

Frequency Distribution for Number of Craft Products Sold in 1999 (N=46)

\begin{tabular}{ccc}
\hline Quantity Sold & Frequency & Percent \\
\hline $100+$ & 27 & 59 \\
$50-99$ & 3 & 7 \\
$10-49$ & 10 & 22 \\
$5-9$ & 1 & 2 \\
$1-4$ & 4 & 9 \\
0 & 1 & 2 \\
\hline
\end{tabular}

Survey question 22 asked respondents to circle a range of numbers representing craft product sales (quantity of items, not monetary gain per item) that they made in the year 1999 due directly to World Wide Web representation, if a site represented them. This question 22, like survey question 6, suffered from problems of confusing language or inappropriate categories as indicated by comments. The group mean from twenty respondents was 2.5 with a standard deviation of 1.23 . The ranges of numbers offered from which to select were $0,1-4,5-9,10-49,50-99$, and 100+ products sold, as represented in Table 11. Less than $30 \%$ of the respondents made sales utilizing the Internet for marketing their craft products.

Table 11 (Survey Question 6 and Survey Question 22)

Frequency Comparison of 1999 Sales in General and by Website $(\mathrm{N}=46)$

\begin{tabular}{ccc}
\hline Quantity Sold & $\begin{array}{c}\text { Sales in General } \\
\text { (Question 6) }\end{array}$ & $\begin{array}{c}\text { Sales Due to Website } \\
\text { Representation } \\
\text { (Question 22) }\end{array}$ \\
\hline $100+$ & 27 & 0 \\
$50-99$ & 3 & 0 \\
$10-49$ & 10 & 6 \\
$5-9$ & 1 & 3 \\
$1-4$ & 4 & 4 \\
0 & 1 & 6 \\
\hline
\end{tabular}


Survey question 7 asked whether respondents planned to continue practicing

their craft. The overwhelming majority (43 of 46) of respondents indicated that they do plan to continue making their craft products. 


\section{Research Question 3: What is the maturity of the existing infrastructure from}

\section{individual craftspeoples' perceptions?}

This study focuses on the communication infrastructure as distinguished from other technological infrastructures such as those of transportation or production. Infrastructure is defined as the basic installation and/or underlying foundation on which the continuance and growth of a community, state or other social organization depends. Every technological infrastructure essentially involves five aspects: human skill, networks/systems, budget/economy, policy/law, and technical devices. Research question three is addressed by analyzing responses to the Budget/Economy and Policy/Law survey questions as they relate to communication and information system use $(11,12-\mathrm{A}, 12-\mathrm{B}, 13,14,15,16$, and 17). Because policy, law, budget and economy seem to be relatively unfamiliar topics for this population, they are addressed as a group under research question three. The other three research questions address overlapping considerations of human skills, all possible networks and systems as well as technical devices, which comprise questions more easily answered by the group under study.

For survey questions 11, 12-A, and 12-B a five-point Likert scale was used, while survey questions 13 through 17 were "Yes/No" questions with additional open-ended responses requested from those who answered "Yes". Responses to those open-ended questions are presented here to enrich statistical data.

Four survey questions address the research question about budget and economy. Respondents in question 11 assessed the overall favorability of national, state and local budgets and economies for marketing crafts electronically. Forty-one respondents, an overwhelming majority, rated the economy as good in general. On a 5-point scale, the group mean was 3.40 with a standard deviation of 1.10 . Five respondents wrote 
unsolicited comments. Two respondents wrote that they did not know. Two respondents clarified that people have money to spend on crafts and are buying art, but whether they will use the Internet to make purchases is uncertain at this time. A fifth respondent emphasized that web-based marketing for crafts is not a viable means for sales: shipping expenses to deliver the product can be a disproportionate amount of the overall financial configuration.

For survey question 12, degree of expense is ranked on a scale of 1 to 5 from "Not Very" to "Very Expensive" first in the context of personal finances and then in the context of time spent marketing electronically. Sixteen respondents indicated a low cost of both money and time to market electronically.

Fourteen respondents (39\%) indicated in response to survey question 14 that they had a business plan accommodating expenses for Internet or related communication services. Purchasing of marketing information from a corporation was not an option for them; however one of the fourteen respondents wrote that Mountainmade.com could eventually provide some guidance once it is set up.

Four survey questions address the research question about policy and law. The lack of responses to survey question 13, inquiring about the existence of policy on electronic marketing, indicated that policy is not an issue for this population. One respondent summarized that basic concepts of honesty and fairness must be followed. Involved in wholesale, s/he wrote that as a bed and breakfast business their emphasis is not on retail except at fairs. None of these craftspeople have a policy that determines how electronic marketing is used.

Survey question 15, which asked about whether one's business or coop regulates how electronic marketing information is compiled and presented to potential customers, 
evoked only four answers, all "No" (12\%). Four respondents wrote comments requested as explanations. The overall pattern was that the craftsperson would personally direct, create and regulate all such information.

Results from question 16, whether respondents knew of any existing business or coop that has a policy(s) about use of electronic marketing which consider the full potential of computers and telephones, supported the data from questions 13 and 15 . Only one of 41 who responded to this question knew about such policies. S/he wrote that this is a very subjective question in regard to the full potential of these technical means. In survey question 17 , respondents were asked if they thought that rules and guidelines set by national and state authorities are useful when creating electronic marketing materials. Those who circled "Yes" were asked to explain how such guidelines have been personally useful. Five of those "Yes" respondents wrote requested comments, including: concerns about tracking and the cost of enforcing copyrights and rules that give small businesses power over public information; the importance of craftspeoples' awareness of laws; and one opinion that little government intervention is preferable. 
Research Question 4: What is the perceived degree of access to electronic media by individual craftspeople for marketing their wares?

Research question four was answered by analyzing the responses to Access/Use survey questions $(18,19,20$ and 21). Survey question 18 offered categories of hours of use. Question 19 about potential used a 5-point Likert scale. Questions 20 and 21 were Yes/No questions about website representation.

Survey question 18 asked respondents to circle the number of hours from 1 or less to 5 or more that they went online, if they used the Internet. Table 12 presents the analysis of forty-one responses out of the forty-six. Almost half of those surveyed use the Internet for five or more hours per week, while a quarter to a third of these craftspeople go online for 1 or fewer hours per week. Therefore, a pattern of polarization appears in that this population either mostly does not use the Internet at all, or it uses it for 5 or more hours per week. It is not evident by this survey analysis how much time was used exclusively for the purpose of promoting self-made craft products.

Table 12 (Survey Question 18)

Frequency Distribution for Use of the Internet $(\mathrm{N}=41)$

\begin{tabular}{lcc}
\hline \multicolumn{1}{c}{ Hours per Week } & Frequency & Percent \\
\hline 1 or less & 11 & 29 \\
2 & 4 & 10 \\
3 & 4 & 10 \\
4 & 3 & 7 \\
5 or more & 19 & 46 \\
\hline
\end{tabular}

Survey question 19 asked subjects about their overall potential to use the Internet for marketing crafts, ranked from no agreement to total agreement on a scale of one to five. The potential that was most highly rated was that the Internet could help 
craftspeople decide on marketing decisions, with a group mean of 3.20 and a standard deviation of 1.30. The need for access to expert help about electronic media followed closely, with a group mean of 3.00 and a standard deviation of 1.50. Results for time, experience, capital and risk factors regarding potential to use the Internet for marketing were grouped between the mean response ranges of 2.66 and 2.03. Those craftspeople responding that they could risk time and money had a group mean of 2.03 with a standard deviation of 1.00. Most respondents indicated that risk of time and money could hinder their potential use of the Internet; they could not risk time and money. Table 13 presents that continuum of using the Internet for marketing purposes.

Table 13 (Survey Question 19)

Mean Scores for Personal Use of the Internet for Marketing Crafts

\begin{tabular}{llll}
\hline \multicolumn{1}{c}{ Internet Marketing Potential } & Mean & S.D. & N \\
\hline Marketing Decision-making & 3.20 & 1.30 & 37 \\
Access to Expert Help & 3.00 & 1.50 & 39 \\
Adequate Time & 2.66 & 1.00 & 38 \\
Electronic Media Experience & 2.60 & 1.50 & 37 \\
Available Capital & 2.40 & 1.30 & 38 \\
Risk of Time and Money & 2.03 & 1.00 & 36 \\
\hline
\end{tabular}

Respondents were asked to answer "Yes" or "No" to question 20 about whether there was a website that represented them as a craftsperson or represented their products. Pragmatically, there was a risk of time and money reported. Twenty-one (48\%) circled "Yes", that they and/or their craft products were represented on a website. Respondents who answered "Yes" were then asked to answer "Yes" or "No" to questions 21-A through 21-D. The responses for survey question 21 A-D about website representation are presented in Table 14. Responses to Question 21-A indicated that about one-fifth of the respondents had designed the website themselves. Question 21-B asked if the website 
included adequate visual representation of their products, and $86 \%$ circled "Yes".

Question 21-C asked respondents if they track the number of hits to their website regularly; over half did. Question 21-D asked respondents if their website has been costeffective; 57\% circled "Yes".

Table 14 (Survey Question 21)

Frequency Distribution for Craftspeople with Website Representation ( $N=46)$

\begin{tabular}{llcc}
\hline \multicolumn{1}{c}{$\begin{array}{c}\text { Survey } \\
\text { Question }\end{array}$} & \multicolumn{1}{c}{ Survey Question Description } & Frequency & Percent \\
& & & \\
\hline $21-$ A & Self-design of Website & 4 & 19 \\
$21-$ B & Adequate Visual Representation & 18 & 86 \\
$21-$ C & Regular "Hit" Tracking & 12 & 57 \\
$21-$ D & Cost Effectiveness & 12 & 57 \\
\hline
\end{tabular}

In addition, survey question 21 prompted unsolicited comments from subjects who had additional insights or concerns that had not been adequately offered as options in the survey instrument. Various Websites were reported as under construction. Several craftspeople mentioned that when a particular arts and crafts marketing site is up and running, they plan to sell on the World Wide Web wholesale.

Analysis was based largely on polarization from a limited set of data. To clarify why the researcher drew the following conclusions, it is important to see the analyses from both the closed and open-ended responses evoked by this survey. Constellations and correlations among and between the responses led to analyses of the findings. Openended comments enriched the statistical data produced by this study. 


\section{Findings}

This section presents a discussion of findings grouped by the four research question survey sections. Analysis of data is interpreted here in order to identify the hindrances that exist and what might be done to facilitate cooperative use of communication technology to market crafts in West Virginia. Data that emerged from analyzing respondent comments are included as relevant. Various respondents added relevant comments to questionnaire items even when the category of "Other" was not offered.

Research Question 1: What are the skills and knowledge individual craftspeople have used to market their wares utilizing electronic media?

Finding 1.1: Individual skills and knowledge of the craft media utilized affected marketing strategies adopted by the craftsperson. Of all the possible crafts to make and market, nearly half of this population worked in the medium of wood. That result was not surprising since the state of West Virginia has an abundance of trees that lend themselves to many practical as well as creative applications.

Finding 1.2: Open-ended comments from some of the respondents indicated concerns about low quality reproduction and copyright issues. This phenomenon exists partly due to two-dimensional and three-dimensional photographic reproduction considerations. However, of those with website representation, $86 \%$ thought the visual representation was adequate, mostly for three-dimensional items. It may be that a lack of actual experience with making images of products supports concerns about low quality reproduction. While awareness of the importance of copyright was made clear by comments (i.e., they will protect our creations and designs) ignorance of the law was evidenced by many comments to the survey instrument. 
Finding 1.3: General marketing skills, which included some electronic media skills, tend to cluster below a mid-point (highest 2.95 and lowest 1.68) with price setting skills on the higher end of a five-point scale. Other skills rated as frequently used to market were "Word-of-Mouth" and "Galleries". The below mid-point skills ratings indicated a very low-level application of general marketing skills among this population.

Finding 1.4: The skills and knowledge craftspeople used to market their wares utilizing electronic media were varied, yet on the basis of the data they tended to be limited in scope with regard to any one particular use; they did not make use of that medium for marketing purposes. Responses to survey question 9 tended to cluster around a relatively low to mid-point (highest 2.60 and lowest 1.39) with Internet skills toward the higher end of a four-point Likert scale. This data implies that although Internet skills were rated high on that scale of electronic media skills for craftspeople, "Web-based Creation" was rated lowest. The top three electronic skills of "Word Processing", "Email" and "Internet Searching" were the same skills typical of the larger population.

Finding 1.5: Use of the telephone and answering devices served many purposes as does e-mail now for timely interpersonal communication by this population. In regard to survey question 9, it was evident that the researcher's lack of listing the use of a telephone as an electronic skill left a gap in the survey instrument.

Finding 1.6: Just over half of the respondents circled five or more hours spent online per week, which means that about half spent so little time on the Internet that they were probably not keeping up with its potential as a marketing tool. While anyone who had website representation was likely to spend more time using the Internet, responses to survey questions 19, 20, 21 and 22 about access to use of electronic media provided support that this population used it very little. 
Research Question 2: To what degree can existing individual readiness (experience and potential) fulfill the objectives of establishing and using electronic media for marketing their West Virginia craft wares?

Finding 2.1: In regard to years of having practiced one's craft and the quantity of sales in 1999, most respondents had plenty of experience producing their work and all planned to continue. Sales statistics varied widely for a multitude of reasons reported, but Price-Setting was a highly-rated marketing skill among this population.

Finding 2.2: The survey responses indicate that a majority of these craftspeople had benefited by marketing as a group, whether cooperatively or not. The feeling of reward for non-cooperative group marketing efforts was rated as more favorable than cooperative endeavors.

Finding 2.3: Quantity of items sold due to Website representation was low compared with sales in general. Less than half of those surveyed reported selling crafts via website advertising. This survey instrument did not statistically address income, yet those twenty respondents reported that they made less than $30 \%$ of their overall quantity of sales on-line.

Finding 2.4: One fourth of the respondents indicated using the World Wide Web as a marketing strategy. Internet Searching was selected as a personal skill, although with a mean of 2.24 and a standard deviation of 2.24 , the use of that skill for marketing was statistically almost insignificant among this population. Therefore, experience and potential to market crafts electronically was low. 


\section{Research Question 3: What is the maturity of the existing infrastructure from}

\section{individual craftpeoples' perceptions?}

These survey questions address issues of policy and law as well as budget and economy, two of five elements essential to any communication infrastructure. Human skills, networks and systems, and technical communication devices are aspects of the infrastructure addressed in the other three research question survey categories.

Finding 3.1: In response to survey question 15, only twelve percent circled that they did have a business or coop that regulated how electronic marketing information was compiled and presented to potential customers. As requested in an open-ended format, those four subjects wrote that they self-regulated, with complete control and created their own information, indicating a lack of formal regulations.

Finding 3.2: In regard to survey question 11, this population rated national, state and local economies good in general for marketing crafts electronically.

Finding 3.3: Resulting answers to survey questions 13, 16 and 17 about policies, rules and guidelines, evidenced very little knowledge about these issues regarding electronic marketing.

Finding 3.4: Approximately one-third of those surveyed responded to question 12 about personal expense (time and money) to market electronically. They indicated spending little on it and that they had a budget that did not accommodate expenses for electronic communication services. In response to the access question 19 about potential to use electronic media for marketing, the risk of time and money was indicated as a hindrance to use electronic media marketing. Respondents reported that they had little personal experience and few had access to expert help. 


\section{Research Question 4: What is the perceived degree of access to electronic media by} individual craftspeople for marketing their wares?

Finding 4.1: E-mail was the most frequent use of the Internet, but very few hours per week were dedicated to being logged-on for any purpose. A pattern of polarization appeared in that this population either mostly did not use the Internet at all, or it used it for five or more hours per week. It is not evident by this survey analysis how much time was used exclusively for the purpose of promoting self-made craft products.

Finding 4.2: The potential of these craftspeople to make the best use of electronic media was dependent on expert assistance. Most reported that use of the Internet for marketing decisions ranked highest, and risk of time and money was a problem for them. Respondents indicated that although they might have had adequate time, available capital was more of a problem.

Finding 4.3: Website representation for craft marketing was infrequently utilized. However, those surveyed who were involved in such electronic marketing reported adequate visual representation, that they regularly tracked their "hits" and that they felt it was cost-effective. About one-fifth of those 21 who responded indicated they had designed the website themselves. 


\section{Summary}

Findings from the survey showed that West Virginia craftspeople did not well use cooperative organizations and certainly did not use electronic marketing to the extent possible. It was concluded that accessing new communication avenues to market craft products led to the following considerations.

\section{Research Question 1: (Skills and Knowledge)}

- There are hindrances for craftspeople to use cooperative organizations and CAIS.

- The major medium used is wood.

- There were concerns about copyright policies.

- Reproduction quality was a concern.

- Few skills with marketing were obviated, particularly in regard to using the Internet.

- Use of the telephone was deemed more beneficial than e-mail for timely communications.

\section{Research question 2: (Readiness)}

- Craft production and price-setting skills were rated high.

- Non-cooperative marketing efforts were considered more favorable than selling cooperatively.

- Use of the Internet for craft sales was reported as very low. Less than half of sales were reported by those who did market on-line.

- Experience marketing crafts in any fashion was rated low across the board. 


\section{Research question 3: (Perceptions)}

- Minimal experience with a business that regulates electronic marketing information was evident.

- Adequate time and money for electronic marketing was rated low in that few budgeted for these considerations in their business plans.

- Knowledge about policy, rules and guidelines for electronic marketing was low.

- Little access to expert assistance was evident. Research question 4: (Access)

- This population reported that they were interested in using the Internet for marketing their crafts, but that they did not know how to best set up a website by themselves and that they are uncertain about its potential usefulness.

- The need for personal assistance to make adequate reproductions at the production location was evident. 


\section{CHAPTER FIVE:}

\section{CONCLUSIONS, IMPLICATIONS AND RECOMMENDATIONS}

This final chapter is comprised of three sections. The conclusions section presents the analysis of the chapter four findings and summary. The implications section includes the researcher's discussion of the conclusions. The recommendations section proposes suggestions for further research.

\section{Conclusions}

Drawing on comments from respondents and the statistical results, the following conclusions may be reached.

1. Craftspeople believe that sales are most effective by word-of mouth and one-onone involvement between the consumer and the craftsperson or with the item (finding 1.3). These beliefs may reduce the likelihood that craftspeople will commit time and money to indirect sales modalities.

2. Craftspeople perceive they lack the time to use electronic media for promoting their products (finding 3.4). There is a tendency to spend more time producing than marketing, for two reasons: one, production is labor-intensive; two, production is generally more enjoyable than marketing for this population.

3. Craftspeople lack the assistance they require to use electronic media (finding 1.4, finding 1.6, finding 2.4, finding 4.2). Overcoming the learning curve on computer software is time-consuming, and a hindrance to computer use.

4. Yet, when craftspeople use electronic media, they report good representation, cost effectiveness and they track hits (finding 3.2, finding 4.3). It is very likely that when Internet use and website representation are fully facilitated those uses will prove to be effective sales strategies. 
5. Survey data indicate that West Virginia craftspeople have low marketing and electronic media skills. The potential to develop electronic media skills is highly dependent on human assistance. When they are self-taught it generally involves transfer of skills using software for one program to applications of another.

6. There appeared to be a lack of practical familiarity about the meaning of a cooperative among this population. Answers to questions regarding cooperative or other group marketing efforts indicate that this population has little experience with coops as characterized by the Rochdale Principles of Cooperatives laid out by Barton (1989, p. 28). Respondents reported that experiences with non-cooperative group marketing involvement were generally frustrating at least, not leading to sufficient sales. For these reasons, fewer conclusions about cooperative endeavors are available than about the use of communication technology for marketing.

\section{Implications}

The survival of craftspeople requires sales, and that selling requires marketing. This option of marketing now seems to require use of electronic media: a phenomenon that calls for skills not previously acquired.

A craft piece is often judged, and even sold, by a reproduction of the work more than by the work itself. Sales brochures, show applications, exhibits and grant applications all require slide submissions to be used for judging quality. If the images are of poor quality, it is assumed that the actual work reproduced is of the same poor quality. Learning to make photographic reproductions of products is very important to the success of craftspeople because often they cannot afford to pay a professional to do this for them. Interestingly, mostly craftspeople working in three-dimensional media stated that their use of graphics programs was a personal electronic media skill, while 
those working in a flat, or two-dimensional media stated less skill using such visual reproduction as a marketing strategy. Given the scanning capabilities available, one might think there would be more use of computer graphics applications by twodimensional craftspeople than was reported. More than half are not using graphics programs, databases or spreadsheets, as would other business people. Overall, we know that electronic marketing and marketing endeavors in general are low, yet cooperative efforts can be about skill sharing which could address some of the problems.

The complications of communication technological revolutions, such as digital options and Internet marketing possibilities abound. Issues such as scrambling, read-only files, and sudden changes in software capabilities equate to reluctance for craftspeople to pursue this avenue of marketing. It seems as if any small business owner must have access to more than one telephone, answering service and computer system to successfully deal with all of the contemporary issues, which include marketing. A variety of needs for assistance and education are implied by the results of this study.

The social implications of using e-mail to leave messages for people who are not readily available to speak over the telephone or in person cannot be under-estimated. The ability to type a brief note and dispatch it to multiple parties almost free of charge in a matter of minutes is a phenomenon of significance to this study. The inundation of unsolicited e-mail messages, however, may likely be a source of discouragement for this population to rely on e-mail for electronic communication as much as they do on telephones and answering machine services for this type of business activity. Laborintensive craftspeople rely heavily on the strengths of their bodies, and this includes their visual acuity. The technological developments of computer screen covers and glareresistant eyeglasses have been addressing the problems of eyestrain that affect many 
computer workers. Ergonomic research might be further addressed as body position strain occurs due to long periods of time looking back and forth at hard copy and the computer screen.

Cooperative marketing efforts might be a viable means to lessen the various stresses on individual crafters who want to apply most of their time and energy to creating the actual products. In fact, the educational component inherent in an ideal coop sets it apart from other forms of business. Electronic marketing would be good because it could lead to audiences not already accessed. These people may be more likely to use new computer-related skills within a cooperative than they would alone. Human energy and compassion are possibilities of a coop that could be similar to family involvement in regard to learning these skills. Access to expert help about use of electronic media can offset risks of time and money, thus facilitating craftspeoples' motivation to make electronic marketing decisions.

As evidenced by the data in Table 10, lack of use of the Internet exists within the population most likely to benefit from it: multiple producers, as contrasted with producers of unique items. Producers of multiples could benefit greatly from website marketing, but most West Virginia craftspeople make more relatively unique items. Mass marketing is contrary to these craftworkers' ethics and style, and may therefore deter website sales representation from happening if Internet marketing implies mass marketing for all craftspeople. Targeted marketing, however, is a method relevant to this population, and it can be accomplished electronically. In non-statistical comments, one respondent wrote that s/he "would sell wholesale to Mountainmade.com that would then sell items both from its gallery in Thomas, WV and on the web." Another respondent wrote that "Having a website in addition to print media is a one-two punch [in that] after 
you reach a client, they can view your entire portfolio immediately." Therefore, cost-effectiveness of electronic media use was proclaimed by those who used these new communication technology methods for marketing.

This population infrequently used cooperative organizations and electronic methods as marketing strategies. However, putting people together with varying interests and skills toward a common goal of marketing craftwork electronically appears to be a viable consideration. Joining forces among individuals with differing skills is a proven promoter of successful endeavors. A cooperative formed for this purpose could be attempted. Based on the research, there is a chance of its success over the next six years, but probably it would become of less interest to members after a decade, for various reasons. These might include changes in communication technology, the definition of what comprises a craftwork, and general changes in the economy.

Craftspeople must sell their products or they cannot survive as such. The largest problem for this population is finding places to market their wares. Living in a rural area far from markets, a need exists for some kind of clearinghouse of information. Because festivals are seasonal events and people need twelve-month incomes, festivals do not provide a means of regular income. Even though crafts are an economic resource, they are mostly considered only as a cultural resource. Consumable craft items (culinary arts) are, however, considered more as economic resources. Some of those products are being successfully marketed electronically by West Virginians in ways that might be viable also for other craftspeople. Because consumable or edible products are more likely to be ordered on-line than other craft items, that sector of the artisan population has more experience putting their information on the Internet. 
An ideal cooperative would subordinate the importance of sales to that of its members' production missions in life. In other words, those members whose involvement might be for their contribution to a team effort in regard to marketing and those who are computer-savvy are sensitive enough to realize profitability as a group by promoting relatively unique items rather than assuming production of multiples.

\section{Recommendations For Further Research}

Following is a short list of possible study topics suggested for other researchers:

1. Why don't customers buy crafts on the spot, and want to purchase later?

2. What are the hindrances to cooperative development for craft sales?

3. Surveys of how craftspeople allocate their time minute-by-minute in regard to development, marketing and promotion would be useful.

4. Tracking website hits to determine how many hits it takes to make a craft sale could be a useful study.

5. Testing the usefulness of an 800 number by providing it on catalogs and websites, and tracking the calls related to sales might lend insight.

6. How would emerging technologies be better exploited?

7. What could we learn from European activity such as in Italy, where cooperative craft endeavors appear to be successful beyond the normal maximum six-year life span experienced in the USA. 


\section{REFERENCES AND BIBLIOGRAPHY}

Adams, G., Miles, M., \& Yoder, L. (eds.) (1986). The sourcebook for women who create. Center for Women's Studies, Morgantown, WV.

Armstrong, R. (1971). The affecting presence: An essay in humanistic anthropology. Urbana, IL: University of Illinois Press.

Barton, D. G. (1989). What is a cooperative? In D. W. Cobia (Eds.) (pp. 1-20). Englewood Cliffs, NJ: Prentice Hall.

Barton, D. G. (1989). Principles. In D. W. Cobia (Ed.), Cooperatives in agriculture. (pp. 21-33). Englewood Cliffs, NJ: Prentice Hall.

Bergeron, F. \& Raymond, L. (1992, January). Planning of information systems to gain a competitive edge. Journal of Small Business Management.

Bitner, M.J. (1992). Servicescapes: the impact of physical surroundings on customers and employees. Journal of Marketing, 56(2), 57-71.

Blake, N. B. (1989). Assessing the nature, status, and needs of regional artisans and craft patrons. (Doctoral dissertation, University of WI- Stout, 1989). Dissertation Abstracts International, .. (University Microfilms No. LD5171.S715h, B581).

Borg, W.R. \& Gall, M.D. (1989). Educational research: An introduction. (5th Edition). NY: Longman.

Clifford, J. (1988). The predicament of culture: Twentieth century ethnography, literature and art. Cambridge, MA: Harvard University Press.

Cobia, D. W. (Ed.). (1989). Cooperatives in Agriculture. New Jersey: Prentice-Hall.

Converse, J. M. \& Presser, S. (1986). Survey questions: Handcrafting the standardized questionnaire. Thousand Oaks, CA: Sage. 
Cook, R. G. \& Barry, D. (1993, January). When should the small firm be involved in public policy. Journal of Small Business Management.

Cowan, R. (1995). The informatisation of government: From choice of technology to economic opportunity. Science/Technology/Industry Review, 16, 195-223. (Organization for Economic Co-operation and Development).

Cummings, L.L. \& Staw, B. M. (Eds.) (1997). Research in organizational behavior. Vol. 19. Greenwich, CT: JAI Press.

DeMaio, T. J. (Ed.). (1983, Nov.). Approaches to developing questionnaires. Statistical Policy Working Paper 10. Washington, DC: Office of Information, within the Office of Management and Budget.

Denny, R. (1995). Speaking to customers: The anthropology of communications. In Sherry, John F. , Jr. (Ed.). Contemporary marketing and consumer behavior: An anthropological sourcebook. (pp. 330-346). Thousand Oaks, CA: Sage Publications.

Dillman (1978). Mail and telephone surveys: The total design method. (pp. 119-160).

Dodge, H. R. \& Robbins, J. E. (1992, January). An empirical investigation of the organizational life cycle model for small business development and survival. Journal of Small Business Management.

Duhaime, C., Joy, A., \& Ross, C. (1995). Learning to “see”. In Sherry, John F. , Jr. (Ed.). $\underline{\text { Contemporary marketing and consumer behavior: An anthropological }}$ sourcebook. (pp.351-398). Thousand Oaks, CA: Sage Publications.

Ellsworth, J. H. \& Ellsworth, M. V. (1995). Marketing on the Internet: Multimedia strategies for the World Wide Web. New York: John Wiley \& Sons. 
Evans, C. A. (1991). An economic analysis of craft cooperatives in Appalachia. (Master's thesis, University of Tennessee, Knoxville, 1991). Master's Abstracts International, ,.

Fallon, S. M. (1995). Perceived readiness of environmentally focused public interest groups in West Virginia to establish and use public access cable television. (Master's thesis, West Virginia University, 1995). Master's Abstracts International, ,.

Fitzgerald, K. (1993, March 29). Calling small business. Advertising age. (64), 29+.

Fowler, J. F., Jr. (1995). Improving survey questions. Applied Social Research Methods Series. (Vol. 38). Thousand Oaks, CA: Sage.

Georgescu, P. A. (1997, April 14). Looking at the future of marketing. Advertising age, (p. 30).

Gillespie, et. al. (1989). Information and communication technology and regional development: An information economy perspective. Science/Technology/Industry Review, 5, 85-111.

Gravetter, F.J. \& Wallnau, L.B. (1992). Statistics for the behavioral sciences. ( $3^{\text {rd }}$ Edition). St. Paul, MN: West Publishing.

Greer, B. (1988). Arts co-operatives: A guide for artists. Victorian Ministry for the Arts, South Melbourne, Australia.

Groves, F. (1985). What is cooperation? The philosophy of cooperation and its relationship to coop structure and operations. (University Center for Cooperatives Occasional Paper No. 6). Madison, WI: University of Wisconsin, College of Agriculture and Life Sciences, Cooperative Extension Service. 
Halket, J. E., Seymour, W. R. \& Ely, G. E. (1985). The cooperative approach to crafts. (USDA Report No. 83). Washington, DC: Agriculture Cooperative Service.

Hoyt, A. (1989). Cooperatives in other industries. In D.W. Cobia (Ed.) Cooperatives in agriculture. (pp. 68-79). Englewood Cliffs, NJ: Prentice Hall.

Hunter, J. (1991). Culture wars: The struggle to define America. NY: Basic Books.

Ichiishi, T. (1993). The cooperative nature of the firm. Cambridge, England: Cambridge University Press.

Kotler, P. (1982). Marketing for non-profit organizations. New Jersey: Prentice Hall.

Leary, D., \& Roy, E. P. (1975). Craftworkers' cooperatives in Louisiana: a case study. (Department of Agricultural Economics Research Report No. 494). Baton Rouge, LA: Louisiana State University, Agriculture Experiment Station.

Lewis, J. \& Jhally, S. (1998, Winter). The struggle over media literacy. Journal of Communication, 48 (1), 109-21.

Mancuso, J. R. (1992). How to start, finance, and manage your own small business. NY: Fireside.

Mangione, T. W. (1995). Mail surveys: Improving the quality. Applied Social Research Methods Series. (Vol. 40). Thousand Oaks, CA: Sage.

Marascuilo, L. \& Serlin, R. (1988). Statistical methods for the social and behavioral sciences. NY: WH Freeman.

McCreery, J. (1995). Malinowski, magic and advertising: On choosing metaphors. In Sherry, John F. , Jr. (Ed.). Contemporary marketing and consumer behavior: An anthropological sourcebook. (pp.309-329). Thousand Oaks, CA: Sage Publications. 
McMillan, J.H. \& Schumacher, S. (1989). Research in education: A conceptual introduction. (2nd Edition). United States: Harper Collins Publishers.

Meziou, F. (1991, October). Areas of strength and weakness in the adoption of the marketing concept by small manufacturing firms. Journal of Small Business Management.

Ministry of Small Business, Tourism and Culture. (1995). Aboriginal artists' project: artist needs and market assessment. (ISBN 0-7726-2509-3). Aboriginal Artists' Project Steering Committee, Province of British Columbia: Canadian Cataloguing in Publication Data.

Nash, R. \& Nash, R. (1976). Art cooperatives: four Iowa models. Dubuque, IA: Art Coop Book.

Neck, A.P. \& Nelson, R. (Eds.). (1987). Small enterprise development: Policies and progress. Geneva, Switzerland: ILO.

Oberhauser, A. M. (1995, Nov.). Gender and flexible production networks in rural Appalachia. Paper presented at the annual meeting of the Southeastern Division of the AAG. Knoxville, TN.

Oberhauser, A. M. (1995). Gender and household economic strategies in rural Appalachia. Gender, Place and Culture. 2(1), 51-70.

Ott, L. (1984). An introduction to statistical methods and data analysis. Boston, MA: PWS Publishers.

Peck, E. (1982). Berea’s first 125 years 1855 - 1980. The University Press of Kentucky.

Peterson, R. T. (1991, October). Small business usage of target marketing. Journal of Small Business Management. 
Perreault \& McCarthy (1997). Applications in basic marketing: Clippings from the popular business press. Chicago, IL: Irwin.

Powlowski, P. (1994). Identification and evaluation of knowledge categories for the study of photovoltaic solar cells. (Master's thesis, West Virginia University, 1994). Master's Abstracts International, ,.

Rose, D. (1995). Active ingredients. In Sherry, John F. , Jr. (Ed.). Contemporary marketing and consumer behavior: An anthropological sourcebook. (pp. 51-85). Thousand Oaks, CA: Sage Publications.

Roy, E. P. (1981). Cooperatives: Development, principles, and management. ( $4^{\text {th }}$ Edition). Danville, IL: The Interstate Printers and Publishers.

Schmiesing, B. H. (1989). Theory of marketing cooperatives and decision making. In D.W. Cobia (Ed.) Cooperatives in agriculture. (pp. 68-79). Englewood Cliffs, NJ: Prentice Hall.

Schrader, L. F. (1989).Future structure, problems and opportunities. In D.W. Cobia (Ed.) Cooperatives in agriculture. (pp. 68-79). Englewood Cliffs, NJ: Prentice Hall.

Shaw, L. \& Rubin, S. (1986). Broadening the base of economic development: New approaches for rural areas. Chapel Hill, NC: MDC, Inc.

Sherry, J. F., Jr. (Ed.). (1995). Contemporary marketing and consumer behavior: An anthropological sourcebook. Thousand Oaks, CA: Sage Publications.

Smith, C. (1997). Art marketing 101, a handbook for the fine artist. Penn Valley, CA: ArtNetwork.

Southeast Alaska Native Artists Cooperative Market Study. (1991, May). Juneau, AK: Sealaska Heritage Foundation. 
Staatz, J. M. (1984). A theoretical perspective on the behavior of farmers' cooperatives. (Doctoral dissertation, Michigan State University, 1984). Dissertation Abstracts International, ,

Tjosvold, D. (1993, February). Prevalence of cooperation and competition: Evidence from diverse organizations. Psychological Reports, 72, 210.

Tjosvold, D. \& Weicker, D. (1993, January). Cooperative and competitive networking by entrepreneurs: A critical incident study. Journal of Small Business Management.

Vilstrup, R. H. \& Groves, F. W. (1989). Communications. In D.W. Cobia (Ed.) Cooperatives in agriculture. (pp. 68-79). Englewood Cliffs, NJ: Prentice Hall. Watkins, W.P. (1986). Cooperative principles. Manchester, England: Holyoake Books. Williamson, K. (1980). The Asylum Hill artists' cooperative: A study and analysis of a cooperative system- organization and history June, 1976 - February, 1979. Storrs, CT: University of Connecticut and Connecticut Commission on the Arts.

Windles, P. (1984, May). Technology, renewable resources and American crafts. Washington, DC: US Government Printing Office.

West Virginia Commission on the Arts (1997, Feb.) Long range plan, fiscal years 19982000. Charleston, WV: Arts and Humanities Section of the West Virginia Division of Culture and History.

World Wide Web Yellow Pages (1997). Indianapolis, IN: New Riders Publishing. Zuboff, S. (1988). In the age of the smart machine: The future of work and power. NY: Basic Books. 


\section{Appendix A: Pilot Survey Instrument with Definitions of Terms}

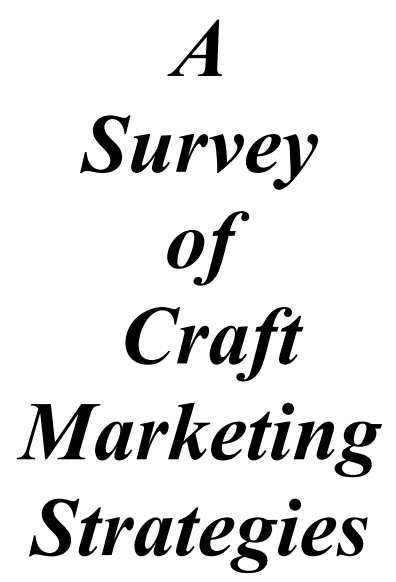

Karen Norwood

Technology Education Program

College of Human Resources and Education

PO Box 6122

West Virginia University

Morgantown, WV 26506-6122

304-864-5958

kknorwood@aol.com

This survey is intended to help us all better understand how West Virginia craftspeople feel about marketing their products in 1999, given new communication technologies.

Please answer every question to the best of your ability. Where appropriate, circle the number or letter that corresponds to your answer. Otherwise, write in your response.

Please return the survey in the enclosed self-addressed stamped envelope by

May 20, 1999.

Thank you for your help.

ID \# 
January 19, 1999

\section{Dear Pilot Participant:}

Enclosed is a survey that I plan to send to up to 946 craftpeople in West Virginia in order to evaluate potential cooperative marketing strategies utilizing communication technologies. This questionnaire is a part of my doctoral dissertation.

I am asking you to complete the survey as a craftsperson, and to add comments that might help me make it a more useful questionnaire.

Please consider my study questions after you have completed the survey and add your comments that might help me make changes important to the questionnaire.

My study questions are as follow:

1. What are the skills and knowledge individual craftspeople have used to market their wares utilizing electronic media?

2. To what degree can existing individual readiness (experience and potential) fullfill the objectives of establishing and using electronic media for marketing their West Virginia craft wares?

3. What is the maturity of the existing infrastructure from individual craftpeoples' peceptions?

4. What is the perceived degree of access to electronic media by individual craftspeople for marketing their wares?
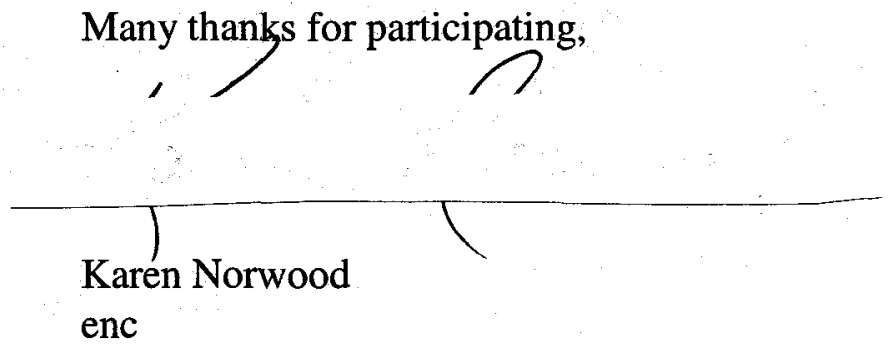


\section{YOUR CRAFT BUSINESS}

1) To what extent have you used the following skills to market your products during the past six years? (Circle a number on the scale of 1 to 5 for each question)

\begin{tabular}{|c|c|c|c|c|c|c|}
\hline \multirow[b]{2}{*}{1.1} & \multirow[b]{2}{*}{$\begin{array}{l}\text { Visual production } \\
\text { (e.g., photos, slides, graphics, etc.) }\end{array}$} & \multicolumn{3}{|c|}{ Little Used } & \multicolumn{2}{|c|}{ Much Used } \\
\hline & & 1 & 2 & 3 & 4 & 5 \\
\hline 1.2 & Writing & 1 & 2 & 3 & 4 & 5 \\
\hline 1.3 & Negotiation & 1 & 2 & 3 & 4 & 5 \\
\hline 1.4 & Bookkeeping & 1 & 2 & 3 & 4 & 5 \\
\hline 1.5 & Audience analysis & 1 & 2 & 3 & 4 & 5 \\
\hline 1.6 & Market analysis & 1 & 2 & 3 & 4 & 5 \\
\hline 1.7 & Price setting & 1 & 2 & 3 & 4 & 5 \\
\hline 1.8 & Computer software skills & 1 & 2 & 3 & 4 & 5 \\
\hline 1.9 & Internet searching & 1 & 2 & 3 & 4 & 5 \\
\hline 1.10 & Web site advertising & 1 & 2 & 3 & 4 & 5 \\
\hline 1.11 & $\begin{array}{l}\text { Budgeting and forecasting } \\
\text { (e.g., deciding on quantity of } \\
\text { production, types of items, } \\
\text { materials required, buying in bulk, etc.) }\end{array}$ & 1 & 2 & 3 & 4 & 5 \\
\hline 1.12 & Other (Please describe): & 1 & 2 & 3 & 4 & 5 \\
\hline
\end{tabular}

2) Which of the following is your primary medium? (Circle all that apply you may select more than one, but please rate the most prevalent as \#1)
$2.1 \quad$ Clay
$2.2 \quad$ Fiber
$2.3 \quad$ Glass
$2.4 \quad$ Leather
$2.5 \quad$ Metal
$2.6 \quad$ Paper
$2.7 \quad$ Plastic
$2.8 \longrightarrow$ Wood
$2.9 \quad$ Other, or mixed media (Please describe): 
3) For how many years have you practiced your craft?

(Circle the number that represents a range of years)

$\begin{array}{llll}3.1 & 4 \text { or less } & 3.7 & 30-34 \\ 3.2 & 5-9 & 3.8 & 35-39 \\ 3.3 & 10-14 & 3.9 & 40-44 \\ 3.4 & 15-19 & 3.10 & 45-49 \\ 3.5 & 20-24 & 3.11 & 50-54 \\ 3.6 & 25-29 & 3.12 & 55-59\end{array}$

4) Are you involved with any non-cooperative (commercial, for profit, commissioned) group marketing effort (yes or no)? (Circle one)

\subsection{YES}

$4.2 \quad \mathrm{NO}$

4.3 If yes, how rewarding is your group marketing involvement?

(Circle a number on the scale of 1 to 5)

\begin{tabular}{|c|c|}
\hline Not rewarding & Very rewarding \\
\hline 2 & 4 \\
\hline
\end{tabular}

4.4 If yes, you market your crafts with a for-profit group, please write the name of the organization and where it is located:

5) Have you ever been involved in a craft cooperative (an organization for the production or marketing of goods, owned and operated for the benefit of members who use its facilities or services in which all money from product sales is returned to the individual craftsperson) (yes or no)? (Circle one)

$5.1 \quad$ YES

$5.2 \quad \mathrm{NO}$

5.3 If yes, how rewarding was (is) your coop involvement in a marketing sense? (Circle a number on the scale of 1 to 5)

Not rewarding

12
Very rewarding

345

5.4 If no, you have never belonged to a craft cooperative for marketing products, why not?

6) Do you presently market your products using means besides participation in fairs and festivals (yes or no)? (Circle one)

6.1 YES

6.2 NO

6.3 If yes, you market using means besides fairs and festivals, circle the letter(s) for the way(s) you market your craft products.
a. Barter system
e. Retail outlet
b. Cooperative
f. Word-of-mouth
c. Gallery
d. Internet World Wide Web
g. Print advertising
h. Other (Please describe) 
7) Have you been involved in a craft cooperative during the past six years (yes or no)? (Circle one)

7.1 YES

7.2 NO

7.3 If yes, please write the name of the cooperative and where it is (or was) located:

8) List the community organizations in which you have regularly participated during the past six years: (e.g., arts groups, chat groups, churches, clubs, guilds, libraries, political organizations, schools, etc.)

9) Do you think that rules and guidelines (e.g., copyright laws, international trade regulations, tax regulations, etc.) set by national and state authorities are useful and fair (good)? (Circle one)

9.1 YES

$9.2 \quad \mathrm{NO}$

9.3 If yes, please rate your perception of how good rules and guidelines are.

(Circle a number on the scale of 1 to 5 )

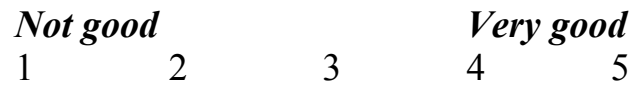

9.4 If no, why are rules and guidelines not good?

10) Do you think the overall status of national, state and local budgets and economies are favorable and appropriate (good)? (Circle one)

10.1 YES

10.2 NO

10.3 If yes, please rate your perception of how good budgets and economies are.

(Circle a number on the scale of 1 to 5 )

\begin{tabular}{|c|c|}
\hline Not good & \\
\hline $1 \quad 2$ & 3 \\
\hline
\end{tabular}

10.4 If no, budgets and economies not good (favorable or appropriate) why not?

11) Is your telephone service dependable (yes or no)? (Circle one)

\subsection{YES}

11.2 NO 
11.3 If you have problems with your telephone service, circle the letter(s) for any potential problem(s).
a. High phone bills
b. Irregular phone service
c. Slow phone service
d. Noisy phone lines
e. Other (Please describe)

11.4 I have no telephone.

11.5 I have a cellular phone.

12) Do you have a fax machine (a device for producing facsimile copies of graphic information by electronic means for transmission over telephone lines)?

(Circle a number and if yes fill in the blank)

12.1 No, I don't have one.

12.2 Yes, I have one.

12.3 If yes, what type of fax is it?

\section{COMPUTER USE}

13) Which type of personal computer (PC) system do you have? (Circle all that apply)

13.1 Macintosh

13.2 IBM

13.3 I have a laptop (portable) computer.

14) Do you have a screen monitor (a visual computer output device)?

(Circle all that apply and fill in the blank)

14.1 No, I don't have one.

14.2 Yes, I have one.

14.3 It is color.

14.4 It is monochrome (black and white).

14.5 What size is your monitor?

15) Do you have a printer (a paper-based computer output device)?

(Circle one and fill in the blank)

15.1 No, I don't have one.

15.2 Yes, I have one.

15.3 What type is your printer?

16) Do you have a CD-ROM (a compact disk on which computer information can be stored and accessed, with read-only memory)? (Circle one and fill in the blank)

16.1 No, I don't have one.

16.2 Yes, I have one.

16.3 What speed is your CD-ROM? 
17) Do you have a modem (a modulator-demodulator device that converts data to a form that can be transmitted by telephone to another similar device which reconverts it)? (Circle all that apply)

17.1 No, I don't have one.

17.2 Yes, I have one.

17.3 Speed in bits per second is 14.4 bps.

17.4 Speed in bits per second is 24 bps.

17.5 Speed in bits per second is $33.6 \mathrm{bps}$.

17.6 Speed in bits per second is 56.6 bps.

17.7 Speed in bits per second is 96 bps.

17.8 I have a fax modem.

18) Do you have a graphics tablet (an input device that translates graphic information into digital information for use with a computer)? (Circle one and fill in the blank)

18.1 No, I don't have one.

18.2 Yes, I have one.

18.3 What kind of graphics tablet do you have?

19) Do you have a scanner (an electronic input device for interpreting graphic information into digital information for use with a computer)?

(Circle all that apply)

19.1 No, I don't have one.

19.2 Yes, I have one.

19.3 Resolution in dots per inch is $300 \mathrm{dpi}$.

19.4 Resolution in dots per inch is 600 dpi.

19.5 I have a hand-held scanner.

19.6 I have a flat-bed scanner.

19.7 I have a slide scanner.

20) Rate the capacity of software and hardware components for your needs (e.g., ease of use, effectiveness, etc.) (Circle a number on the scale of 1 to 5 for each use)

20.1 Usefulness for presentation

20.2 Usefulness for product design

20.3 Usefulness for word processing

20.4 Usefulness for purchasing

20.5 Usefulness for sales

20.6 Usefulness for bookkeeping

20.7 Usefulness for Web site construction

20.8 Usefulness for advertisement

20.9

Other (Please describe)
1

1
Not useful

12

12

1

1

Very useful

345

$3 \quad 4 \quad 5$

$\begin{array}{lll}3 & 4 & 5\end{array}$

345

$\begin{array}{llll}2 & 3 & & \\ 2 & 3 & 4 & 5\end{array}$

$\begin{array}{llll}2 & 3 & 4 & 5\end{array}$

$\begin{array}{llll}2 & 3 & 4 & 5\end{array}$

$2 \quad 3 \quad 4 \quad 5$

$\begin{array}{lllll}1 & 2 & 3 & 4 & 5\end{array}$


21) What are your personal skills using electronic media (e.g., computer hardware and software, such as CD-ROM, databases, desktop publishing, faxing by modem, graphics programs, Internet, spread sheets, word-processing, etc.)? (Please list)

21.1 Tasks you perform using the computer:

21.2 Computer courses, tutorials, and/or workshops in which you have participated:

\section{INTERNET USE}

22) Do you have access to the Internet at your home (yes or no)? (Circle one)

22.1 YES

22.2 NO

23) If no, you do not have an Internet connection at home, do you have access to any computer that does have an Internet connection (yes or no)? (Circle one)

23.1 YES

23.2 NO

23.3 If yes, you have some Internet access, where?

24) Do you use the Internet (yes or no)? (Circle one)

24.1 YES

24.2 NO

24.3 If yes, you use the Internet, how many hours per week to you go on line?

(Circle a number on the scale of 1 to 5 to represent hours per week)

$$
\begin{array}{llll}
\multicolumn{7}{c}{\text { Hours per week }} \\
1 \text { or less } & 2 & 3 & 4
\end{array} \text { or more }
$$

\section{Hours per week}

25) Estimate your overall potential to use electronic (or Internet) marketing for moving your products to consumers, considering the following concerns.

(Circle a number on the scale of 1 to 5 for each question)

25.1 I have capital or financial

No

Agreement

commitment available.

25.2 I have adequate time to commit.

25.3 I can risk time and money.

25.4 I can decide on marketing approaches.

25.5 I have personal experience.

25.6 I have access to expert help.

25.7 I have willingness, or desire, to market electronically. 
26) Is there currently an Internet Web Site that represents your products for sale (yes or no)? (Circle one)

26.1 YES

26.2 NO

26.3 If yes, rate how helpful it is for your product sales promotion.

(Circle a number on the scale from 1 to 5) Not helpful

12

Very helpful

45

26.4 If no, why not?

27) Do you currently have your own personal Web Site (yes or no)? (Circle one)

27.1 YES

27.2 NO

27.3 If yes, rate it's usefulness to your craft business.

(Circle a number on the scale from 1 to 5 )

Not useful

$1-2 \quad 3-4=5$

27.4 If no, why not?

If you are marketing electronically, please continue answering questions \# 28 through \# 33 and beyond. (Circle a number on the scale of 1 to 5 for each question) If you are not marketing electronically, please continue beginning with question \# 34 .

Not very

Very

28) Is electronic marketing expensive in the sense of your finances?

29) Is electronic marketing expensive in the sense of your time?

30) Has your work recently (in the past year) been noticed by new audiences?

31) Has your involvement with $\begin{array}{llllllll}\text { electronic marketing been aggravating? } & 1 & 2 & 3 & 4 & 5\end{array}$

32) Has your involvement with $\begin{array}{llllllll}\text { electronic marketing been rewarding? } & 1 & 2 & 3 & 4 & 5\end{array}$

33) Has use of electronic marketing helped make you successful?

$\begin{array}{lllll}1 & 2 & 3 & 4 & 5\end{array}$




\section{CRAFT SALES}

34) How many craft products did you sell last year?

(Circle a number for the range of quantity of items sold)

$\begin{array}{ll}34.1 & 0 \\ 34.2 & 1-4 \\ 34.3 & 5-9 \\ 34.4 & 10-49 \\ 34.5 & 50-99 \\ 34.6 & 100+\end{array}$

35) Estimate additional craft sales (if any) due to your electronic marketing efforts. (Circle a number to represent increased sales percentages)

$\begin{array}{ll}35.1 & 0 \% \\ 35.2 & 1-10 \% \\ 35.3 & 11-20 \% \\ 35.4 & 21-30 \% \\ 35.5 & 31-40 \% \\ 35.6 & 41-50 \% \\ 35.7 & 50+\end{array}$

36) Estimate additional time you have spent (if any) due to expanding efforts into marketing your crafts electronically.

(Circle a number for the percentage of increased time)

$\begin{array}{ll}36.1 & 0 \% \\ 36.2 & 1-10 \% \\ 36.3 & 11-20 \% \\ 36.4 & 21-30 \% \\ 36.5 & 31-40 \% \\ 36.6 & 41-50 \% \\ 36.7 & 50+\end{array}$

37) If no, you are not marketing your products electronically, please comment on why you are not using the Internet for this purpose. (If yes, you are marketing your products electronically, please skip this question)

38) Estimate the number of pieces typical of your regular monthly output.

38.1 In production season:

38.2 Out of production season: 
39) Estimate the dollar amount of product sales typical of your regular monthly income.

39.1 In production season:

39.2 Out of production season:

40) Is your work as a craftsperson cost-effective (yes or no)? (Circle one)

$40.1 \quad$ YES

$40.2 \quad \mathrm{NO}$

41) If no, your craft activity is not cost-effective, is that situation threatening your ability to continue creating products (yes or no)? (Circle one)

41.1 YES

41.2 NO

Your contribution to this effort is very greatly appreciated. If you would like a summary of results, please print your name and address on the back of the return envelope (NOT on this questionnaire). We will see that you get it.

\section{Please return the survey in the enclosed self-addressed stamped envelope by May 20, 1999}




\section{Definitions}

Some of the terms used in this study are defined as follows:

Access is a way or means of approaching, getting, using, etc. In this study access means to gain or have access to electronic media or communication and information systems for marketing craft wares.

Art is used in this study to imply 'fine art', or any highly creative or intricate skill in visual, design, photography, media or performance categories at the exclusion of the crafts category. A making or doing of things that display form, beauty, and unusual perception: the creative ability to make something or execute a plan for a product that may not have a utilitarian functional purpose.

Artisan and 'craftsperson' as well as 'artist' are used interchangeably in some of the literature. In this study, an artisan is one who creates out of basic materials from a personal design or from established forms. The production evolves because of one's skill and the best technique of one's craft or trade to produce an object that fulfills its functional purpose to the satisfaction of the user and the beholder. An artisan (like a craftsperson) is sometimes distinguished from an artist by being skilled in the mechanics of the art (or craft), but lacking artistry in a 'fine art' sense.

Consignment is a method of inventory financing whereby merchandise is sent to a distributor or retailer who, acting as an agent for the supplier, holds it until it is sold. The title to the merchandise is retained by the supplier (or craftsperson). The distributor, or retailer, holds the merchandise in trust and sells or disposes of it pursuant to the supplying craftperson's instructions. Upon sale, the proceeds less any pre-arranged commission or mark-up are immediately forwarded to the supplier/craftsperson. 
Cooperative is a type of business formed by a group of people to obtain services more effectively or more economically than they can get on their own. Members of crafts coops own, finance, and operate the business for their mutual benefit. The terms 'cooperative', 'coop' and 'co-op' are used interchangeably. (Cobia, 1989)

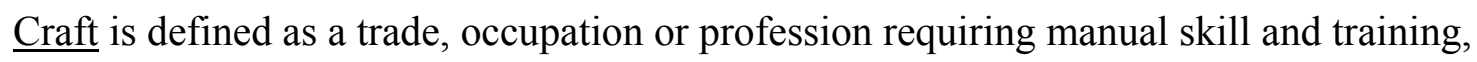
combined with a knowledge of and creative use of the principles of art. Crafts normally include a wide range of goods not ordinarily mass-produced but creative in the sense that the product is designed and completed on an individualized basis. The term crafts frequently includes fine art products, but in this study they are differentiated, with crafts implying more utilitarian items than purely aesthetic. Crafts are generally categorized according to medium such as clay, fiber, glass, leather, metal, paper, plastic, wood, and mixed media.

Craftsperson is one who creates out of basic materials from a personal design or from established forms. The production evolves because of one's skill and the best technique of one's craft to produce an object that fulfills its purpose to the satisfaction of the user and the beholder, much like an artisan. Craftsperson as well as 'artist' and 'artisan' are used interchangeably in some of the literature. A craftsperson is sometimes distinguished from an artist by being skilled in the mechanics of the art (like an artisan), but lacking artistry in a 'fine arts' sense.

Electronic media includes communication and information systems and devices related to computers, radio, telephones and television.

Fine artist is one with any highly creative or intricate skill in visual, design, photography and media categories. 'Fine' arts widely include traditional visual folk arts and contemporary visual arts (i.e., painting, drawing, printmaking, sculpting, photography, 
filmmaking, video, holography, computer-generated imagery, etc.). Also included as fine artists are those who do conceptual art (a work in which the medium is the concept itself and in which the process is more important than the conclusion), performance art (a visual work using one's own physical presence), and inter-media art (a work in which music, dance, video, and film are integrated into a total concept, e.g., a fluid living sculpture using more than one person). Writers, composers, media artists and performers are also considered fine artists, and involve individuals not included in this study. The category of design arts (including architecture, fashion, graphic, industrial, interior, landscape architecture and urban/metropolitan) is usually considered part of the 'fine arts', but is not included specifically in this study of craftspeople. The crafts category (generally including clay, fiber, glass, leather, metal, paper plastic, and wood as media) is also frequently included here as defined by much of the literature. In the case of this study, however, the arts and crafts are delineated for clarification by the following factors: 'fine' art is considered purely aesthetic, as distinguished from the 'useful' arts (crafts).

Flexible production and marketing networks are alternative economic strategies adopted in rural and semi-peripheral regions employing spatially dispersed individuals and homeworkers to earn income from participation in group artisan production. Coordination of orders and trouble-shooting during production typically is facilitated by using a telecommunications network. (Oberhauser, 1995)

Homebased business means that production usually involves a single craftsperson, or sometimes a family producing a product in the home. The product may be of traditional design passed from one generation to another, supplied by some other person for production in the home, or created and executed by the craftsperson. (Oberhauser, 1995) 
$\underline{\text { Infrastructure }}$ is the underlying foundation upon which a community depends for continuance and growth. In this study it is conceptually modeled to include: human skills, all networks and systems, technical communication devices, budget and economy as well as policy and law.

Knowledge is the awareness, recognition and understanding of information and facts. In this study, the term is used regarding the specific body of information and facts in the area of marketing craft products: e.g., 'know that'.

Marketing of craft products has typically been through either retail or wholesale outlets, or informally by word-of-mouth. Retail sales has been perceived as a method of last resort by many craftspeople because of high commission rates added to the price of wares and an unfavorable attitude with regard to typical inventory requirements. Fairs and festivals have been popular as means of marketing, advertising, promotion and sales. 'Micro' industry includes what has been termed 'cottage' industry. In this study, the term refers to those craftspeople who produce their wares in a central location with approximately 1-15 craftworkers employed to complete an individual piece from beginning to end. (Oberhauser, 1995)

Practice is a usual method, customary habit, action, or convention; a frequent or usual action. In coops, substantial flexibility exists in designing and using practices to meet the objectives of the business while respecting the cooperative definition, principles, and policies. (Barton, 1989)

Principle is a governing law of conduct, a general or fundamental truth, a comprehensive or fundamental law. Abiding by the definition of a cooperative and its principles should preserve the essential objectives and uniqueness of the cooperative form of business. (Barton, 1989) 
Policy is a wise or expedient rule of conduct or management. It is not a universal, unchanging truth but a highly recommended course of action, given the situation. (Barton, 1989)

$\underline{\text { Readiness }}$ is the ready quality or state of being prepared or equipped to act immediately to achieve an identified goal. It depends on experience and current potential. In this study readiness refers to the skills that are available to an individual or an organization to establish or use electronic media for marketing craft products.

$\underline{\text { Skills }}$ are the acquired abilities needed to manipulate tools and materials; a performance accomplished by applying the knowledge related to the specific body of information and facts: e.g., 'know how'. 


\title{
Appendix C: Survey Instrument
}

\section{A Survey \\ of \\ Craft \\ Marketing Strategies}

\author{
Karen Norwood \\ Technology Education Program \\ College of Human Resources and Education \\ PO Box 6122 \\ West Virginia University \\ Morgantown, WV 26506-6122 \\ 304-864-5958 \\ kknorwood@aol.com
}

This survey is intended to help us all better understand how West Virginia craftspeople feel about marketing their products at the turn of the millenium, given new communication technologies. Please answer all of the questions. If you wish to comment on any questions or qualify your answers, please feel free to use the space in the margins and on the back of the cover. Your comments will be read and taken into account. Thank you for your help.

ID \# 


\section{DEMOGRAPHICS}

1. Which one of the following is your primary medium? (Circle one)

$\begin{array}{ll}\text { Clay } & \text { Paper } \\ \text { Fiber } & \text { Plastic } \\ \text { Glass } & \text { Wood } \\ \text { Leather } & \text { Other, or mixed media (Please describe): }\end{array}$

Metal

2. How long have you practiced your craft? (Circle a range of years)

4 or less

5-9

10-14

15-19

20-24
25-29

30-34

35-39

40-44

45-49

$50+$

3. If you have been involved in a craft cooperative (an organization for the production, supply \&/or marketing of goods, owned and operated for the benefit of members who use its facilities or services in which all money from product sales is returned to the individual craftsperson) any time during the past decade, is or was it rewarding for you? (Circle one)

YES NO

4. If you have been involved with any other group marketing effort (i.e., commercial, commissioned, guild, for profit) is or was it rewarding for you? (Circle one)

YES NO

5.A. Do you presently market your products by means other than participation in fairs and festivals? (Circle one)

YES NO

5.B. If yes, which of these marketing means do you mostly use to sell your products?

(Circle the major marketing strategies besides fairs and festivals that you use)

Barter system

Cooperative

Gallery (indirect marketing)

Internet World Wide Web
Print advertising

Retail outlet (consignment)

Word-of-mouth

Other (Please describe) 
6. How many craft products did you sell last year? (Circle a range of numbers)
0
$10-49$
$1-4$
$50-99$
$5-9$
$100+$

7. Do you plan to continue practicing your craft? (Circle one)

YES NO

\section{SKILLS}

8. To what extent have you used the following skills to market your products during the past decade? (Circle a number on the scale of 1 to 5 for each skill)

Little Used

Audience analysis

Bookkeeping

Budgeting and forecasting

(e.g., deciding on quantity of production, types of items,

materials required, buying in bulk, etc.)

Computer software skills

Internet searching

Market analysis

Negotiation

Price setting

Visual production

(e.g., photos, slides, graphics, etc.)

Web site advertising

Writing

12

12

3

4

5

Much Used

$4 \quad 5$

45

(


9. What are your personal skills using electronic media?

(Circle a number, or not applicable, on the following scale for all that apply)

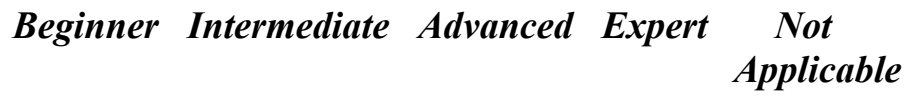

\begin{tabular}{|c|c|c|c|c|c|}
\hline Databases & 1 & 2 & 3 & 4 & $\mathrm{n} / \mathrm{a}$ \\
\hline Desktop publishing & 1 & 2 & 3 & 4 & $\mathrm{n} / \mathrm{a}$ \\
\hline E-mail & 1 & 2 & 3 & 4 & $\mathrm{n} / \mathrm{a}$ \\
\hline Graphics programs & 1 & 2 & 3 & 4 & $\mathrm{n} / \mathrm{a}$ \\
\hline Hardware configuration & 1 & 2 & 3 & 4 & $\mathrm{n} / \mathrm{a}$ \\
\hline Internet searching & 1 & 2 & 3 & 4 & $\mathrm{n} / \mathrm{a}$ \\
\hline Spread sheets & 1 & 2 & 3 & 4 & $\mathrm{n} / \mathrm{a}$ \\
\hline Web-based creation & 1 & 2 & 3 & 4 & $\mathrm{n} / \mathrm{a}$ \\
\hline Word processing & 1 & 2 & 3 & 4 & $\mathrm{n} / \mathrm{a}$ \\
\hline Other (Please list) & 1 & 2 & 3 & 4 & $\mathrm{n} / \mathrm{a}$ \\
\hline
\end{tabular}

10. How have you developed skills using electronic media? (Circle all that apply)

Computer-based tutorials

Courses / Workshops

One-on-one coaching

Self-taught

Other (Please list)

\section{BUDGET / ECONOMY}

11. To what degree do you think the overall status of national, state and local budgets nd economies are favorable and appropriate (good) for marketing your crafts electronically? (Circle a number on the scale of 1 to 5)

\begin{tabular}{rrrrr}
\multicolumn{2}{c}{ Not good } & & \multicolumn{2}{c}{ Very good } \\
1 & 2 & 3 & 4 & 5
\end{tabular}


12. If you are marketing electronically, please answer the following questions about expense. (Circle a number on the scale of 1 to 5 for each question)

Not very Very

Is electronic marketing expensive

in the context of your finances?

Is electronic marketing expensive in the context of your time?

\section{POLICY / LAW}

13. Does your business or coop have a policy(s) that determines how electronic marketing is used? (Circle one)

YES NO

If yes, please summarize what the policy $(\mathrm{s})$ is

14. Does your business plan accommodate expenses for Internet (or related communication) services? (Circle one)

YES NO

15. Does your business or coop regulate how electronic marketing information is compiled and presented to potential customers? (Circle one)

YES NO

If yes, please explain how you do this

16. Do you know of any existing business or coop that has a policy(s) about the use of electronic marketing which considers the full potential of computers and telephones? (Circle one)

YES NO 
If yes, please explain how you know

17. Do you think that rules and guidelines (e.g., copyright and patent laws, international trade regulations, protection, tax regulations, etc.) set by national and state authorities are useful when creating electronic marketing materials? (Circle one)

YES NO

If yes, please explain how these have been useful to you

\section{ACCESS / USE}

18. If you use the Internet, how many hours per week do you go online?

(Circle a number on the scale of 1 to 5 to represent hours per week)

Hours per week

1 or less $\quad 2 \quad 3 \quad 4 \quad 5$ or more

19. Estimate your overall potential to use the Internet for marketing your products to consumers, considering the following concerns.

(Circle a number on the scale of 1 to 5 for each statement of potential)

\section{No \\ Agreement}

I have capital or financial commitment available. $\begin{array}{lllllll}1 & 2 & 3 & 4 & 5\end{array}$

$\begin{array}{llllllll}\text { I have adequate time to commit. } & 1 & 2 & 3 & 4 & 5\end{array}$

$\begin{array}{lllllll}\text { I can risk time and money. } & 1 & 2 & 3 & 4 & 5\end{array}$

$\begin{array}{llllllll}\text { I can decide on marketing approaches. } & 1 & 2 & 3 & 4 & 5\end{array}$

I have personal experience using electronic media. $1 \quad 2 \quad \begin{array}{llll}3 & 4 & 5\end{array}$

I have access to expert help about electronic media.1 $2 \begin{array}{llll}3 & 2 & 4 & 5\end{array}$

20. Is there currently a web site that represents you as a craftsperson or your craft products? (Circle one)

YES NO 
21. If yes, you have Web site representation, (Circle yes or no for each question)

Did you design the the Web site yourself?

YES NO

Does the Web site include adequate visual representation of your products?

YES NO

Do you track the number of "hits" to your Web site regularly? YES NO

Has your Web site been cost-effective?

YES NO

22. If yes, you have a web site, how many craft products did you sell during the year 1999 directly because of your web site representation? (Circle a range of numbers)
0
$10-49$
$1-4$
$50-99$
$5-9$
$100+$

Your contribution to this effort is very greatly appreciated. If you would like a summary of results, please print your name and address on the back of the return envelope (NOT on this questionnaire). We will see that you get it.

\section{Please return the survey in the enclosed self addressed stamped envelope by July 17, 2000}

Technology Education Program

College of Human Resources and Education

PO Box 6122

West Virginia University

Morgantown, WV 26506-6122 
June 26,2000

\section{Appendix D: Cover Letter to Survey Questionnaire}

Dear Craftsperson,

I am writing to request your participation in a survey designed to assess the perceptions of West Virginia craftspeople about marketing their products. This questionnaire should take you about half an hour (time to enjoy a cup of tea).

You have been randomly selected from a mailing list made available to me by the West Virginia Division of Culture and History. I am conducting this research as partial fulfillment of the Doctoral of Education Degree in Technology Education at West Virginia University.

As you may know, marketing of any product has experienced changes in recent years due to advances in electronic media and the connected infrastructure. Therein lies the context of my research.

The enclosed survey includes questions regarding your perceptions about the availability of certain skills and resources. The results of this survey will provide information about the readiness of West Virginia craftspeople to apply those skills and resources toward the establishment of cooperative organizations for marketing their products electronically.

Return the questionnaire as soon as possible in the enclosed self-addressed stamped envelope, by July 17, 2000. Your responses will be treated confidentially, and your anonymity will be protected. Of course, your participation is voluntary. I would like you to answer all of the questions on the survey, however you may answer only the questions to which you wish to respond.

Thank you very much for your help and cooperation. If you participate, I would be happy to share the results of the research with you. If you have any questions please feel free to contact me by mail at: Karen Norwood, Technology Education, College of Human Resources and Education, PO Box 6122, West Virginia University, Morgantown, WV 26506. Otherwise, call me at (304) 864-5958, or call my advisor, Professor George Maughan, at (304) 293-3803, x1702.

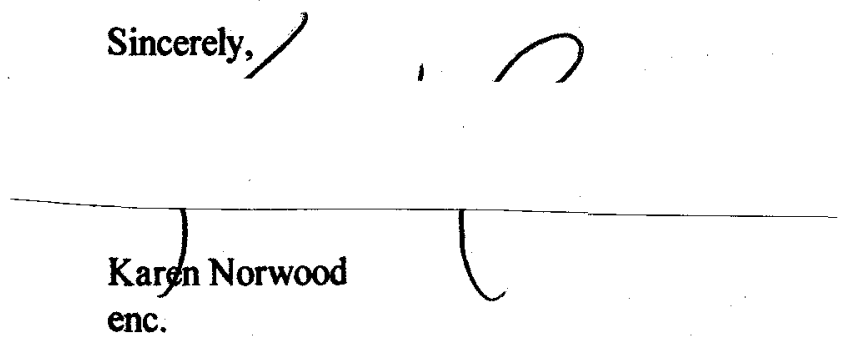




\section{Appendix E: Follow-up Postcard Reminder}

\section{Dear Craftsperson:}

Approximately two weeks ago you should have received a Survey of Craft Marketing Strategies seeking your input related to your own experiences and opinions.

If you have already completed the questionnaire and returned it to the Technology Education Program at West Virginia University, please accept my sincere thanks. If you have not yet responded, please do so today. Because you were selected to be an important part of this study, your responses are essential. I will be happy to share the results with you.

If you did not receive this questionnaire or if it was misplaced, please contact me at 304-864-5958, and I will mail another survey to you.

Thank you for your help and assistance with this very important project. 


\section{Appendix F: Comments Evoked by the Survey}

\section{$\underline{\text { Non-Statistical Data Collected Through Survey Instrument }}$}

\section{DEMOGRAPHICS}

1. Which one of the following is your primary medium?

Other, or mixed media (Please describe):

Airbrush

Basket Making

Book Arts

Bronze Figurative Sculpture

Cook Books

Cornhusks

Decorative Painting

Custom Stone \& Wheel Engraving on Glass

Deer Horn Baskets

Pre-Manufactured Mailboxes

Fine Jewelry

Painting

Soap

Wool

2. How long have you practiced your craft?

(No additional comments were written in response to this question, answered by all).

3. If you have been involved in a craft cooperative any time during the past decade, is or was it rewarding for you?

-All money is never returned to the craftsperson: a coop always takes a percentage to cover costs.

-It was rewarding to me before we closed. When other shops in the area left, leaving us the only shop, people stopped exiting the Interstate to visit only one shop.

4. If you have been involved with any other group marketing effort is or was it rewarding for you?

-State Parks and Tunpike shops bought allot, but their turnover costs were too high, given their markup prices.

5A. Do you presently market your products by means other than participation in fairs and festivals? Comments were requested in $5 \mathrm{~B}$.

-Non-consignment retail involves too much paperwork and it's easy to loose track of sales.

5B. If yes, which of these marketing means do you mostly use to sell your products?

(Circle the major marketing strategies besides fairs and festivals that you use)

Other, (Please describe):

Commissions

Donations E-mail

Gifts

Gift Shops Give-aways

Guilds

Home Shows

Museums

National Parks

State Parks Repeat Business

Tamarack

-Have own store/shop/studio/pamphlet/bed and breakfast.

-Internet with mountainmade.com, if it ever becomes operational.

-One sale per month via $W W W$.

-Wholesale agencies.

-Wholesale: some through a representative.

-Wholesale to retailers; retail to wholesalers. 
6. How many craft products did you sell last year?

-If you mean variety of products, not actual pieces sold, I earned $\$ 1000+$.

- Do you mean product lines or individual items? For example, I made twelve types of pots, plus two special designs for one customer in 1999.

$-N / A$ : I earned \$86,000.

-Number of pieces or dollar amounts?

-This is an unclear question.

7. Do you plan to continue practicing your craft?

(No additional written responses were given to this question, answered by all).

\section{SKILLS}

8. To what extent have you used the following skills to market your products during the past decade?

-I wish I were more skilled: these considerations hinder my growth, especially the questions about computers.

-Just starting to do website advertising.

9. What are your personal skills using electronic media?

-Telephone: I am computer challenged.

-Digital images: photo scans with digital camera.

-I employ someone else to do all of the above items; I request data and make my own analysis of the results.

10. How have you developed skills using electronic media?

-Continuing education courses at local high school.

-College courses 1970-72.

-I employ someone to do these things.

-I do know computers are the future! And really the present, too.

-My son and husband show me.

-None; if and when a need is felt, the county school system should fill the need, as it seems true in past years.

-Have none: lack of interest.

\section{BUDGET / ECONOMY}

11. To what degree do you think the overall status of national, state and local budgets and economies are favorable and appropriate (good) for marketing your crafts electronically?

-An important question: customers want one-on-one contact with an artist, which makes web-based marketing not viable. Shipping is also expensive and thus becomes a disproportionate dollar amount of the overall configuration.

-What is this question?: unclear, unknown, don't know, who knows. Is it a "good" economy in which people buy art?

12. If you are marketing electronically, please answer the following questions about expense.

-These are the two reasons I don't own a computer.

-I am having a website made.

-I use e-mail whenever possible to confirm orders and to send invoices, which saves time and money.

-I don't think electronic marketing will be expensive in terms of money, but it will cut into my time.

-I'm thinking about marketing electronically, but have no business yet with Tamarack or Mountainmade.com. Probably I will be. 


\section{POLICY / LAW}

13. Does your business or coop have a policy(s) that determines how electronic marketing is used?

-Must follow basic concepts of honesty and fairness. Our emphasis is on wholesale (i.e., bed \& breakfast) not on retail, except at fairs.

14. Does your business plan accommodate expenses for Internet (or related communication) services?

-Our Internet server is our primary (long-term) expense. Our website is linked to our local chamber of commerce.

15. Does your business or coop regulate how electronic marketing information is compiled and presented to potential customers?

-Every word will be directed/created/regulated personally in the future.

-Government?

-I will have complete control; as the sole owner, I keep my own information.

-Mountainmade.com is just now setting up.

16. Do you know of any existing business or coop that has a policy(s) about the use of electronic marketing which considers the full potential of computers and telephones?

-No, do you?

-This is a very subjective question.

-Of 41 respondents only one answered yes, and wrote: Through Jeff Reid (Byrd)?

17. Do you think that rules and guidelines set by national and state authorities are useful when creating electronic marketing materials?

-Copyright lawyers do not work on contingency, and small business owners and artist can't afford to enforce a copyright because it's difficult to track. One must only hope people will respect a copyright.

-Don't know. ??? - Ignorance of the law.

-Don't know: less government is better.

-Guidelines are not personally useful, yet rules will control power that business has over the information of the public.

- Haven't yet gotten into it.

-How could they not be? Otherwise you could do something illegal and not know it.

-They will protect my designs.

-To protect our creations. 


\section{ACCESS / USE}

18. If you use the Internet, how many hours per week do you go online? -Primarily for e-mail.

19. Estimate your overall potential to use the Internet for marketing your products to consumers, considering the following concerns.

-I have no interest in marketing my' product' on the Internet.

20. Is there currently a web site that represents you as a craftsperson or your craft products?

-Having a website in addition to print media is a one-two punch: after you reach a client, they can view your entire portfolio immediately. Web-only advertising is difficult because there is so much out there. The big question is "How do they find you?" in all of that information.

-Not yet, by September 2000.

-WWW.Mtarts.com, mountainmade.com, wvmade.com (when up and running).

21. If yes, you have Web site representation:

-Active share by Adobe.

-Mountainmade.com now setting up.

- Not yet on line, either personally or with mtnnet.com. Hopefully by 9/00.

-Under construction: I won't know for a few weeks.

-Will be cost effective via mountainmade.com.

22. If yes, you have a web site, how many craft products did you sell during the year 1999 directly because of your web site representation?

-Just started in 2000.

-Money versus number of pieces sold is relevant.

-My product is sold only wholesale. My buyers and their company handle most marketing. I know very little about their policies.

$-N / A$.

-Selling crafts on the Internet is counter to the reason we became craftsworkers. It does help with overall exposure but not for specific sales of an item. 


\section{Appendix G: Research Questions}

The study addressed individual West Virginia craftspeople concerning four areas:

1) skills and knowledge, 2) readiness, 3 ) perceptions of infrastructure, and

4) perceptions of access to communication and information systems. A fifth set of questions involved demographics.

1. What are the skills and knowledge individual craftspeople have used to market their wares utilizing electronic media?

2. To what degree can existing individual readiness (experience and potential) fulfill the objectives of establishing and using electronic media for marketing their West Virginia craft wares?

3. What is the maturity of the existing infrastructure from individual craftpeoples' perceptions?

4. What is the perceived degree of access to electronic media by individual craftspeople for marketing their wares? 


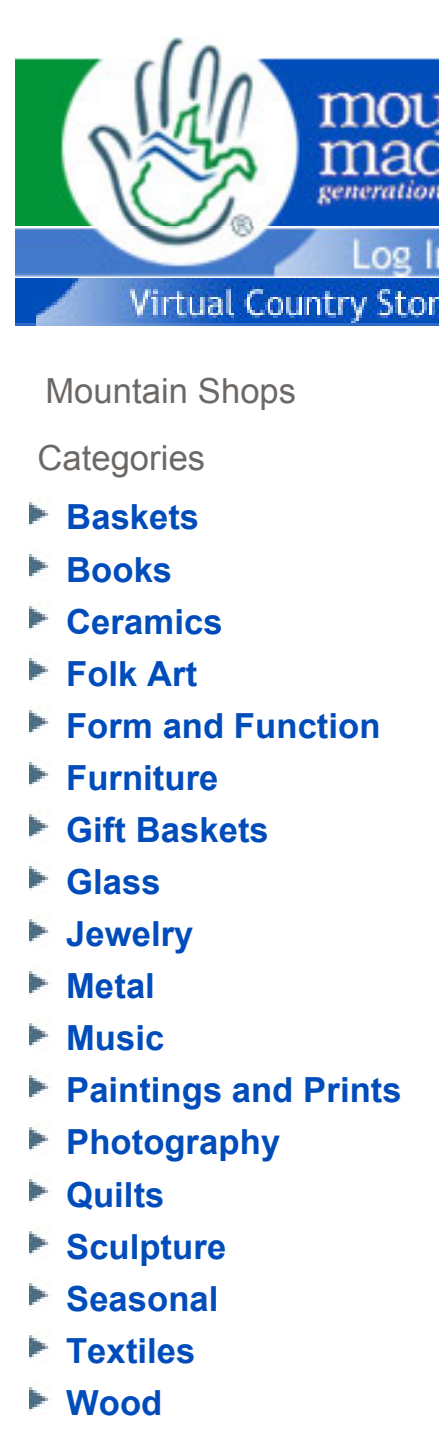

Appendix H: Relevant Marketing Website Information

\section{Mountain Shops}

\section{Categories}

- Baskets

- Books

- Ceramics

- Folk Art

- Form and Function

Furniture

- Glass

- Jewelry

- Metal

- Music

Paintings and Prints

Photography

Quilts

Sculpture

Seasonal

Textiles

Wood
- Gift Baskets

\section{About MountainMade.com}

Who We Are State. programs: handmade by West Virginia artisans.

\section{A Strategic Partnership} creations on the World Wide Web.

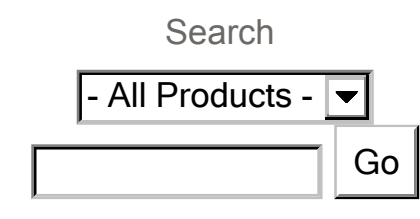

Advanced Search

Check Out

MountainMade.com is a gallery of handcrafted items created in the mountains of West Virginia. This site is one of a family of programs operated by the MountainMade Foundation of Thomas, West Virginia. This foundation, with the assistance of the U.S. Small Business Administration, supports the West Virginia arts community through the preservation and advancement of the arts in the Mountain

In addition to the MountainMade.com web site, the MountainMade Foundation operates the following

VirtualCountryStore.com, a website that offers handcrafted house wares, food (coming soon) and functional items, including kitchenware, toys, stationery and clothing. All items are

MountainMade Artisan Gallery, a bricks-and-mortar shop offering the goods of MountainMade.com and VirtualCountryStore.com for sale in the 100-year-old historic Buxton \& Landstreet Building in Thomas, West Virginia, in the heart of Canaan Valley.

Though beautiful and majestic, the landscape of West Virginia provides a number of challenges to the state's talented and diverse art and craft community. In the early-1990s, Congressman Alan B. Mollohan (D-W.Va.), realized that, through the use of technology, West Virginia artists and craftspeople could overcome some of these challenges and gain world-wide exposure for their

A new school of thought, based upon grass-roots community development and self-sufficiency through the use of technology, has been developed. To carry out this vision, the MountainMade Foundation was incorporated in June 2001 and begins a new journey as a sole entity.

Our Mission and Goals

The MountainMade Foundation seeks to support the West Virginia arts community through the preservation and advancement of the arts in the Mountain State. The Foundation provides marketing, logistics, technical support, training and education to artists in the areas of e-commerce and business, expands regional participation in the arts and fosters the growth of heritage arts and crafts in West Virginia through the use of technology. The Foundation works to enhance the economic stability of the state through the effective use of the Internet as a tool to market the works of West Virginia artists to a worldwide audience.

If you would like more information about MountainMade.com, please send an e-mail to info@mountainmade.com.

If you experience technical difficulties with our site, please contact webmaster@mountainmade.com.

\section{Privacy Statement | Affiliate Links | Shipping Info | Free Membership | Request Catalog}




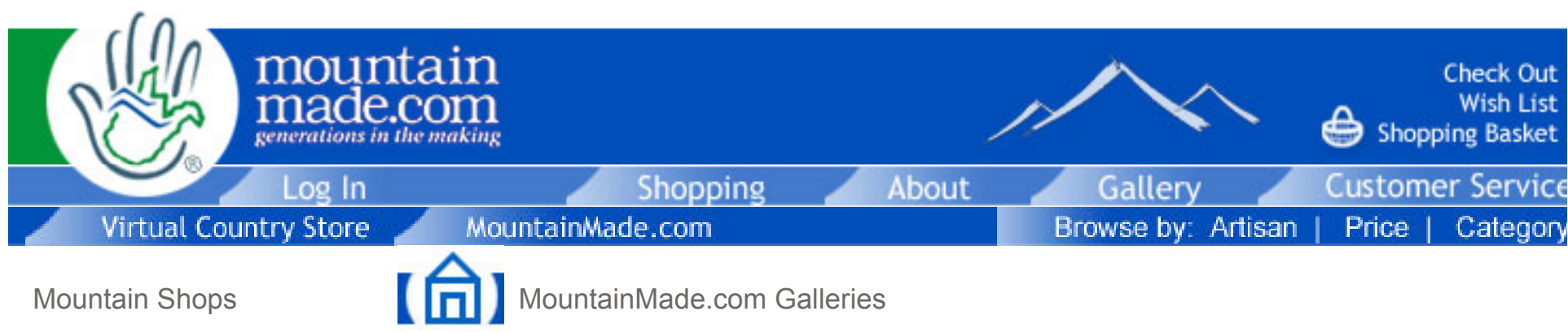

Categories

- Baskets

- Books

- Ceramics

- Folk Art

- Form and Function

- Furniture

- Gift Baskets

- Glass

- Jewelry

- Metal

- Music

- Paintings and Prints

- Photography

- Quilts

- Sculpture

- Seasonal

- Textiles

- Wood
Master Artists and Artisans of the Mountain State

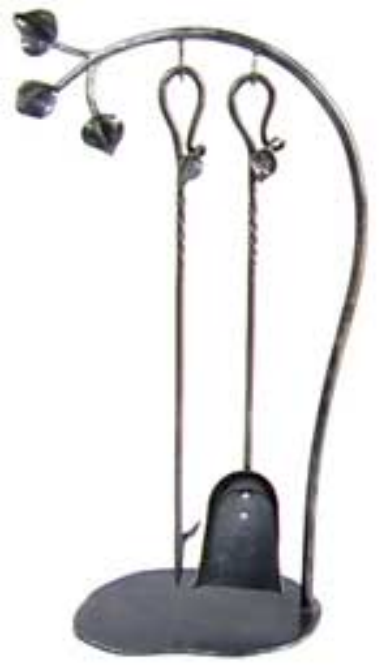

Contemporary Firetools

This hand-forged shovel and poker comes with an arched stand and is accentuated with forged leaves.

Potomac Tray

MountainMade.com News

Artisan of the Month

MountainMade.com to Host Chair Weaving...

Next MountainMade Jury Session...
Zeramics

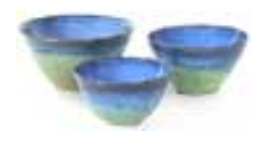

Set of Three Bowls Z Jewelry

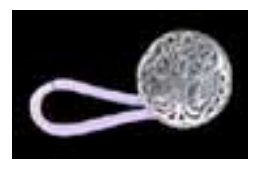

Celtic Oak Tree Hair T $\checkmark$ Wood

Search

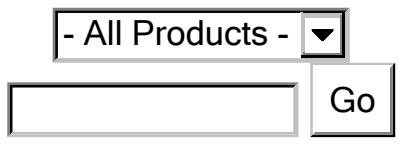

Advanced Search

Featuring the Best of West Virginia in a Virtual Gallery

Privacy Statement | Affiliate Links | Shipping Info | Free Membership | Request Catalog Gift Ideas | Gift Certificates | Help | Artist Resources | Catalog Order 

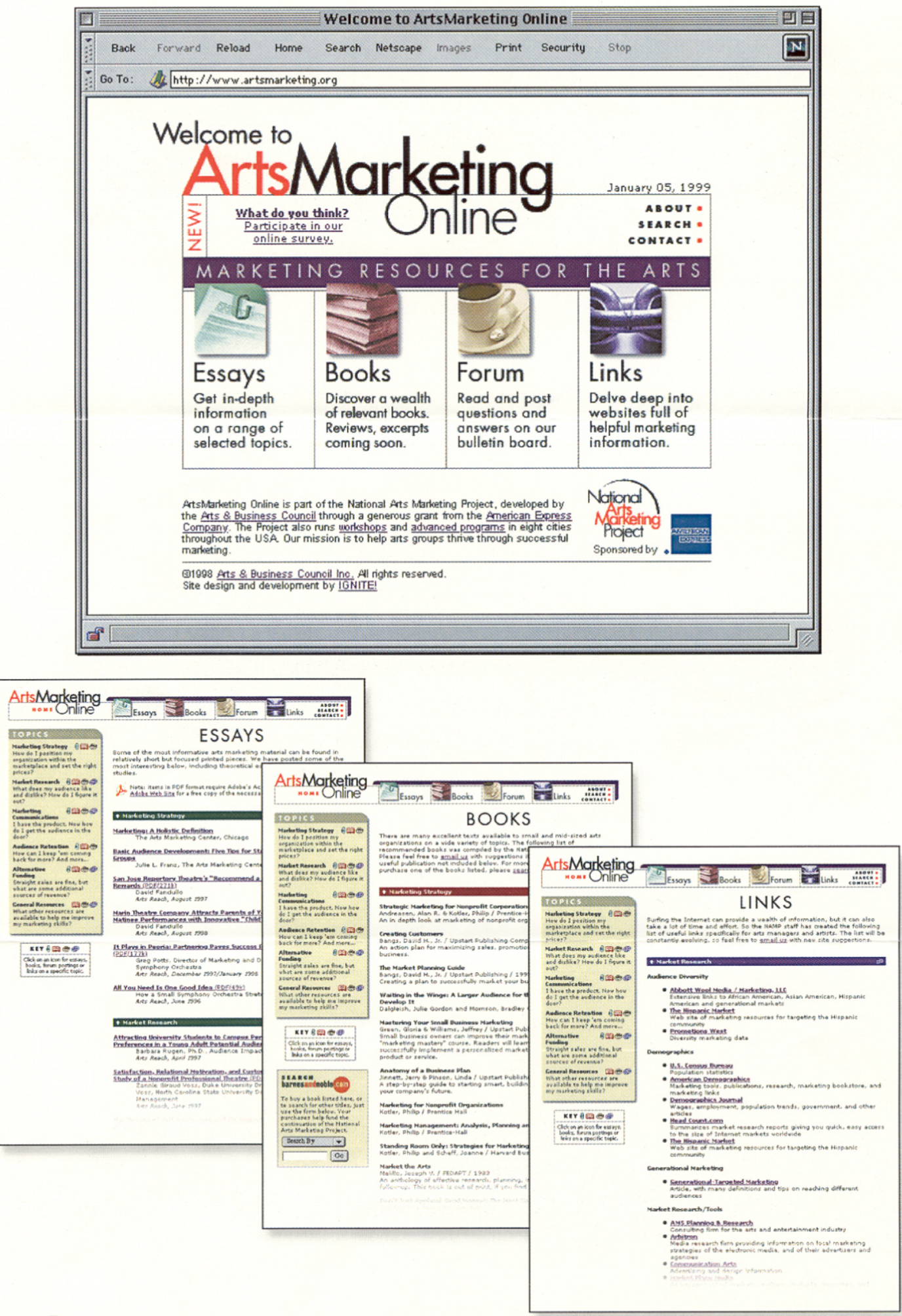


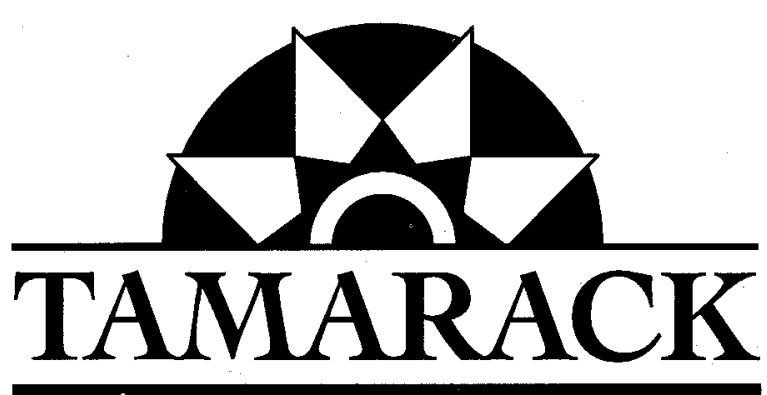

September 13, 2000

\title{
Dear Juried Artisan:
}

As you may know, the West Virginia Parkways Economic Development and Tourism Authority has retained the services of research and planning specialists at Tripp, Umbach \& Associates to conduct a marketing and expansion study for the Tamarack System.

It is our intention that the project will:

- Determine the most viable options for expanding and enhancing the Tamarack System

- Identify opportunities for attracting additional visitors to Tamarack (the Caperton Center)

- Lead to increased revenues for the Tamarack System and its artisans, and

- Enhance Tamarack's economic impact for the State of West Virginia.

As part of a detailed assessment of our current operations and future opportunities the researchers need to hear your opinions and thoughts. Many of you have been intimately involved with the Tamarack concept and its mission. We hope very much that you will complete the enclosed confidential questionnaire and return it to Tripp Umbach.

Please note that your individual survey response will be held in confidence at Tripp Umbach and they will not reveal any individual responses to any outside party, including Tamarack's management and the WVPEDTA Board. They do ask for your name and contact information on the survey, but that is in case they wish to contact you to discuss any other issues or to gain your thoughts on expansion concepts. So please feel free to be completely candid on the survey.

Your immediate response is important. Please take a few moments to complete the survey now, or sometime today. Mail the survey back to Tripp Umbach in the enclosed envelope (no postage is required) by September 26th. If you have any questions regarding the survey please feel free to call Candace Creely at Tripp Umbach at 1-800-250-6724.

You are an integral part of Tamaracks expansion and enhancement plan. We NEED to hear your opinion and thoughts.

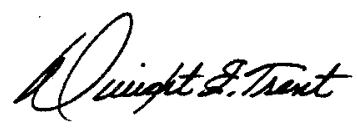

\author{
Dwight E. Trent \\ Tamarack Deputy Manager
}

One Tamarack Park, Beckley, WV USA 25801 


\section{APPALACHIAN I $Y, D E S, G N$}

Appalachian By Design is a nonprofit organization that provides merketing and training services to a flexible business network of handloom knitters in rural West Virginia and bordering states. AtBD currently works with over 50 home-bused producers, coordinating the production of $500-2,000$ piece orders. The network produces high-end knitwear, primarily sweaters, that renil for $\$ 75$ to $\$ 250$.

Managing large joint orders from production sites throughout the mountains requires efficient communicutions. This summer $A B D$ will begin implementing a telecommunication sygtem that will link lead knitters with cach other and establish the Lewisburg office as the network server. Funds and technical assistance are being sought to support Phase $l_{1}$ which involves creating a local area network and an E-mail system that will join the Lewistourg office to four sites.

The estimated cost of Phase $I$ is roughly $\$ 5,000$. Future phases will involve installation of additional telecommunication sites and the use of video conferencing for on-the-job training.

ABD was started as a project of the Center for Economic Options, Inc. and has beeth in operation for three years. It has been suppointed by the West Virginia Govemor's Gunimateed Workforee Training Program, Claude S. Worthington Bcnedum Foundation, Charles 8towart Mott Foundation, the Episcopal Church and tho FDA University Center at West Virginis Institute of Technology.

A Training and Development Corporation for Appalachian Artisans

117 East Washington Street - Leopishurg, West Virginia 24901 - 304-647-3455 - FAX 304.647-3466

$07 / 20 / 95 \quad 12: 29 \quad$ TX/RX N0.2723 


\title{
Appendix I: Curriculum Vitae
}

\section{KAREN NORWOOD}

\author{
Rt. 1, Box 73A \\ Masontown, WV 26542 \\ 304-864-5958 \\ karennorwood@Icrnet.zzn.com
}

\section{PROFESSIONAL EMPLOYMENT HISTORY}

Substitute Teacher in all subjects Grades K-Eight, Preston County, WV (8/2000-1/2001)

Italian Teacher, Monongalia Arts Center, Morgantown, WV (11/2000-12/2000)

Sales Representative and Art Framing Consultant, The Art Attic, Morgantown, WV $(3 / 2000-7 / 2000)$

Italian Teacher for Grades One-Three, St. Francis Elementary After School Program, Morgantown, WV (3/2000-4/2000)

Instructor of Italian for January Term, West Virginia Wesleyan College, Buckhannon, WV $(1 / 1998)$

Instructor of Italian, West Virginia University, Morgantown, WV (8/1996-5/1997)

Instructor of Reading and Composition, ESL Intensive English Program, West Virginia University, Morgantown, WV (8/1996-12/1997)

Graphic Designer for Promoting Residential Life, West Virginia University, Morgantown, WV (4/1996-7/1996)

Research and Training Assistant for the National Alternative Fuels Training Program, West Virginia University, Morgantown, WV (8/1993-3/1996)

Slide Curator, Art Department, Middlebury College, Middlebury, Vermont. (8/1992-7/1993)

Research and Training Assistant for the Appalachian Technology Education Consortium, West Virginia University, Fairmont State College, Salem-Teikyo University and California University of Pennsylvania. (1/1991-7/1992)

Technical Coordinator and Instructor of Photography, Department of Art and Architecture, Northeastern University, Boston, Massachusetts. (1987-1990)

Assistant Professor of Art: in photography, art fundamentals, drawing and art history, Austin College, Sherman, Texas. (1984-1986) 
Co-Director and Instructor of printmaking, Santa Reparata Graphic Art Centre, Florence, Italy. (1981-1983)

\section{EDUCATION}

Ed.D., Technology Education Program, West Virginia University, Morgantown, West Virginia. Dissertation Title: "Propensity of West Virginia Craftpeople to Use Electronic Media for Marketing Their Products". (1991-2002)

Certificate in Electronic Design and Publishing, Northeastern University, Boston, Massachusetts. (1988-1990)

M.F.A. and M.A., Rosary College Graduate School of Fine Arts, Florence, Italy. (1979-1981) Winner: full-tuition scholarship. Major: printmaking; minor: photography.

B.F.A. and Teaching Certificate for K-12 art and psychology, University of Wyoming, Laramie, Wyoming. (1974-1979) Phi Kappa Phi. Winner: nine scholarships.

Ellen Battel Stoeckel Fellow at Yale University Summer School of Music and Art, Norfolk, Connecticut. (1977)

\section{ASSOCIATION ACTIVITY}

Art Libraries Society of North America, 1982 founding member of the Association for Directors of American Academic Programs in Florence, Italy, Association for Educational Communications and Technology, Boston Computer Society, College Art Association, International Technology Education Association, International Teleconferencing Association, Society for Photographic Education, Visual Resources Association, and the American Educational Research Association.

\section{PRESENTATIONS}

"Futuristic Learning Organizations: What Are They? Who Are They For?", International Teleconferencing Association Annual Conference, Dallas, Texas (June 1994) and WVNET User Conference, Morgantown, WV (November 1994).

\section{EXHIBITIONS}

International-exhibiting artist of photo-etchings and photo-montage images. More than thirty exhibitions given throughout the USA, Florence, Italy, and Vancouver, British Columbia, Canada included solo, group, invitational, and competition activity from 1977-2002.

(Exhibition details and references available upon request) 


\section{LANGUAGES}

Fluent in English and Italian; some conversational skills in Spanish and French.

\section{CONSULTANCIES AND VOLUNTEER WORK}

Italian Teacher, Cheat Lake Elementary School International Day, West Virginia (2000)

Researcher for the Classroom of the Future, Wheeling Jesuit College, Wheeling, West Virginia. (April-July 1992)

Observatory Evaluator and Liaison for the Pennsylvania training site of the Mon Valley Tri-State Leadership Academy, West Virginia University. (January-July 1992 and August-December 1993)

Coordinator of Visual Arts track of Annual ArtSpeak Conference, Wyoming Arts Council, Department of Commerce, Cheyenne, Wyoming. (September 1990)

Assistant Conference Coordinator, Business for Boston, Boston, Massachusetts. (June 1990)

Interior Design Consultant and Advertising Photographer, Tile Showcase, Boston, Massachusetts. (March-July 1987)

Interpreter/Translator of English and Italian for Italian film-making firm and American technicians and actors, Media Associates, Jackson, Wyoming. (January 1984) 
Table 1: Strengths and Weaknesses Related to Marketing

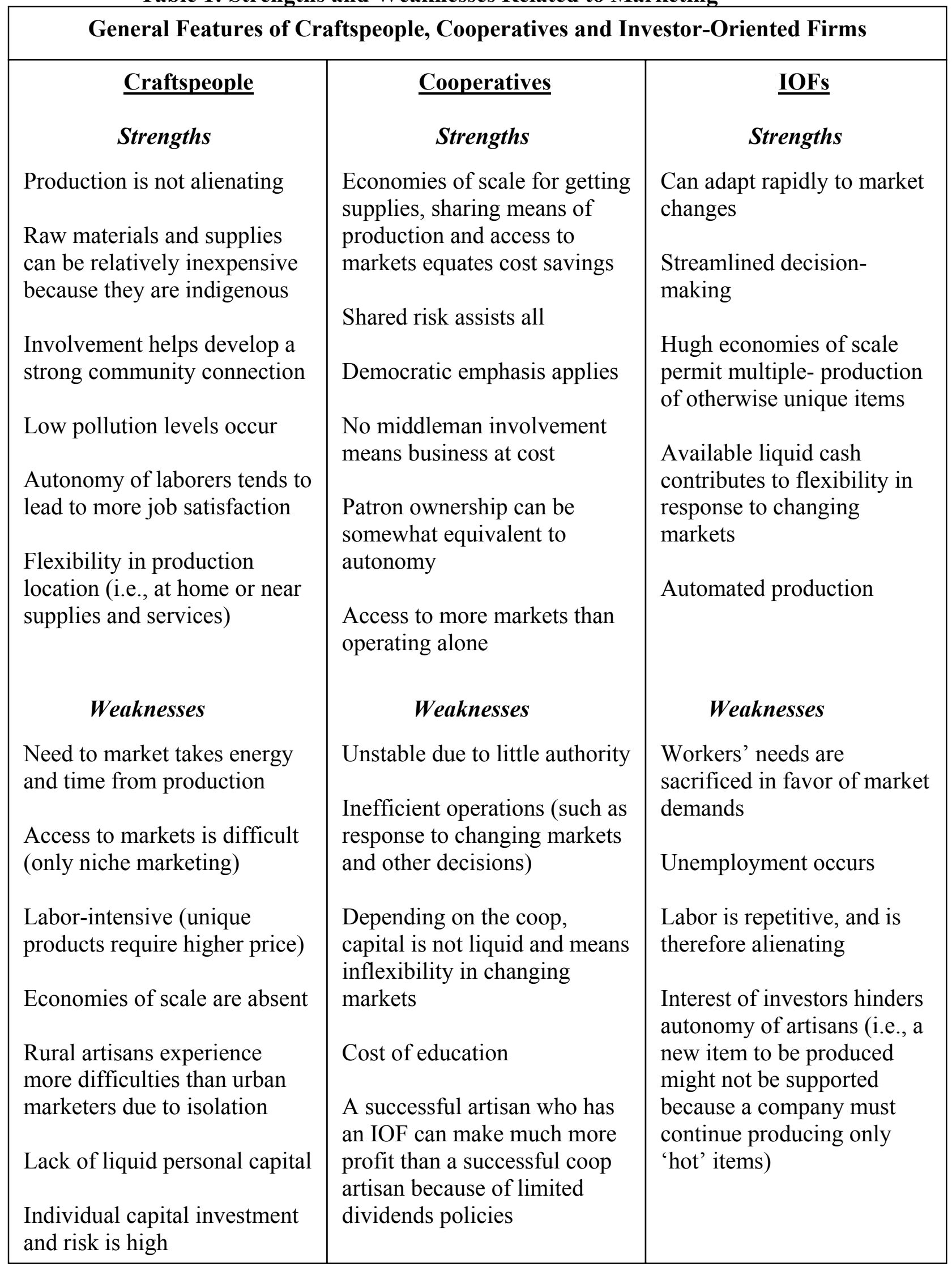




\section{Any Communications Infrastructure Requires Some Combination Of These Five Elements}

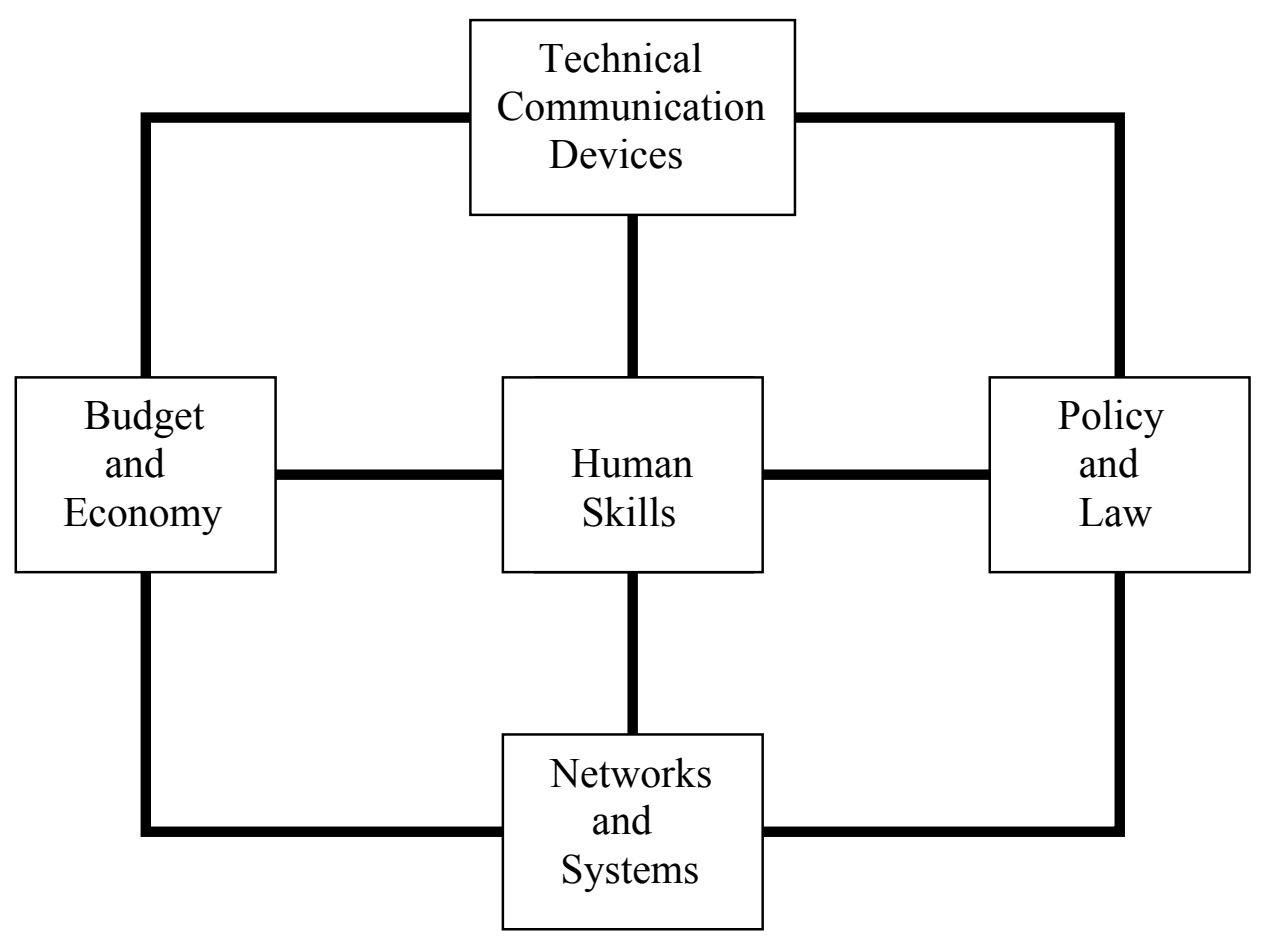

Figure 1: Communication Infrastructure Diagram 